\title{
Yaari Dosti: Young Men Redefine Masculinity, A Training Manual
}

Horizons Program

CORO for Literacy

MAMTA

Instituto Promundo

Follow this and additional works at: https://knowledgecommons.popcouncil.org/departments_sbsr-hiv

Part of the Family, Life Course, and Society Commons, Gender and Sexuality Commons, and the International Public Health Commons

How does access to this work benefit you? Let us know!

\section{Recommended Citation}

Horizons Program, CORO for Literacy, MAMTA, and Instituto Promundo. 2006. "Yaari Dosti: Young Men Redefine Masculinity, A Training Manual." New Delhi: Population Council. 


\section{Yaari Dosti: Young Men Redefine Masculinity}

\section{A Training Manual}

Population Council, New Delhi

CORO for Literacy, Mumbai

MAMTA, New Delhi

Instituto Promundo, Rio de Janerio

1 Population Council H $\mathrm{H}$ rizons
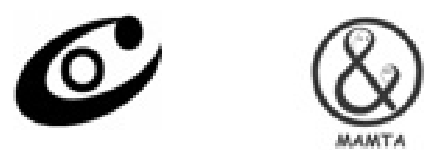
Yaari Dosti is an adaptation of Program H: Working with Young Men Series, originally developed by Instituto Promundo, ECOS (Brazil), Instituto PAPAI (Brazil) and Salud y Genero (Mexico). In India the adaptation was compiled and produced by Population Council, CORO (Mumbai) and other collaborative partners.

This training manual aims to promote gender equity and addresses masculinity as a strategy for the prevention of HIV infection. The Manual is based on operations research that was undertaken in Mumbai and Uttar Pradesh to develop educational activities targeted to young men.

For additional copies of this manual, please contact:

Population Council

142, Golf Links

New Delhi 110003

Tel: +91 1141743410-11

Fax: +911141743412

Email : vthomas@popcouncil.org

Website: www.popcouncil.org/horizons

South \& East Asia Regional Office

Zone 5A, India Habitat Centre

Lodi Road

New Delhi 110003

Tel: $+911124642901 / 02$

Fax: +911124642903

Email: info-india@ @opcouncil.org

The Population Council, an international, nonprofit, nongovernmental organization, seeks to improve the well-being and reproductive health of current and future generations around the world and to help achieve a humane, equitable, and sustainable balance between people and resources. The council conducts biomedical, social science and public health research, and helps build research capacities in developing countries.

Copyright @ 2006 Population Council

This document may be reproduced in whole or part without permission of the Population Council provided full source citation is given and reproduction is not for commercial purposes.

Suggested citation: Population Council, 2006. Yaari Dosti: A Training Manual. New Delhi: Population Council. 


\section{Contents}

Foreword vii

Acknowledgement $\quad$ ix

Introduction $\quad$ xi

\section{Section 1. Gender}

Activity 1.1: Gender $\quad 3$

Activity 1.2: Sexuality and Reproduction $\quad 5$

$\begin{array}{ll}\text { Activity 1.3: Labeling } & 7\end{array}$

Activity 1.4: Objects and People $r$

Activity 1.5: Domestic chores 11

Activity 1.6: My Emotions $\quad 13$

Activity 1.7: Reason for taking a decision and related sentiments 17

$\begin{array}{ll}\text { Activity 1.8: Lottery of Life } & 20\end{array}$

\section{Section 2. Sexuality and Reproductive Health}

Activity 2.1: Me and my body 25

$\begin{array}{ll}\text { Activity 2.2: Sexuality and Contraception } & 27\end{array}$

$\begin{array}{ll}\text { Activity 2.3: Reproductive Body } & 31\end{array}$

Activity 2.4: Sexual Anxiety: Answer if you can...

Activity 2.5: Story of Raghu and Pinki $\quad 39$

$\begin{array}{ll}\text { Activity 2.6: Erotic Body } & 41\end{array}$

Activity 2.7: STI, HIV \& AIDS and Health 44

Activity 2.8: Didn't I tell you so... 46

\section{Section 3. Violence}

Activity 3.1: Sexual Violence $\quad 51$

Activity 3.2: Violence in Sexual Relationship $\quad 55$

Activity 3.3: Diversity and rights: Me and others $\quad 57$

Activity 3.4: From Violence to Respect in Intimate Relationships $\quad 59$

$\begin{array}{ll}\text { Activity 3.5: From Violence to peaceful co-existence } & 61\end{array}$

$\begin{array}{ll}\text { Activity 3.6: What do I do when I become angry? } & 63\end{array}$ 


\section{Section 4. Living with HIV and AIDS and its Prevention}

Activity 4.1: Story of Raju

Activity 4.2: Signature Hunt

Activity 4.3: I am vulnerable when ...

Activity 4.4: Some people don't want to use condom because...

Activity 4.5: Want..don't want, want...don't want 
Foreword

Yari-Dosti: Young Men Redefine Masculinity, a training manual developed by the Population Council in collaboration with Instituto PROMUNDO, CORO for Literacy, MAMTA - Health Institute for Mother and Child and DAUD, is an important resource for government and non-government organizations (NGOs) that aim to promote gender equity and address masculinity as a strategy for the prevention of HIV infection. A significant feature of this Manual is that it has been validated through community-based research in several urban and rural areas of India where it is now being used.

The Manual is adapted from a program entitled "Program H: Working with Young Men Series" that was developed in Brazil by Instituto PROMUNDO and was evaluated by the Population Council. It promotes the positive aspects of masculinity, encourages men's participation in sexual and reproductive health, promotes respect for sexual diversity and improves the understanding of the body and sexuality. In this Manual, HIV prevention is addressed within the larger framework of gender roles and relationships.

Several activities have been discussed in the Manual. The activities are organized around four key themes: (1) gender; (2) sexuality and reproductive health; (3) violence; and (4) HIV and AIDS prevention. The Manual has been prepared through a three-year long participatory research process. It is published in Hindi and in English to encourage wide-spread use in India. It will also be translated into other local languages. I encourage all users to adapt it for their particular contexts using local examples, the local idiom and context-specific characterization.

Gender disparity, widely prevalent in Indian society lies at the root of most sexual and reproductive health problems. Yet, efforts to address this deep-rooted, insidious problem have, thus far, had limited success. Feminists and women activists concerned with these issues have focused primarily on addressing women's needs and problems. But given the gender-power imbalance in our society, there is a growing realization that these problems cannot effectively be addressed unless men are involved. There are, as yet, few efforts to do so. Examples of work on these issues in the community are very scarce. And therefore there is an important unmet need for designing, implementing and evaluating community-based interventions for reaching boys and men effectively. This Manual is based on operations research that was undertaken in Mumbai, Goa and Uttar Pradesh to develop educational activities targeted to young men; rigorously test interventions designed and implemented by them, and thereby, ensure community ownership of the programme.

I encourage both government and non-government organizations to adapt this Manual for their various settings. I feel confident that it will serve as an important tool for programming. By stimulating community involvement and discussion on important but sensitive issues that are usually not addressed, this Manual would be useful for many engaged in programmes to prevent HIV and reduce gender-based violence.
Dr. Saroj Pachauri Regional Director South and East Asia Population Council 



\section{Acknowledgement}

This training manual tries to promote the positive aspects of masculinity, encourages young men to participate in sexual and reproductive health, promotes respect and understanding in sexual diversity. This manual can be an important tool for young men, trainers and related organizations. The present format of this manual is the collective out come of several people with months of rigorous research.

This Yaari Dosti manual is adapted from Program H: working with young men series. It is edited and produced collectively by; Population Council/Horizons, CORO, MAMTA and Instituto PROMUNDO.

Population Council/Horizons : Ravi Kumar Verma, Julie Pulerwitz, Vaishali Sharma Mahendra and Ajay Kumar Singh

CORO for Literacy

: Sujata Khandekar, Vilas Samalkar, Mahendra Rokade and others

MAMTA Health Institute for

Mother and Child

: Subha Shanker Das, and Imitiyaz Khan

DAUD Memorial Christian

Gramin Vikas Samiti, Gorakhpur

: Anita Noora and Vijay Kumar

Instituto PROMUNDO, Brazil : Gary Barker, Marcos Nascimento and Christine Ricardo

We acknowledge Instituto PROMUNDO's partner institutions; Instituto Papai (Brazil), ECOS, and Salud Y Genero (Mexico) for their efforts in developing Programme H manual.

We would also gratefully like to acknowledge the assistance and participation of the all those individuals and organizations who at different stages gave important contributions for publishing this manual.

We would like to thank our funding partners; USAID, Macarthur Foundation, SSL International and Hewlett Foundation for their timely assistance in implementing Yaari Dosti in India.

We are grateful to Vineeta Nathani (PRERNA), Prabha Nagaraj (TARSHI), Sunayna Walia (ICRW), Veera Mandonca (UNICEF), Jameel Zamir and Anjali Kapila (IPPF) and Satish Kumar Singh (MASWA) for their critical inputs leading to important modifications in the manual.

We would also like to acknowledge the contribution made by Vijaya Nidadavolu, VL Thomas and Anurag Mishra (Population Council), Jitendra Verma (SHRISTI) for their assistance in adapting and editing this manual.

Last but not the least the team acknowledges the contributions made by peer leaders and their teams, who were instrumental in giving insights in making this manual relevant to the youth. 



\section{Introduction}

There is increasing recognition of the influence of norms that support inequitable gender relations on HIV/ STI risk and partner violence. In recent years, some innovative programs that aim to reduce gender-related inequities, improve partner communication, and reduce HIV/STI risk have been developed. Program $\mathrm{H}$ (hombres or homens for men in Spanish or Portuguese) in Brazil is one such program implemented by Instituto Promundo and its partners. This program seeks to tap into the "alternative" voices that exist in low income communities, that is of young and adult men who have already been questioning traditional views about what it means to be a man. The program was developed in collaboration with young men from several low-income communities in Brazil. The young men helped define project objectives, test and develop project materials and provide advice on how to reach other young men with messages about gender equity. The Program has two main intervention components. The first component includes interactive group discussions via group educational activities guided by a field-tested curriculum or manual. and a no-words cartoon video to promote reflection on the "costs" of masculinity and encourage HIV/STI and violence prevention. The training manual includes a 20 -minute cartoon video and 70 participatory group activities, each with a focus on gender and organized under five themes. The second component is a lifestyle social marketing campaign that reinforces gender equitable and HIV prevention messages from the group education sessions.

A rigorous evaluation study was undertaken by Horizons, in collaboration with Instituto PROMUNDO, in Brazil to assess program impact. Using the Gender Equitable Men Scale (GEM Scale) researchers attempted to assess whether young men's norms about gender roles was shifting towards more egalitarian attitudes. After participating in program activities (6 months after the baseline), young men's gender related attitudes improved significantly. In addition, selfreported symptoms of sexually transmitted infections (STIs) significantly decreased by more than 45 percent in the intervention group with both the group education and the lifestyle social marketing campaign, and condom use significantly increased with stable partners as well. These positive changes continued-and in some cases increased-at one-year follow-up (Pulerwitz, Barker, and Segundo, 2004). These findings have important implications for program implementers and policy makers concerned about gender inequity and HIV prevention among young men. It has shown that such an intervention with young men is feasible and acceptable, it fostered support for gender equitable norms and can reduce young men's level of HIV risk. This intervention has subsequently been adapted and piloted in other country settings including India. This manual is an adaptation of the 'Program H: Working with men series' curriculum which was used in Brazil. The rest of the section provides the context for the work with young men, details about the manual, its adaptation and use in the Indian setting.

\section{Why Focus on Young Men?}

Worldwide, the behavior of many men-adult and adolescents - puts themselves and their partners at risk of HIV. HIV infection among women is spreading more rapidly than among men in some regions, but the number of men infected worldwide is higher. (18.7 million men and 17 million women estimated to be living with HIV and AIDS at the end of year 2003) (UNAIDS 2004). Young men are at particular risk: About one in four persons infected with HIV and AIDS in the world is a young man under age 25 (Green, 1997). And because both young and older men on average have more sexual partners than women - and because 
HIV is more easily transmitted sexually from man to woman and man to man than from woman to man - an HIV-infected man is likely to infect more persons than an HIV-positive woman. As one UNAIDS official stated, "the HIV epidemic is driven by men... worldwide women may be more affected by the consequences of HIV and AIDS, but it is the sexual and drug taking behavior of a large minority of men which enables the virus to spread" (Forman, 1999).

In addition to involving young men, it needs to be recognized that young men also have their own vulnerabilities to HIV and AIDS that have not been thoroughly examined. Research is helping us understand how societies often reinforce rigid ways of what it means to be men and women. Studies show us how boys feel obliged to prove themselves as "real men" through unprotected sex, how male peer groups may encourage men's violence against women, and how men may be discouraged from talking about their feelings or from seeking health services. The roots of many of boys' and men's behaviors - whether they negotiate with partners about condom use, whether they take care of children they have fathers, and whether they use violence against a partner — are found in the way boys are raised. We sometimes assume that the way that boys and men behave is "natural" - that "boys will be boys." However, boys' violence, their greater rates of substance use and suicide and the disrespectful behavior of some young men toward their partners stems mainly from how families and societies raise boys and girls. Changing how we raise and view boys is not easy, but it is a necessary part of changing some negative aspects of traditional versions of masculinity. UNAIDS devoted the 2000-2001 World AIDS Campaign to men and boys, recognizing that the behavior of many men puts themselves and their partners at risk, and that men need to be engaged in more thoughtful ways as partners in HIV and AIDS prevention and the support of persons living with AIDS.

\section{Young men in India}

In the study conducted with young men in urban slums of Mumbai by CORO and Horizons/Population Council, it was evident that young men described an asli mard ("real man" in Hindi) as someone who was physically attractive, dominant, aggressive, and sexually powerful. Controlling women and violent behaviour were important parts of a definition of a real man. They also thought that young women sought this type of real man. Young men stated that it was important to prove one's manhood, and that proving manliness was characterised by violence against women, risky sexual behaviour, and alcohol and drug use.

Finally, rethinking young men and HIV and AIDS also requires discussing men who have sex with men (MSM), an issue that has too often been hidden. Discussion of sexual activity between men is often distorted by simplistic assumptions that only men who have "effeminate" behavior, or men who define themselves as gay or bisexual have sex with other men. But sexual behavior seldom corresponds neatly to identities of being heterosexual, homosexual, or bisexual. For this reason, UNAIDS and WHO generally use the terms "same-sex sexual behavior" or men who have sex with men (MSM) rather than saying gay or homosexual men. Prejudice, hostility, denial and misconceptions toward men who have sex with men, and with men who define themselves as gay or homosexual, is directly responsible for inadequate HIV prevention measures. Thus, engaging young men in HIV and AIDS prevention is central to reducing the spread of the disease, both for their current sexual activity and their future activity.

However, few programs apply a gender persepctive and incorporate the gender question, seeking to promote gender equality and equity in their daily life. What does it mean to apply a "gender perspective" to working with adolescent boys and young men? Gender - as opposed to sex - refers to the ways that we are socialized to behave, act and dress to be men and women; it is the way these roles, usually stereotyped, are reinforced and internalized and taught. Applying a gender perspective to working with young men implies two major points:

(1) Engaging boys to discuss and reflect about gender inequities in their socio-cultural set up. This includes reflecting on the way that women have often been at disadvantage and that women have often been expected to take responsibility for things like child care, sexual and reproductive health matters and domestic tasks.

(2) Reviewing the specific needs that boys have in terms of their health and development because of the way they are socialized. This means, for example, engaging boys in discussions about substance use or risky behavior, helping boys understand why they may feel pressured to behave in those ways. 


\section{Why focus attention on young men and HIV and AIDS?}

\section{Young men's behavior puts women at risk}

On average, men have more sexual partners than women. HIV is more easily transmitted sexually from man to woman than from woman to man. An HIV-infected man is likely to infect more persons than an HIV-positive woman. Engaging men more extensively in HIV prevention has a tremendous potential to reduce women's risk of HIV.

\section{Young men's behavior puts themselves at risk}

While HIV among women is growing faster, men continue to represent the majority of HIV infection. Young men are less likely to seek health care than young women. In stressful situations - such as living with AIDS-young men often cope less well than young women. In most of the world, young men are more likely than women to use alcohol and other substances - behaviors that increase their risk of HIV infection.

\section{The issue of young men who have sex with men (MSM) has been largely hidden}

Surveys from various parts of the world find that between $1 \%-16 \%$ of all men-regardless of whether they identify themselves as gay, bisexual or heterosexual-report having had sex with another man. Hostility and misconceptions toward MSM led to inadequate HIV and AIDS prevention measures.

\section{From a developmental perspective, there is evidence that styles of interaction in intimate relationships are "rehearsed" during adolescence}

Viewing women as sexual objects, delegating reproductive health concerns to women, use of coercion to obtain sex and viewing sex as performance generally begin in adolescence (and even before) and may continue into adulthood. While ways of interacting with intimate partners change over time, context and relationship, there is strong reason to believe that reaching boys is a way to change how men interact with women.

5. Men need to take a greater role in caring for family members with AIDS, and to consider the impact of their sexual behavior on their children

The number of men affected by AIDS means that millions of women and children are left without their financial support. Caring for HIV-infected persons is mostly carried out by women. Both young and adult men need to be encouraged to take a greater role in this care giving. Young men who are fathers must consider the potential of their sexual behavior to leave their children HIV-infected or orphaned due to AIDS.

\section{Finally, there is a pragmatic and cost-effective reason}

Boys and younger men are often more willing and have more time to participate in group educational activities than do adult men.

\section{From Young Men as Obstacles to Young Men as Allies}

Discussions about boys and young men have often focused on their problems - their lack of participation in positive ways in reproductive and sexual health or their sometimes violent behaviors. Some adolescent health initiatives have seen boys as obstacles or aggressors. This manual starts from the assumption that young men should be seen as allies - potential or actual-and not as obstacles. Boys, even those who sometimes are violent or do not show respect toward their partners, have the potential to be respectful and caring partners, to negotiate in their relationships with dialogue and respect, to assume responsibility for children they father, and to interact and live in peace and coexistence instead of violence. 
It is clear from research and from our personal experiences as educators, parents, teachers and health professionals that boys respond to what we expect for them. If we expect boys to be violent, if we expect them not be involved with the children they may father, if we expect them not to participate in reproductive and sexual health issues in a responsible way, then we create self-fulfilling prophecies. This manual starts from the premise that young men and boys should be viewed as allies. Some young men do in fact act in irresponsible and even violent ways. We do not condone their behavior. But we believe it is imperative that we start from the things that many young men are doing right and believe in the potential of other young men to do the same.

\section{About the manual}

This manual was adapted from the Program $\mathrm{H}$ curriculum and piloted in urban slum communities in India by Committee for Resource Organization (CORO) and Horizons as part of an operations research study aimed at reducing HIV risk among young men by addressing gender norms. This manual can be used by health educators, teachers and/or other professionals or volunteers who want to work, or are already doing so, with young men between 15 and 24 years old, which corresponds to the "youth" age group, as defined by the WHO. We realize that such an age range is extremely wide and we are not necessarily recommending that one works with 15 to 24 year olds in the same group. However, the activities included here have been tested and elaborated for working with young men in this age group and in various places and settings.

The manual has been divided into four subsections:

i. Gender

ii. Sexuality and Reproductive Health

iii. Violence

iv. Preventing and Living with HIV and AIDS

Each sub-section contains a series of activities, lasting from 45 minutes to 2 hours, planned for use in groups of young men, and which with some adaptations can be used with mixed groups. The manual seeks to understand the gender and gender specific roles and how they are reflected upon reproductive health and sexuality. These issues are important and to link them with gender will develop critical thinking among young people. Also this manual seeks to change the taboo about PLWA so that the risk can be reduced.

The first section on Gender has 8 activities. These activities conveys message about positive aspects of masculinity among the young people and also to understand that there should be equity in the way men and women are seen in the society.

The second section of the manual tries to explore the notions and perceptions related with reproductive and sexual health among youth and also how to challenge the age old practices and perceptions on such issues. It has 8 activities which primarily focuses on men's participation in Reproductive and Sexual Health and how it is important for healthy relationship. In one of the activities, pictorial description about human reproductive organs have been given for better understanding of human body.

The third section has 6 activities. This section focuses mainly on the violence which are perpetuated on women and men, particularly on women. The coercion in sexual relationship has been discussed in detail and at the end of every activity more emphasis has been given on to respect and understand partner's feeling.

Issues related with Preventing and Living with HIV and AIDS have been discussed in detail in fourth section of the manual. This section has 7 activities and major emphasies have been on to develop a positive thinking towards PLWA, the infected people need love and sympathy from us and not hatred. Prevention from HIV has also been discussed separately.

Though this manual is developed primarily for male youth in the age group of 15-24 but it can be effectively used for upper age group as well.

We hope that this manual will expedite the efforts on youth related activities in India

\section{How the activities were adapted and implemented}

In India, CORO and Horizons, undertook a study to explore young men's construction and expression of masculinity to inform adaptation and piloting of the Program $\mathrm{H}$ intervention in India. Located in three urban slum communities, the team of peer-educators (who were also involved as researchers in data collection and analysis) from CORO adapted and developed the intervention called Yari-dosti, which means friendship or bonding among men. A key component of the YariDosti intervention is the adaptation and implementation 


\section{Recommendations}

What do we recommend: work with young men in groups of only males or in mixed groups (boys and girls)? Our response is in two forms. Those organizations that are working with groups of men, both adolescents and adults, as well as with groups of women and mixed groups, we believe that sometimes it is more effective to work in only male groups. Some boys and young men feel more comfortable discussing subjects like sexuality and anger among themselves, or express their emotions without women around. In a group context with a facilitator and other young males, men have the capacity to speak about their emotions and subjects which were previously never expressed.

In our experience, some young men complain or show little interest if there are no women in the group. Of course having a girl in the group can make it more interesting. Nevertheless we have also found in many occasions that the presence of women inhibits young males from exposing themselves. They do not open up or allow the women to speak more about intimate subjects. In some groups we see the women even acting as the emotional "ambassadors" of the men, that is to say, the men do not express their emotions, delegating this role to the women.

In applying this activity, it was confirmed that for many of the men present it was the first time they had taken part in a group with only men. Although some said it had been difficult at first, afterwards they thought that it was important to have some time with an all-male group.

However, we recommend, at least part of the time should be dedicated to working with girls and boys together. Men and women live together, they work together; some form couples and families in diverse ways. We believe that educators, professors and professionals that work with young people, should promote respect and equality in their relationships, and at least part of the time, we should work with them in mixed groups.

of group educational activities with young men on the lines of the Working with Men curriculum. Since the young men from the community were also involved in both the formative research and also adaptation process, they used research findings extensively to adapt the group educational activities by way of changing characters, story lines and examples and in some cases even format of exercises provided in the Program $\mathrm{H}$ module ${ }^{1}$. During a weeklong workshop, followed by two months of community consultations, the team adapted over 20 group educational exercises for the Indian context. Among the main themes covered in the exercises were STI/HIV risk and prevention, partner, family and community violence, gender and sexuality, and the reproductive system.

These exercises were then piloted and tested with a group of young men from low-income communities in Mumbai. Selected peer leaders underwent an intensive two-week training programme to strengthen their knowledge and facilitation skills. Peer leaders then recruited young men from the community to participate in the intervention. The young men were recruited from vocational training groups, political, cultural and religious youth groups, youth on the street and through friends network. The 126 participants thus recruited were divided into four groups of 30-35 participants each. The pilot started with an intensive week of group educational activities, facilitated by peer leaders and gender specialists and was followed by two to threehour sessions every week, led by peer leaders only, for a duration of six months.

\section{Purpose of the manuals and the activities}

We hope and believe that the activities included here can in fact change the behavior in certain cases of certain young men. However, to confirm changes of behavior as a result of participating in theses activities, we will need more time and adequate conditions to make an assessment of the impact with control groups, which we do not have at the moment. What we can say through the field tests carried out is that using these activities as part of a group process with young men encourages changes of attitudes and the assimilation of new knowledge concerning violence and the need for greater equality between men and women, whether among young men in the public sphere or among young men and their partners, both male and female, in their intimate relationships.

Process evaluation of the Yari-Dosti intervention indicate that the great majority of young men (118 out of 126 recruited) participated in all activities. Also, most were greatly interested in the activities, as it was their 
first opportunity to discuss these issues with other men. While participants were especially interested in factual/ biological information (e.g., on the human body, sex, HIV), they found sessions on contemplating their sexual and gender attitudes very engaging and often the sessions led to heated discussions. Researchers observed that the process of change began with denial of existing norms and their links to risk, to gradual acceptance that these norms existed, and that change would be worthwhile, and then to exploring ways to challenge these norms and behaviours.

Responses on a gender equity measurement scale during pre and post-tests indicated that a significant proportion of young men moved away from more inequitable attitudes to more egalitarian attitudes towards gender. For example, the proportion of men who said that "it is okay for a man to hit his wife if she refuses sex with him" declined from $28 \%$ during the pre-test to 3\% during the post-test. Similarly, the proportion of young men who believed that "a man should have the final word about decisions in his home" declined from $34 \%$ to $11 \%$. Self-reported harassment of girls (referred to as "eve teasing" in India) significantly declined from $80 \%$ during the pre-test to $43 \%$ during the post-test. A trend towards increasing condom use with casual and partners in sex work was observed (Verma, Pulerwitz and Mahendra, 2005).

\section{What is the ideal adolescent/young man profile we are all looking for?}

The objectives of the training manual is based on assumptions about what we-educators, parents, friends, male and female partners - want young men to be. The work in the areas of gender equity, violence prevention, mental health and HIV and AIDS prevention also has common objectives about the sort of person we believe young men should become. And finally - and most importantly - the expression of the desires of the young men themselves - of what they want to be and how they should be treated by their male peers. With all this in mind, the activities included in the manual has the overall goal of forming young men that:

- Believe in dialog and negotiation instead of violence to resolve conflicts, and who do in fact make use of dialog and negotiations in their interpersonal relationships.
- Show respect toward persons from different backgrounds and styles of life, and who query those who do not show this respect.

- Show respect in their intimate relationships and seek to maintain relationships based on equity and mutual respect, irrespective of whether the young men consider themselves as heterosexual, homosexual or bisexual.

- In the case of men who consider themselves as heterosexual, take part in decisions related to reproduction, discussing with their partners the question of reproductive health and safe sex, using or collaborating with them in the use of contraceptives or other methods when they do not want to have children.

- In the case of men who consider themselves as homosexual or bisexual, or who have sexual relations with other men, talk with their partner or partners about the practice of safe sex.

- Do not believe in or use violence against their intimate partners.

- Believe that taking care of other human beings is also a male attribute and are capable of taking care of someone, whether from friends, relatives, partners and their own children, in the case of young men that are already fathers.

- Believe that men can also express other emotions besides anger and are able to express emotions and seek help — whether from friends or professionals - whenever necessary on questions of health in general and also mental health.

- Believe in the importance and have the ability to take care of their bodies and their own health, including persons with AIDS or HIV positive.

\section{How to use these activities?}

The central point of this manual consists of a series of activities for working with young men in groups. These activities were developed and tested with groups of 15 to 30 participants. Our experience shows that using this material with smaller groups (15 to 20 participants) is more productive, but the facilitator can also use the outlined activities for larger groups. Many of the activities included here deal with deep and complex personal themes, such as promoting peaceful coexistence, sexuality and mental health. We recommend that these activities be facilitated by 


\section{Note for facilitators}

- Experience in using these materials has shown that it is preferable to use the activities as a complete set and not in an isolated way.

- It is useful, whenever possible, to have two facilitators present.

- A suitable space for working with the young men should be used, allowing the activities to be carried out without any restriction of movement.

- One should try and produce a free and respectful environment, where there are no judgments or criticisms of the attitudes, language or behavior of the young men.

- Situations of conflict may occur. It is up to the facilitators to intervene, seeking to establish a consensus and respect for different opinions. The work should endeavor to go as deep as possible, moving beyond the standard "politically correct discourse".

- It should be remembered that physical contact for male adolescents is not always easy. Activities that require physical contact can and should BE presented with the choice or not of participating, respecting each person's limits

- The discussion points suggested in the activities presented do not necessarily have to be used at the end of the activities, but can be used while it is being executed, as the facilitator thinks fit.

persons that feel comfortable dealing with these themes, have experience of working with young men and have support from their organizations and/or other adults to carry out such activities.

We acknowledge that applying such activities is not always an easy task and not always predictable. The themes are complex and sensitive-violence, sexuality, AIDS. There may be groups of young men that open up and express their inner feelings during the process, while others simply do not want to talk. We do not suggest that these activities be used as group therapy. They should be seen as part of a process of reflection and participatory education. The key factor in this process is the educator or facilitator. It is up to

\section{Where and how to work with young men?}

These activities can and should be used in various circumstances - in school, sporting groups, youth clubs, military barracks, juvenile correction centers, community groups, etc. They can also be used with groups of young men in a waiting room of a clinic or health center. In other words, what it needs is a private space, available time and willing facilitators.

Bearing in mind that the young men are generally still in a growing stage, it is recommended-that some type of snack be offered and physical and/or movement activities be included.

him/her to know whether they feel comfortable with these themes and are able to administer the activities. The purpose behind this type of intervention is to go beyond this stage, prompting reflections and changes in attitudes.

\section{Men or Women Facilitators?}

Who should facilitate the group activities with young men? Should only men be facilitators? The experience of the collaborating organizations is that in some settings young men appreciate the opportunity to work with and interact with a male facilitator who can listen to them in a thoughtful way and who can serve as a model in some ways for thinking about what it means to be a man. However, our collective experience suggests that the qualities of the facilitator - the ability of a facilitator, man or woman, to engage a group, to listen to them, to inspire them - are far more important than the sex of the facilitator. We have also found it useful to have facilitators work in pairs, and sometimes male-female pairs, which has the important benefit of showing the young men ways that men and women can engage as equals and with respect.

\section{Adapting the material}

We want this material to be used and adapted in the broadest possible way. It may also be reprinted on requesting permission from Population Council/CORO 
and the other collaborating organizations. Should there be any interest in reprinting this material with the name and logo of your organization, please contact Population Council. Reproduction of this material is permitted, provided the source is cited.

\section{References}

Bhatalwande, Prakash, Gangakhedkar, Raman (2002), Yauvan Ki Dahliz Par, UNICEF

Green, C. (1997). Young men: The forgotten factor in reproductive health. Washington, DC: FOCUS on Young Adults, Occasional Paper No. 1 (Unpublished draft).

Hathcher, RA, Rinehart, W, Blackburn, R, Geuer, JS and Shelton, JD. The Essentials of Contraceptive Technology. Baltimore, Johns Hopkins University School of Public Helath, Population Information Program, 1997.

HORIZONS Report (December) 2004. Involving Yong Men in HIV Prevention Programs: Operations research on gender-based approaches in Brazil, Tanzania, and India.

Instituto PROMUNDO and collaborators. 2002 Project $H$ : Working with Young Men Series.

Joint United Nations Programme on HIV and AIDS (UNAIDS) 2004. Report on the global HIV and AIDS epidemic. Geneva.

Pulewitz J, Barker G, Segundo M. 2004 "Promoting healthy relationships and HIV/STI prevention for young men: Positive findings from an intervention study in Brazil" Horizons Research Update. April.

Srivastava, Alok, Mardangi:Purushon ke liye margdarshak, a publication of Youth Alliance of AIDS Removal (YAAR), New Delhi.

UNESCO, 2006, Masculinity for Boys: Resource Guide for Peer Educators.

Verma R K, Mahendra VS, Pulerwitz J, Khandekar S, van Dam J, Flessenkaemper S, Rangaiyan G, Barker G; 2005 "From Research to action: Addressing Masculinity as a strategy to reduce HIV risk behavior: From Research to Action"; Indian Journal of Social Work (special issue); January. 

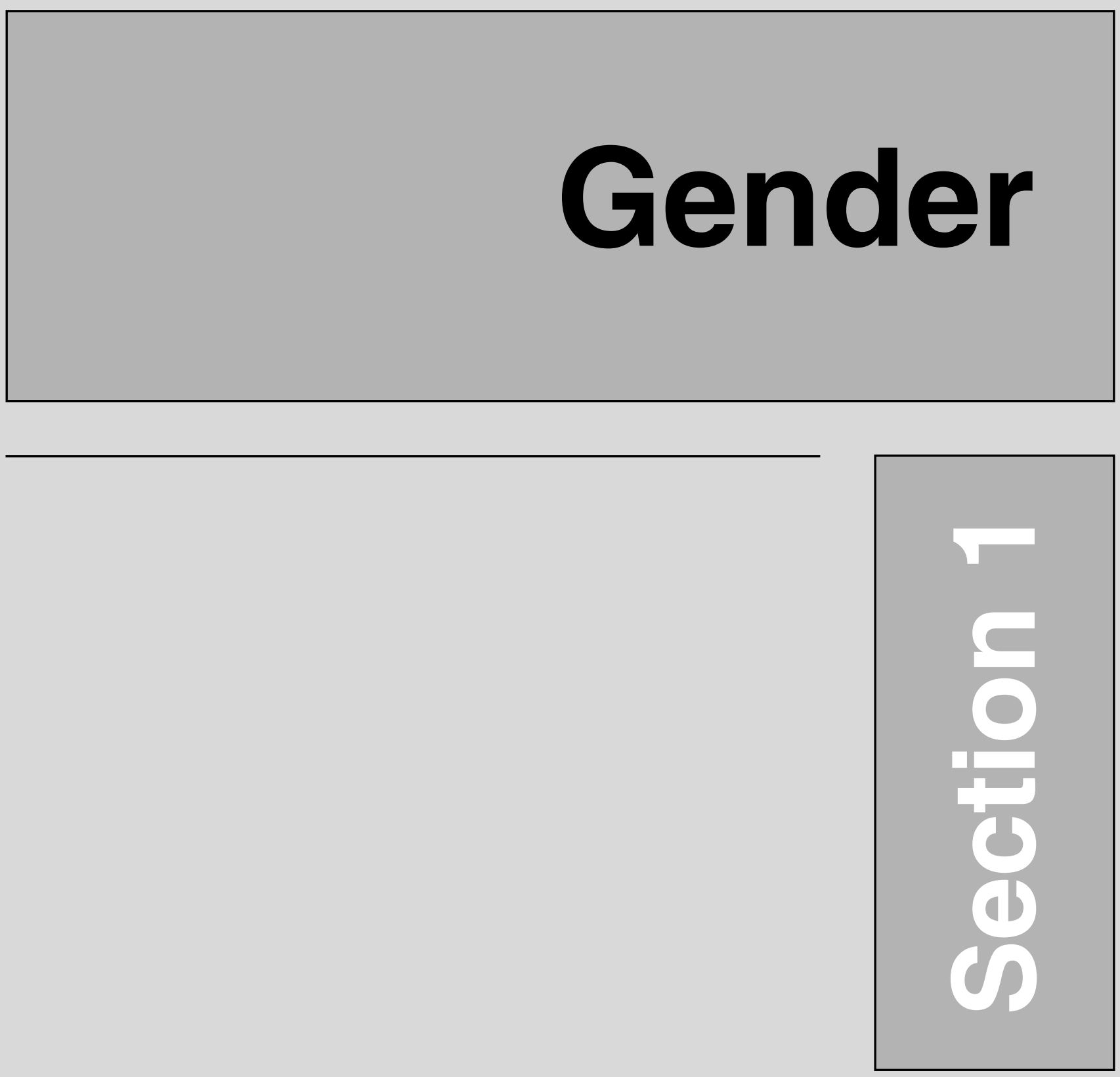



\section{Activity 1.1}

Gender

At the end of this activity we can understand the underlying meaning of gender and how young men define and construct masculinity and feminity.

Purpose: To understand the various terms and action related with Gender

Recommended time: 1 hour

Materials Required: Wall Board (or wall can be used in case wall board is not available), color marker, chalk and A4 paper.

\section{Procedure}

Draw a vertical line across the wall board so that the board is divided into two equal parts. On one part write 'Man' and on other part write 'Woman'. To start the discussions follow the following questions. All responses should be listed separately for 'man' and 'woman' for discussion. This process is termed as Free listing.

- What comes to your mind when you hear the word Male?

- What comes to your mind when you hear the word Female?

\begin{tabular}{|c|c|}
\hline \multicolumn{2}{|l|}{ Example for free listing } \\
\hline $\begin{array}{l}\text { What comes to your mind when you } \\
\text { hear the word Male? }\end{array}$ & $\begin{array}{l}\text { What comes to your mind when you hear } \\
\text { the word Female? }\end{array}$ \\
\hline 1. Strong & 1. Beautiful \\
\hline 2. Fraud & 2. Housewife \\
\hline 3. Drunkard & 3. Prostitute \\
\hline 4. Gambler & 4. 'Item' \\
\hline
\end{tabular}




\section{Discussion questions}

- What it means to be a 'Man'?

- What it means to be a 'Woman'?

- What are the differences between a man and a woman?

- What are the similarities between a man and a woman?

- Who created these differences?

- List the social and biological differences and similarities between a man and a woman?

- Why is it that men do not respect or appreciate women for their doing the domestic chores?

- Men do cook and wash, and sew (considered 'women's work') when they are paid for the work. Why is this so?

- Who takes the decisions at home and why?

\section{Highlight the following}

- Differences between men and women have been created by our own society.

- We should understand the social and biological differences between men and women.
- There are distinct biological differences between a man and a woman which are essential for reproduction; but this should not lead to differences at the societal level.

- The difference created by society is called gender related discrimination.

- The work division between men and women is not allocated at birth?

\section{Tips for facilitator}

- It is important to use the words and phrases in the local languages during the free listing and discussion.

- Be careful about words and phrases which could hurt either religious or individual sentiments.

- Motivate all members of the group to participate.

- During such discussions, having two facilitators is ideal, as one can facilitate and other can write down the important issues raised during the discussions. 


\section{Sexuality and Reproduction}

This activity will improve the understanding of how do young people understand and perceive sexuality and reproduction.

Purpose: To understand the meanings and explanations related with sexuality and reproduction and also to understand the importance of male involvement in reproductive health

Time: $1 \frac{1 / 2}{2}$ to 2 hours

Materials required: Wall board, color marker

\section{To start with}

\section{Ask the Group}

- What is the meaning of sexuality?

- Do the sexualities of men and women differ? What are the differences?

- How does a man express his affection? And how does a woman express her affection? Why are there differences in the ways of expression?

- What are the roles of men in reproductive health?

\section{Highlight the following}

Involve the participants and highlight the following issues:

- The meaning of being a man and a woman in society.
- The sexuality of a human being is the outcome of his/her mental and societal environment.

- Insist that even in close relationships there are some boundaries which we need to respect. We should always respect our partner's likes and dislikes in a sexual relationship. In general, women do not come out with their sexual desires openly and so the sharing of power in a relationship is based on ambiguous age old tradition. For example, man is always ready for sex and he should always have control over his woman or women should always look to men for sex. Women should always depend upon men. Men can have sex with women, whenever and wherever they want, even if she is not willing. Such unilateral behavior leads to health risk in sexual and intimate relationships. STIs and HIV can be the outcome of such sexual behavior. 


\section{Reading List}

\begin{tabular}{llll}
\hline Sr. No. & References & Author & Organization \\
\hline 1 & Emerging Leadership & Ms. Sujata Khandekar & CORO, Mumbai \\
2 & Stepping stone & Action Aid International & Action Aid International \\
3 & Yeh Gender Kya hai $?$ & Kamla Bhasin & Jogeshwari 2000 \\
4 & Mardangi & Alok Srivastava & YAAR, Delhi \\
5 & Niramaya Kaamjeevan & Dr. Vithal Prabhu & Mumbai \\
6 & Yauvan ki Dahliz par & UNICEF & UNICEF \\
7 & Laal Kitab & Shalini & TAARSHI \\
8 & Neeli Kitab & Shalini & TAARSHI \\
9 & Aamachya Bharirawar Aamcha Haq & Manisha Gupte & CEHAT \\
\hline
\end{tabular}

\section{Closings}

Sexuality is a total sensory experience, involving the whole mind and body-not just the genitals. Sexuality is shaped by a person's values, attitudes, behavior, physical appearance, beliefs, emotions, personality, likes and dislikes, and spiritual selves, as well as all the ways in which one has been socialized.

Reproduction is the process of generating offspring. The cycle of reproduction starts with sexual contacts between a man and a woman up till the birth of the child. 
This activity promotes a discussion about how labeling people can limit our individual potential.

Purpose: To recognize how personal characteristics are transformed into labels that affect human relations.

Materials required: Self-adhesive labels, felt-tip pens

Recommended time: One hour and thirty minutes

Planning tips/notes: It is important for the facilitator to help the young men get involved by participating in the dynamics of the exercise. The facilitator should also make sure that none of the participants become aggressive or offended by any of the labels used.

\section{Procedure}

- Ask the participants to form groups of 5 or 6 people and tell them that they will have to carry out a task: develop a program to work with children on the issue of HIV and AIDS prevention.

- At random, stick a self-adhesive label on the back of each participant with a characteristic (prostitute, homosexual, doctor, eunuchs, rowdy, housewife, leader, thief, liar, poor, rich, officer etc). The participants cannot see the labels on their own backs; they can only see other people's.

- To carry out this task they have to relate with the other members of the team, who should treat them according to the characteristic they have on the label.

- After 10 to 15 minutes working on the task, ask them to stop.
- Reflect with the group about what happened to each of them and how they felt. At the same time, each person should try to guess what their label is based on the way they were treated.

\section{Questions for discussion}

- What happened in the Activity? How did they feel?

- Did you manage to fulfill the task?

- Did the types of attitudes that emerged in the group hamper or facilitate completing the task?

What does this Activity have to do with real life?

- How do labels affect relationships between people? What other examples of labels do they know?

- How do we react when these situations occur?

- How can one live with "labels?" 


\section{Closing}

- Discuss how labels and stereotypes affect people and where they come from.

- Emphasize the importance of "unlearning" some of the ways that we interact with others, for example:

- Using punishment, blackmail and being judgmental

- Using labels or negative nicknames.

- Using discrimination based on skin color, social class, or sexual orientation.

- Making someone in the family and/or classroom a scapegoat.

- Being inflexible or stubborn.

- Showing indifference, silence or spite.

- The feeling of belonging to a group, group integration and genuine participation are fundamental for learning and for developing our individual and collective potential.

Link: This activity is related to violence. We should recall from the introductory section on violence that labeling young men as delinquents or violent actually encourages violence.

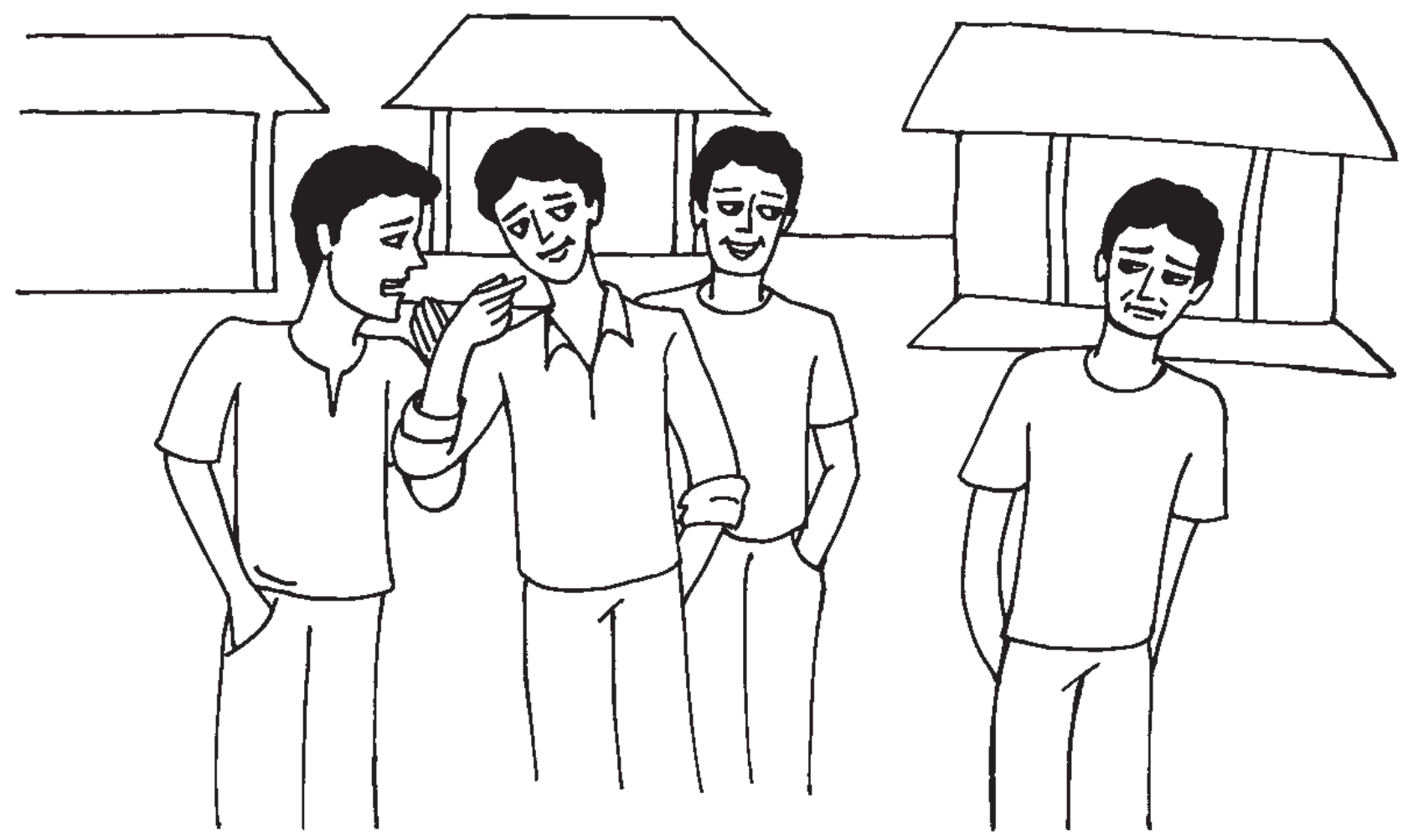




\section{Activity 1.4 \\ Persons and Things ${ }^{1}$}

Purpose: To increase awareness about the existence of power in relationships and reflect on how we communicate about and demonstrate power in relationships, and to analyze how power influences the negotiation of safer sex.

\section{Recommended time: 1 hour}

Planning tips/notes: Generally, when power roles are inverted and those who hold power are forced to be submissive, the person repeats the same power relationships, despite having undergone experiences that were considered unjust. It is important, as facilitators and educators, to emphasize power in relationships and in our lives. Discuss how people who use and abuse power often do not even respect or accept themselves, are generally dissatisfied with themselves, and often feel they have to exercise power over others to feel that they are in control. In sum, emphasize that the way some men (and women) use power over others is harmful to others, but usually has a cost for men as well.

\section{Procedure}

1. Divide the group in two with an imaginary line. Each side should have the same number of participants.

2. Tell the participants that the name of this activity is: Persons and Things. Choose, at random, one group to be the "things" and the other the "persons" or people.

3. Explain the rules for each group:
4. Ask the group of "persons" to take "things" and do what they want with them. They can order them to do any kind of activity.

5. Give the group 15 to 20 minutes for the "things" to carry out the designated roles (in the room itself).

6. Finally, ask the groups to go back to their places in the room.

\begin{tabular}{|c|c|}
\hline Things & Persons \\
\hline $\begin{array}{l}\text { - } \text { cannot think } \\
\text { - } \text { cannot feel } \\
\text { - } \text { hake decisions } \\
\text { - have to do whality } \\
\text { - } \text { If a thing wants to move or do something, it has } \\
\text { to ask the person for permission. }\end{array}$ & $\begin{array}{l}\text { - } \quad \text { can think } \\
\text { - } \text { can make decisions } \\
\text { - } \text { have sexuality } \\
\text { - } \quad \text { can feel } \\
\text { can the things they want. }\end{array}$ \\
\hline
\end{tabular}

${ }^{1}$ This activity was reproduced and adapted from the publication Guia para capacitadores y capacitadoras en Salud Reproductiva. New York: IPPF. 1998. 


\section{Discussion questions}

- What was the experience like?

- For the "things," how did your "person" treat you?
- What did you feel? Why?

- In our daily life, do we treat others like this? Who? Why?

- How can we change this kind of treatment?

\section{Closings}

Return to the feelings generated by the Activity and discuss what the power relationships were like and why they were like this. In general, "things" feel angry toward "persons" and in turn feel rebellion against submission, aggression, dependency, anger and resentment.
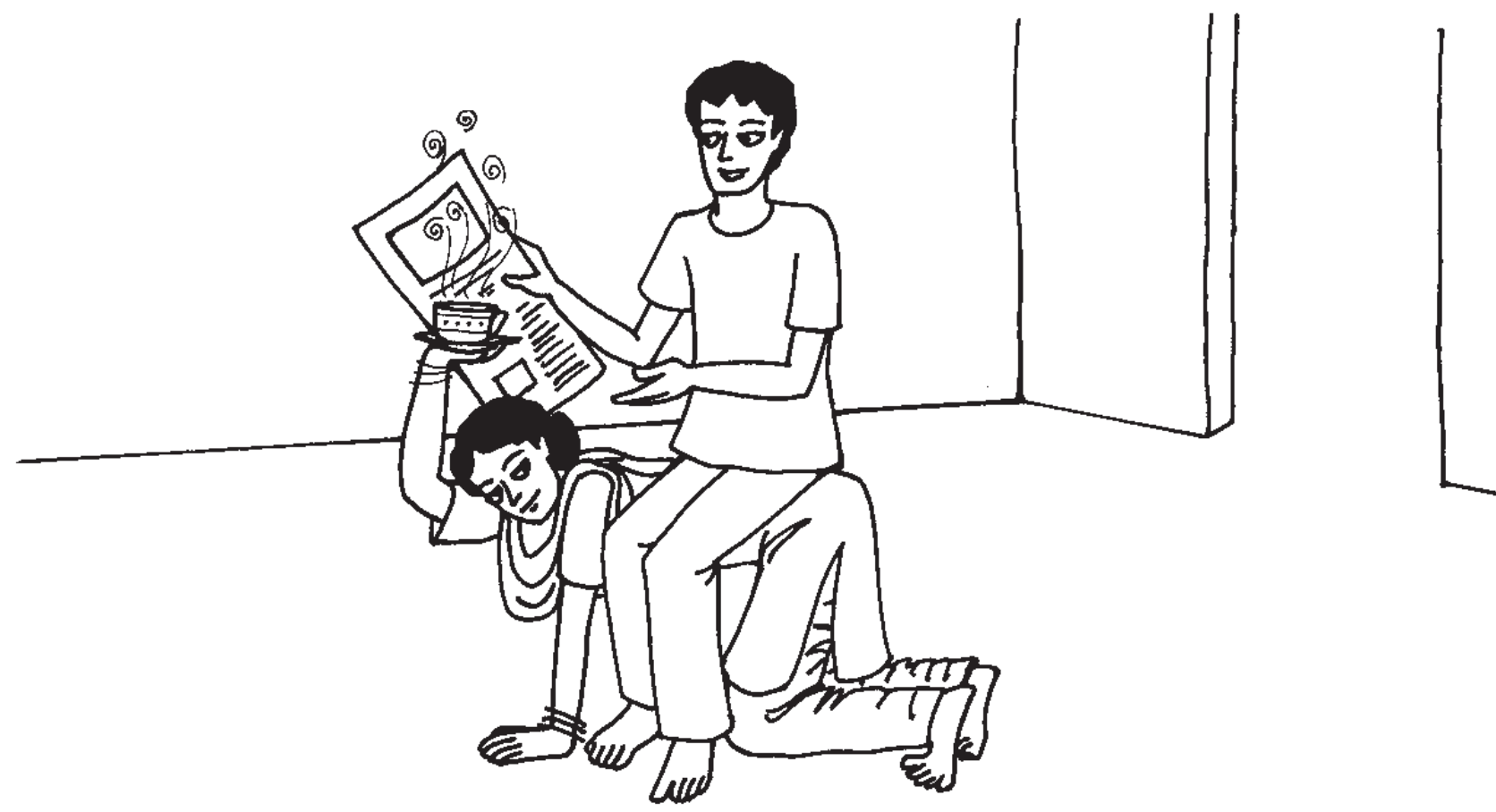
Activity 1.5

\section{Domestic Tasks: We Only Notice when Nobody Does Them!}

This activity discusses domestic chores - generally daily, repetitive, undervalued and barely visible activities and usually performed by women.

Purpose :To discuss the lack of visibility and low value attached to domestic tasks and to question the different ways that boys and girls are raised to view domestic chores.

\section{Material required : None}

\section{Recommended time : 1 hour}

\section{Planning tips/notes}

- The facilitator can include real objects in staging the scene, such as a broom, feather duster, apron, dish towels, etc.

- During the activity, jabs or jokes about the masculinity or manhood of certain participants might crop up. The facilitator should be alert to any possible embarrassment and employ strategies to minimize the effect of these comments.

- The majority of men, at one time or other, have already been engaged in some kind of daily domestic activity, even though we seldom talk about this. Such experiences, when evoked, can be worked on as an illustration of other possibilities of action, showing that performing domestic activities in no way affects a young man's masculinity.

\section{Procedure}

- Ask the participants to role play or stage as a group the "tidying up" of a home. Each participant performs a function.

- Ask one of the participants to stop working and for the others to divide the activities among themselves.

- Tell another participant to stop working.
- Proceed like this, until only one person remains.

- At the end, ask the last participant to stop working.

- Ask the group: "A week later, what would the house be like?"

- Open up the discussion, inviting the participants to reflect on their personal involvement in domestic chores in their own

\footnotetext{
${ }^{1}$ Inspired by an episode from the series Retrato falado, a humorous sketch of the show Fantástico on Rede Globo de Televisão, Brazil.
} 
homes and the value that they attach to these tasks.

\section{Questions for reflection}

- How did each participant feel when the other stopped working?

- How did the last worker feel?

- Which of the activities staged do the participants really perform in their own home?

- Who generally performs these activities?
- What kind of domestic activities do men frequently perform?

- What kind of domestic activities do men perform only occasionally?

- Do people notice house work, or is it only noticed when it is not done?

- In a place like the army, who does the chores? What is the difference between these tasks and domestic activities?

- In childhood, who is encouraged to do domestic work, boys or girls?

- Whose toys - boys' or girls' — have more to do with domestic chores?

\section{Closing}

The educator should point out the importance of daily domestic work, little valued and rarely noticed by those who do not do it, and stress that men and women are equally capable of performing domestic activities. There is nothing in a woman's nature that makes her specifically good at housework. Thus, the differences in attitude between men and women is due to socially constructed male and female models - that is how we are raised to be men and women.
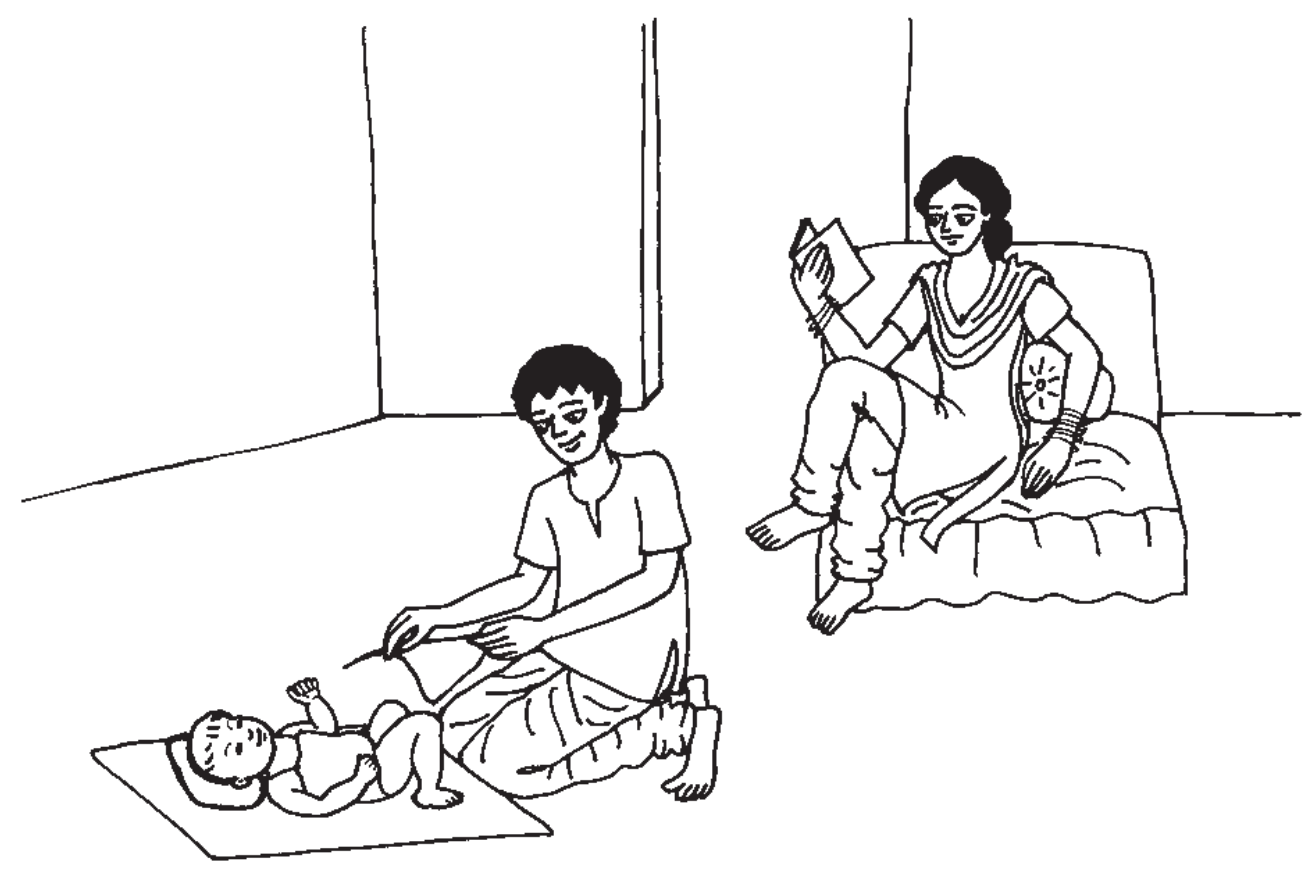


\section{Activity 1.6 \\ Expressing My Emotions}

This activity uses a short story to promote an individual reflection about how we express our emotions.

Purpose: To recognize the difficulties that exist in expressing certain emotions, and analyze the impact of this on our mental health, and to promote a personal reflection about how we suppress or exaggerate our emotions.

Materials required:Large sheets of paper/ flip chart, post- it, adhesive tape, color pencils, water color paints.

Recommended time: Two hours and thirty minutes.

\section{Planning tips/notes}

We recommend that the facilitator go through this activity individually and reflect about his/her own emotions and emotional expressions before facilitating the activity with young men. When carrying out the activity, the facilitator should emphasize that how each person expresses his or her emotions varies. However, it is important to note a number of tendencies that emerge, particularly related to how boys are brought up. For example, it is common for young men to hide their fear, sadness and even their kindness. But it is common for them to express their anger via violence.

The facilitator should emphasize that a person who does not know his own emotions, not only can not express them, but also runs the risk of being carried away by them. It is fundamental to distinguish between "feeling" and "acting" in order to find forms of expression that do not cause damage to others. For this reason, this activity is very useful in working with violence prevention.

It is important to emphasize that promoting our emotional intelligence starts first by learning to recognize our emotions and to see the emotions of others. Because of the way men are socialized, they often have difficulty looking another young man in the eye, which can be interpreted either as a challenge (or a call to fight) or a sign of sexual attraction. This is an opportune moment to clarify to the young men that looking another young man in the eye is another way of expressing and improving communication and not a challenge or a sexual invitation. 


\section{Procedure}

- Ask the group to sit in a circle and read the story : "The other me."

When they finish, reading, ask:

- What most attracted your attention in the story?

- What do you find in the story which is very like what happens in real life?

- Reflect for a while on the aspects, attitudes, emotions that you think have been left out. Why do you think this happened?

- What was the point of leaving out these aspects, and what areas, attitudes and emotions should have been developed further?

- What was the cost of this omission?

- Ask the group what their favorite food is. Allow various persons to reply. Do the same with the question: what food do you like the least? Explain that just as with food, there are likes and dislikes in dealing with emotions; there are also certain emotions that we feel more often and express with greater facility, just as there are others that are more difficult to manage and which we even try to avoid.

- Write up on the board five basic emotions ${ }^{2}$ and tell the group that these are the emotions they will be discussing in this activity:

\section{Fear \\ Affection \\ Sadness \\ Happiness \\ Anger}

- Explain that from now on, the exercise will be to identify in which parts of the body each emotion is felt and how can we differentiate one emotion from the other.

- Tell the group that the exercise will be carried out individually in the following way:

- Put a number (1) on the emotion that they express with the greatest ease.

- Put a number (2) on the one they express easily but not as much as the first.
- Put a number (3) on the emotion that falls in between, that is, it is neither too hard nor too easy to express.

- Number (4) on the one they have some difficulty in expressing.

- Number (5) on the one they have great difficulty in expressing, and which they may often deny.

- After finishing this individual Activity, ask them to share their results with the rest of the group. It is important that everybody takes part. If the group is very large, form sub-groups.

- With the complete group, reflect on the similarities and differences found within the small groups. Explain that:

- The emotions that we numbered as 1 and 2, are the ones we have often learned to express in an exaggerated way

- Numbers 4 and 5, are those that we have learned to express less, or maybe even to repress;

- Number 3 may represent the emotion that we do not exaggerate nor repress but probably deal with more naturally.

\section{Questions for discussions}

- Why do we either repress or exaggerate certain emotions? How did we learn to do this? What has been the cost for you in doing this?

- How does my FASHA influence the relationships that I establish with other people (partners, family, friends, etc)?

- What is the function of emotions? Give examples (fear helps us in situations of danger, anger to defend ourselves) and ask the group for examples.

- What can we do to express our emotions more openly? How can I be more flexible in expressing what I feel? (Each person can make a note of his personal reflections and, if they so desire, they can share their reflections with the others in small groups).

\footnotetext{
${ }^{1}$ Benendetti, Mario, A morte e outras coisas, Ed.. Século XXI.

${ }^{2}$ Other proposals of feelings might emerge from the group which, generally speaking, fit in with or are related to one of those already mentioned, for example, hate related to anger. Once a young man proposed indifference, but in working on it, he discovered that more than a feeling, it was a mask that hid fear and sadness. Also shame, guilt or violence might come up. One can give support to the participants encouraging reflection on the costs and consequences and whether these help us to grow as human beings.
} 


\section{Closing}

- At the end, the facilitator should emphasize that emotions can be seen as a form of energy that allows us to perceive what is oppressing us or bothering us and perhaps even causing harm internally. Being able to express them without causing harm to others helps to make us stronger and to relate better with the world around us. Different emotions are simply the reflection of affective needs, and it is best to learn how to deal with all of them as they appear in our lives. Generally speaking, from the time we are born, certain ideas are imposed on us, such as, for example, that boys should not be cowards and girls should not show anger. Emotional health has to do with being flexible in dealing with our emotions.

- Explain that emotions are neither good nor bad, nor female nor male, but are part of all human beings. Explain that we are not responsible for feeling certain emotions, but for what we do with what we feel. In terms of anger, it is important that the group recognizes the difference between violence and the direct and verbal expression of anger.

- Close the session with the question: Have you discovered anything new about yourselves from this activity?

\section{"The Other Me"}

This is a story about an ordinary boy: his pants were worn at the knees, he read comic books; he made a noise when he ate; he picked his nose; he snored when he slept. He was called Vijay. He was ordinary in everything, except one thing: he had an Other Me.

The Other Me had a romantic look in his eye, fell in love with movie actresses, could make up stories and lie easily, and got all emotional when he saw the sun set. Vijay was worried about his Other Me, which bothered him when he was with his friends. In addition, the Other Me was often sad and sensitive, which meant that Vijay couldn't laugh everything off like he wanted to.

One afternoon, Vijay came home from work feeling tired, took off his shoes, wiggled his toes and turned on the radio. The radio was playing classical music, a piece by Naushad, and Vijay fell asleep. When he woke up the Other Me was sobbing. At first Vijay didn't know what to do, but then he pulled himself together and rudely insulted the Other Me. The Other Me was silent while Vijay insulted him, but the next morning the Other Me committed suicide.

At first, the death of the Other Me was a bitter blow for poor Vijay, but then he thought about it and realized that now he could finally be rude all the time without feeling sad or sensitive. The thought of this made him feel better.

After just five days of mourning, Vijay went out with the express purpose of showing off his new and improved rudeness. From a distance, he saw his friends walking along in a group. The sight of them filled him 


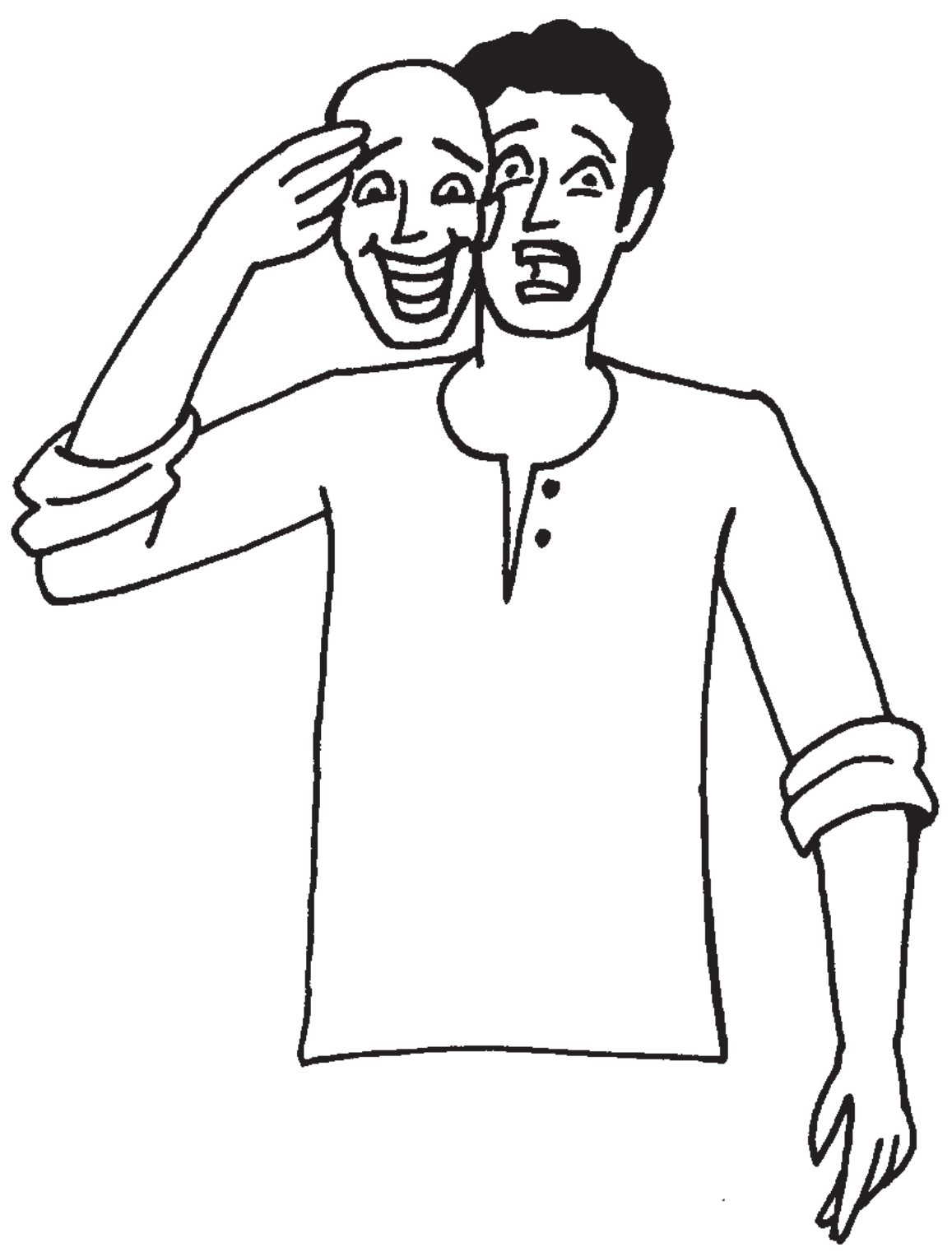

with joy and he immediately burst into laughter. However, when they walked past him they didn't even notice he was there. And what was worse, he overheard what they were saying: poor Vijay, who would have believed it, he seemed so strong and healthy.

On hearing this, he immediately stopped laughing and at the same time, felt a tightening in his chest, which seemed like nostalgia. But he could not feel real sadness, because the Other Me had taken all the sadness with him. 
In this activity, participants practice making decisions related to alcohol use.

Purpose: To reflect on decision-making related to alcohol use.

Materials required: Questionnaire for each participant, flip-chart and felt-tip pens.

Recommended time: One hour and thirty minutes

Planning tips/notes: It is important to maintain an atmosphere of frankness and respect toward different opinions and attitudes. It is worth making copies of the questionnaire or reproducing it in a flip-chart with large letters.

\section{Procedure:}

\section{First Part}

- Hand out the questionnaire to be completed individually with two possible answers: "Yes, and why" or "No, and why" (Resource Sheet).

- Having answered the questions, the participants should share their replies with each other. If the group is large, it can be divided in groups of 8 to 10 participants.

- Ask each participant to read their answers and keep a note of the findings in the flip-chart.

- At the end, reinforce the following ideas:

- Since peer pressure and group imitation is one of the most important factors behind adolescents drinking, we need to question these.

- Stress that drink or not drink is a decision that we make based on various factors: personal beliefs, religious beliefs, health concerns, out of respect for certain family or social standards and, above all, because we have alternatives for having fun and making friends.
- Work with the participants to consider alternatives where friendship and belonging to the group can be achieved without alcohol.

\section{Second Part}

- Continue the activity by asking the group other questions:

- What happens to someone who, to feel good in a social situation, needs to drink?

- Why would someone be so concerned that you drink? Is it friendship or complicity?

- How do we know if someone is already alcohol-dependent?

- Tell the group that it is worth remembering that one of the early symptoms of alcoholism, according to Heilman's criteria, is to use alcohol deliberately with the intent of obtaining some subjectively agreeable effect, such as to lose your inhibitions in a social context.

- To provide some guidance to the group on recognizing the early signs of alcohol dependency, use the following table: 


\section{Heilman's ${ }^{1}$ Criteria for the early recognition of alcohol abuse or dependence}

1. To think about, talk about or plan when the next occasion to drink will be.

2. Tolerate a greater amount than the average.

3. Drink rapidly.

4. Drink to obtain some effect, as a tranquilizer or to have courage to do something.

5. Forget some detail or event of what happened while drinking.

6. To protect, store or ensure the supply of alcohol.

7. To drink more than planned or without having planned.

8. An additional highly sensitive criteria is: to express concern or regret to someone close about what you did (or did not do) while under the effects of alcohol.

Note: The presence of more than two criteria indicates a need to consider or assess the person's alcohol abuse risk.

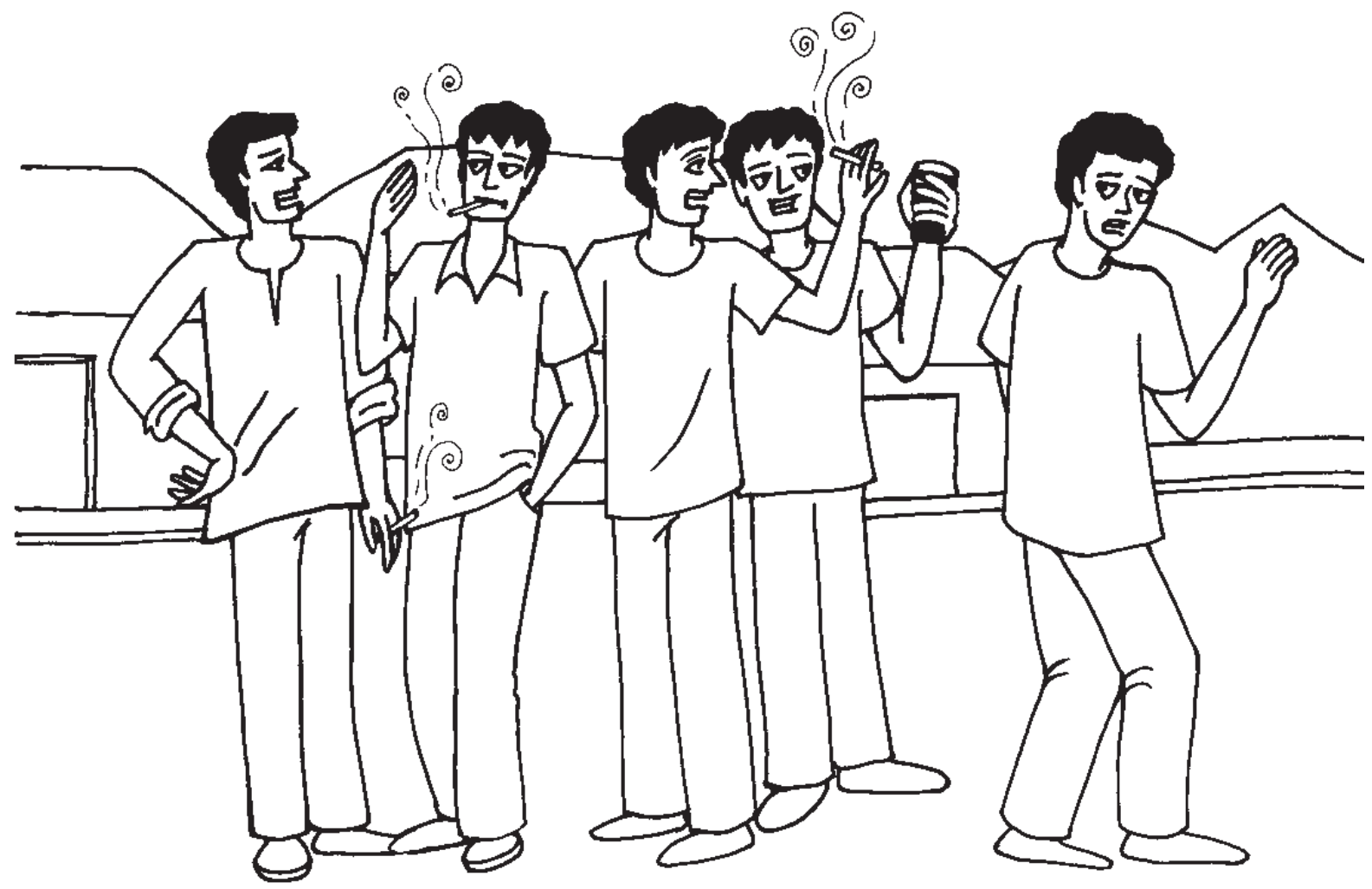

${ }^{1}$ Heilman Richard. "Early recognition of alcoholism and other drug dependencies." Hazelden, 1990. 


\section{Resource Sheet: Decision-Making}

\section{Answer the following questions sincerely}

\begin{tabular}{|c|c|c|c|}
\hline & & Yes & No \\
\hline & $\begin{array}{l}\text { Would you feel out of place at a party or gathering with your friends if } \\
\text { they offered you a drink (with alcohol) and you decided not to have one? } \\
\text { Why? }\end{array}$ & & \\
\hline & $\begin{array}{l}\text { Imagine that you are at a party or social gathering where they are serving } \\
\text { alcohol and you are drinking, but one of your friends doesn't want to drink. } \\
\text { Would you view your friend as an oddball, a drag, or a nerd? } \\
\text { Why? }\end{array}$ & & \\
\hline & $\begin{array}{l}\text { Would you defend your friend's decision not to drink to the other friends? } \\
\text { Supposing that you decided to defend him/her, how do you think the other } \\
\text { friends would judge you? } \\
\text { Why? }\end{array}$ & & \\
\hline & $\begin{array}{l}\text { Do you believe that to be accepted in a group you have to do what the } \\
\text { other persons in the group want? } \\
\text { Why? }\end{array}$ & & \\
\hline & $\begin{array}{l}\text { Do you think that is possible for a person to lead an enjoyable social life } \\
\text { without consuming alcoholic drinks? } \\
\text { Why? }\end{array}$ & & \\
\hline & $\begin{array}{l}\text { Can a person feel good about himself even without drinking? } \\
\text { Why? }\end{array}$ & & \\
\hline & $\begin{array}{l}\text { Can an adolescent feel accepted without drinking? } \\
\text { Why? }\end{array}$ & & \\
\hline
\end{tabular}




\section{Activity 1.8 \\ "Lottery of Life"1}

Purpose : To promote greater awareness among young men about the need to care for their own bodies and health.

Material required: Lottery cards (see Back-up Sheet), pencil, markers.

Recommended time: 1 hour and thirty minutes

\section{Planning tips/notes}

- The cardboard can be replaced with a blackboard or flip-chart. If no such material is available, one can simply read out the questions and answers.

- For groups with reading difficulty, the card can be replaced by reading out loud.

\section{Procedure}

1. Divide the participants into groups of 5 or 6 .

2. Tell the participants that they will be taking part in a lottery and the person that scores the highest will win a prize.

3. Hand out a "lottery of life" card to each group.

4. Explain the card to the participants, pointing out that there are three columns: Man, Woman and Both. The group should answer the questions on the card, marking with an $\mathrm{X}$ the reply they think correct.

5. Allow 20 minutes for the group to discuss and mark the answers.

6. Then collect the cards.

7. Write the questions on a large poster, flipchart paper or on the blackboard and then read out each question; ask how the groups replied and mark with an X the correct answer. (The correct answer for every question is Men!)
8. Explore the replies of the group, asking them to justify their replies, particularly when they have marked Woman or Both.

9. At the end, clarify that for all the categories, men are in the majority. Open up the discussion: Did you know this? Why do you think this happens? How is it possible to avoid this?

\section{Questions for reflection}

- If men took more care of themselves, would this situation be the same?

- What kinds of stresses do men face? Why?

- What kinds of stresses do women face? Why?

- When you are ill or sick, what do you do?

- Do you usually look for help as soon as you feel ill, or wait?

\footnotetext{
${ }^{1}$ Inspired by the activity in the manual Fatherhood Development: A Curriculum for Young Fathers, by Pamela Wilson
} \& Jeffery Johnson - Public Privates Ventures, 1995. 
- How often do you go to the doctor?

- Can a man be vain or worried about his appearance?
- Who usually worries more about their appearance, women or men? Why?

\section{Links}

For further information about the male mortality rate due to external causes, particularly related to violence, see the related section in this manual on Violence.

\section{Closing}

In closing the session, remind them that the majority of the causes of death for men are associated with the self-destructive lifestyle that many men follow, but that through taking care of themselves and rethinking their health, they can change this.

\section{Important information for facilitator}

\begin{tabular}{|lcc|}
\hline Causes of death & Male & Female \\
\hline Due to infections & 15.4 & 13.5 \\
Mental disorder & 0.2 & 0.1 \\
Cardio related & 24.6 & 22.4 \\
Digestion related & 5.1 & 2.8 \\
& & \\
Death due to external reasons & 19.7 & 15.8 \\
15-24 age & 23.7 & 11.4 \\
25-34 age & 17.0 & 11.4 \\
35-44 age & 15.5 & 14.7 \\
45-59 age & & \\
& 7.2 & 11.3 \\
Death due to Accidents & 13.2 & 7.2 \\
15-24 age & 10.2 & 7.2 \\
25-34 age & 19.2 & 10.3 \\
35-44 age & & \\
45-59 age & & \\
\hline
\end{tabular}

Source: Survey of Causes of Deaths (1998, Registrar General) in Health Information of India

The above table shows the number of men exceeds women in terms of major causes of death. Though death causes due to external reasons depends largely on age of the diseased and situation there in. But what this table tries to say is that there are larger number of men who dies and it can be precisely due to the fact that the men takes more unwanted risk in day to day life and many a times due recklessness they loose their life. And also sometimes in order to prove their masculinity, men try all wrong things which can cause death. 


\section{Resource Sheet: Lottery of Life}

\begin{tabular}{|l|c|c|c|}
\hline & $\begin{array}{c}\text { Man } \\
\text { Boman }\end{array}$ \\
\hline 1. Who has a shorter lifespan? & & & \\
2. Who dies more from homicide? & & \\
3. Who dies more in road accidents? & & \\
4. Who dies more from suicide? & & \\
5. Who kills more? & & \\
6. Who steals more? & & \\
7. Who consumes more alcohol and gets drunk more? & & \\
8. Who dies more from an overdose (substance abuse)? & & \\
8. As infants, who dies more? & & \\
9. Among adolescents, who dies more? & & \\
10. Among the elderly, who dies more? & & \\
11. Who dies more in work accidents? & & \\
12. Who is more likely to be infected by HIV \& AIDS? & & \\
\hline
\end{tabular}



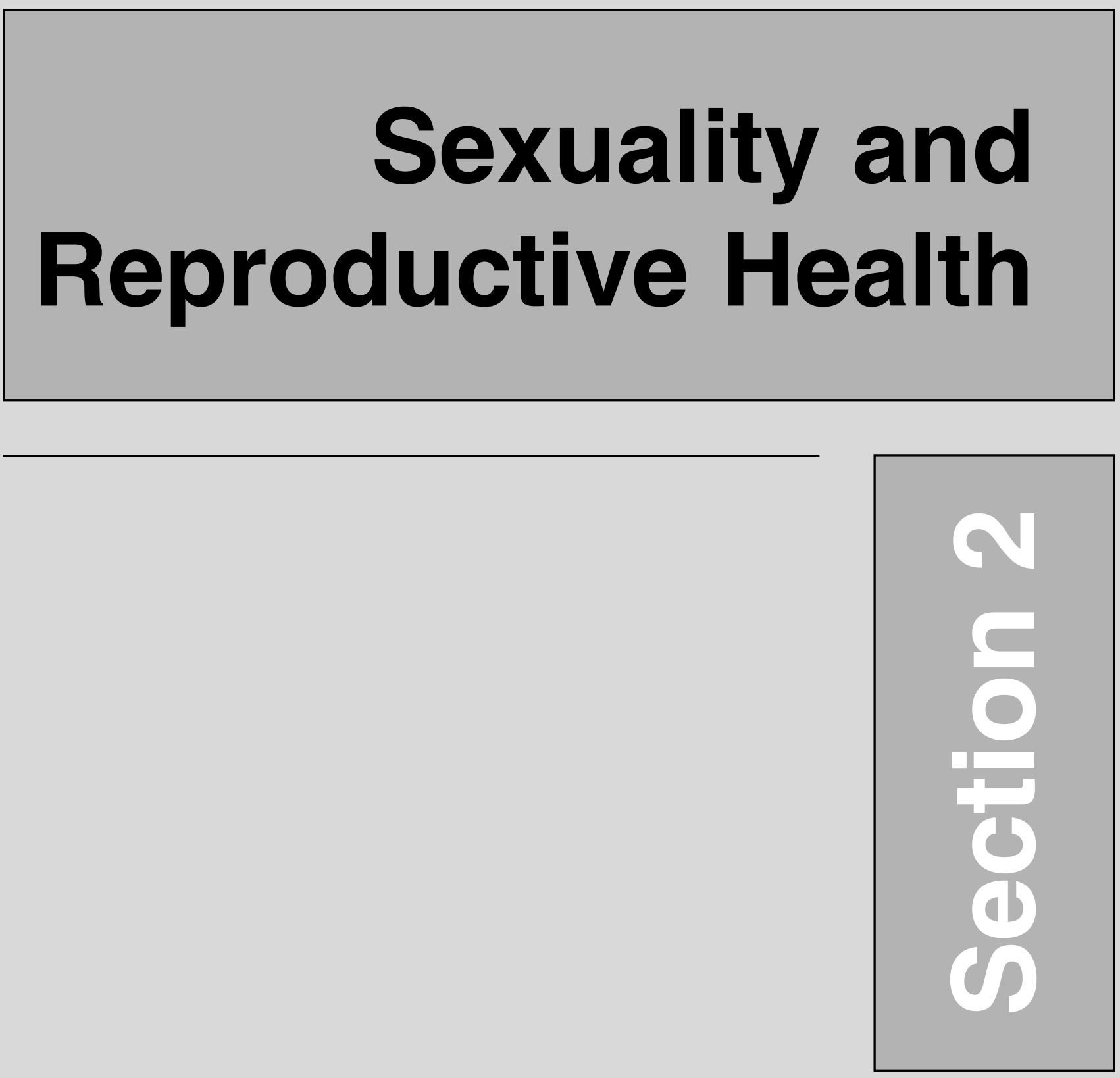



\section{Activity 2.1 \\ Me and My Body}

Summary : This activity helps the educator explore the special care that young men should take with their own bodies, promoting preventive health measures, particularly in relation to genital hygiene, and consequently, to the prevention of AIDS and other sexually transmissible infections (STI).

Purpose : To stimulate the discussion on personal body care, exploring the relation between hygiene and sexual health.

Materials required: Marker pen, Sheets of paper stuck together so that the overall size is larger than a human body, old magazines

\section{Recommended time: 1 hour}

\section{Planning tips/notes:}

- The facilitator can suggest to the group that they give a name and other characteristics to the drawing of the man's body.

- If the participants in the group are too embarrassed to draw the genital organs, the facilitator can do so, naturally, providing a little light relief in the proceedings.

\section{Procedure}

- Place on the floor one (or more) sheet(s) of paper, the size of a human body

- Ask a volunteer form the group to lie down on the paper for someone else to draw the outline of his body.

- Ask another volunteer to add the male genitals to the drawing.

- Next, encourage the group to stick little pieces from the magazine (or rolled into balls) in the places where dirt can accumulate on the body. For example, the facilitator says: "the person had ice-cream and didn't wash his hands: where will the dirt accumulate?" Then, the participants place the little pieces of paper in the region that got dirty.
- Encourage the group to do this with the various parts of the body, discussing what the consequences of inadequate hygiene are on the health. The back-up sheet which accompanies this activity can be very useful.

- Afterward, ask them what alternatives they found to avoid or correct what happened to the person in question. The group should then remove the bits of paper, part by part, until the body is clean again.

\section{Questions for reflection}

- What is hygiene?

- What is the importance of hygiene in our life?

- What is the importance of hygiene in our sexual life? 
- Besides hygiene, what else is required for taking care of your sexual health?

- Do men and women take care of their body in the same way? Why?
- Can a lack of hygiene increase the possibility of acquiring an STI?

\section{Closing}

At the end the facilitator should highlight the importance of body care and specialist sexual health care, taking advantage of what the group themselves have to say during the workshop, mentioning the possible relationships between lack of hygiene and STI, with the back-up sheet as a guide. 


\section{Sexuality and Contraception}

Purpose: To provide information on contraceptive methods and discuss male involvement in contraceptive use, as well as criteria for choosing a suitable contraceptive method.

Recommended time: 1 hour and 30 minutes

Materials required: Samples of contraceptives and/ or drawings of methods; paper; pencil and pens; Resource Sheet.

Planning tips/notes: If possible, bring samples of each of the methods to the session. In the discussion about each of the methods, discuss both technical advantages and disadvantages, as well as cultural and personal beliefs about each method.

\section{Procedure}

1. Divide the participants into 6 teams. Distribute the samples of methods and other specific information about each method to each of the teams:

Group 1. Hormonal Methods.

Group 2. Intrauterine Device (IUD)

Group 3. Barrier Methods

Group 4. Rhythm Methods

Group 5. Tubal Ligation and Vasectomy.

Group 6. Emergency Contraception

2. Ask each group to try to answer the following questions about the methods they have received:

- How does this method prevent pregnancy? How is it used?

- What are the myths and facts about this method?

- What are its advantages?

- What are its disadvantages?

- What is the group_s opinion about this method?
3. When they have finished, distribute the Resource Sheet to each of the groups for them to clarify any doubts and obtain additional information about the methods.

4. Ask them to use their creativity to prepare a presentation about their method. They can dramatize it, produce posters, a comic strip, a TV commercial, etc.

5. Each group should then present their method.

\section{Discussion questions}

- Who has to think about contraception? Man or the woman? Why?

- Who has to talk about it, the man or woman? Why?

- How do you imagine this conversation would go?

- What are the most recommended contraceptive methods for adolescents?

- Why is it important to seek medical advice when starting one's sexual life? 
- How should the couple choose contraceptive method they are to use?

- What are the main precautions that should be used with the condom?

- What is the only method that prevents pregnancy and protects against sexually transmissible infections and AIDS?

- If you forget to use a condom, or condom breaks, what can you do?

\section{Emergency Contraception}

This is not a contraceptive method. It is a fertilized egg from attaching itself in the uterus. way of avoiding pregnancy for someone who The first pill should be taken within 72 hours of sexual intercourse without protection or in the case of condom breakage. In the government distribution system it is available as E-Pills.

Important Note: This method should not be by either impeding or retarding the release used routinely to avoid pregnancy but only in emergency situations.

\section{Closings}

- Depending on the young men's need for additional information, discuss further each of the contraceptive methods and clear up any remaining doubts.

- Be sure to discuss the aspects related to male fertility. This subject is important because it is known that men, particularly young men, often lack information about fertility. Many young men do not think about their own fertility, forgetting that potentially they can get a woman pregnant every time they have sexual intercourse. Men are potentially always fertile, while women have a specific ovulation cycle.

- Discuss the difficulties that the participants identify in the use of some of these contraceptive methods and explore how they might negotiate contraceptive use with a partner. In addition, it is also necessary to discuss with the young men issues of access to services and to contraceptives. Explore the difficulties of access that they are faced with; if they know about health services and if there are obstacles and difficulties in using them.

- It may also be useful to consider the theme of privacy, and the right of an adolescent to use health services and seek contraceptives without being afraid that his/her parents will be notified.

- Finally, emphasize that contraception is a responsibility that should be shared. If neither of the partners want sexual intercourse to result in pregnancy, it is essential that both take precautions so that this does not happen. 
Resource sheet Contraception type ${ }^{1}$

\begin{tabular}{|c|c|c|c|c|c|c|}
\hline & Periodic & Mechanical & Barrier & Chemical & Hormonal & Surgical or \\
\hline 离 & $\begin{array}{l}\text { These are } \\
\text { practices that } \\
\text { depend basically } \\
\text { on the behavior of } \\
\text { the man or } \\
\text { woman and on } \\
\text { observation of the } \\
\text { body. }\end{array}$ & $\begin{array}{l}\text { A small plastic } \\
\text { and copper device } \\
\text { with a nylon } \\
\text { thread at the tip } \\
\text { which is placed } \\
\text { inside the uterus. }\end{array}$ & $\begin{array}{l}\text { Methods that form } \\
\text { a barrier, } \\
\text { preventing the } \\
\text { contact of } \\
\text { spermatozoa with } \\
\text { the ovum. }\end{array}$ & $\begin{array}{l}\text { Substances which, } \\
\text { when placed in the } \\
\text { vagina, kill or } \\
\text { immobilize the } \\
\text { spermatozoa. }\end{array}$ & $\begin{array}{l}\text { Pills or } \\
\text { injections made } \\
\text { with synthetic } \\
\text { hormones. }\end{array}$ & $\begin{array}{l}\text { This is not exactly } \\
\text { a contraceptive } \\
\text { method, but a } \\
\text { surgery that is } \\
\text { performed on the } \\
\text { man or woman } \\
\text { with the purpose } \\
\text { of preventing } \\
\text { conception } \\
\text { permanently. } \\
\text { Female steriliza- } \\
\text { tion is better know } \\
\text { as tubal ligation; } \\
\text { male sterilization } \\
\text { is known as } \\
\text { vasectomy. }\end{array}$ \\
\hline 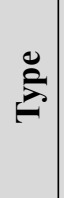 & $\begin{array}{l}\text { Rhythm Method, } \\
\text { Cervical Mucus, } \\
\text { Temperature, } \\
\text { Coitus Interruptus } \\
\text { (Withdrawal). }\end{array}$ & $\begin{array}{l}\text { IUD (Intrauterine } \\
\text { Device). }\end{array}$ & $\begin{array}{l}\text { Diaphragm, Male } \\
\text { and Female } \\
\text { Condoms. }\end{array}$ & $\begin{array}{l}\text { Cream, Jellies, Ova } \\
\text { and Foam. }\end{array}$ & Pill, Injections. & $\begin{array}{l}\text { Vasectomy, } \\
\text { Tubal Ligation. }\end{array}$ \\
\hline 氞 & $\begin{array}{l}\text { To stop fecundation } \\
\text { through sexual } \\
\text { abstinence in the } \\
\text { presumed fertile } \\
\text { period. Should only } \\
\text { be used in } \\
\text { combination with } \\
\text { condom/ } \\
\text { diaphragm. }\end{array}$ & $\begin{array}{l}\text { Impedes access of } \\
\text { the spermatozoa to } \\
\text { the ovum. } \\
\text { Requires medical } \\
\text { checkup every } 6 \\
\text { months. }\end{array}$ & $\begin{array}{l}\text { Impedes contact } \\
\text { of the } \\
\text { spermatozoa } \\
\text { with the ovum. }\end{array}$ & $\begin{array}{l}\text { Spermicide, } \\
\text { which kills or } \\
\text { immobilizes the } \\
\text { spermatozoa, } \\
\text { should be used } \\
\text { in combination } \\
\text { with the } \\
\text { condom/ } \\
\text { diaphragm. }\end{array}$ & $\begin{array}{l}\text { Prevent } \\
\text { ovulation. Used } \\
\text { with medical } \\
\text { guidance. }\end{array}$ & $\begin{array}{l}\text { Vasectomy: } \\
\text { interrupts the flow } \\
\text { of spermatozoa in } \\
\text { ejaculation. Tubal } \\
\text { Ligation: prevents } \\
\text { contact of the } \\
\text { ovum with the } \\
\text { spermatozoa. }\end{array}$ \\
\hline ֻ & $\begin{array}{l}\text { Permits greater } \\
\text { awareness of the } \\
\text { body itself. }\end{array}$ & $\begin{array}{l}\text { An efficient and } \\
\text { comfortable } \\
\text { method for most } \\
\text { women. }\end{array}$ & $\begin{array}{l}\text { The condom, male } \\
\text { and female, } \\
\text { protects against the } \\
\text { risks of STIs/HIV/ } \\
\text { AIDS. Condoms } \\
\text { require no medical } \\
\text { prescription or } \\
\text { exams and are } \\
\text { generally easy to } \\
\text { acquire. Male } \\
\text { condom use } \\
\text { enables the man to } \\
\text { participate actively } \\
\text { in contraception. }\end{array}$ & $\begin{array}{l}\text { Efficient when } \\
\text { used with the } \\
\text { condom or } \\
\text { diaphragm. }\end{array}$ & $\begin{array}{l}\text { When correctly } \\
\text { used, birth } \\
\text { control pills are } \\
\text { one of the most } \\
\text { effective } \\
\text { contraceptive } \\
\text { methods. }\end{array}$ & $\begin{array}{l}\text { Efficiency is very } \\
\text { high. }\end{array}$ \\
\hline . & $\begin{array}{l}\text { Does not protect } \\
\text { against STIs/ HIV } \\
\text { and AIDS. }\end{array}$ & $\begin{array}{l}\text { Increases the flow } \\
\text { and duration of } \\
\text { menstruation. Not } \\
\text { recommended for } \\
\text { women who have } \\
\text { not had children. } \\
\text { Does not protect } \\
\text { against STIs/ HIV } \\
\text { and AIDS. }\end{array}$ & $\begin{array}{l}\text { The diaphragm } \\
\text { does not protect } \\
\text { against STIs/ } \\
\text { HIV. }\end{array}$ & $\begin{array}{l}\text { The isolated use of } \\
\text { the spermicide has } \\
\text { a high incidence of } \\
\text { failure and also } \\
\text { does not prevent } \\
\text { STIs/HIV. }\end{array}$ & $\begin{array}{l}\text { Requires discipline } \\
\text { to take the pill } \\
\text { every day at the } \\
\text { same time. Women } \\
\text { who smoke, have } \\
\text { high blood } \\
\text { pressure or } \\
\text { varicose veins } \\
\text { should not use this } \\
\text { method. If used } \\
\text { alone, do not } \\
\text { protect against } \\
\text { STIs/HIV. }\end{array}$ & $\begin{array}{l}\text { A definitive } \\
\text { method with little } \\
\text { chance of being } \\
\text { reversed. }\end{array}$ \\
\hline
\end{tabular}

${ }^{1}$ Source: Petta. C.A and Faundes, A. Métodos Anticoncepcionais. São Paulo: 1998. Editora Contexto. 


\section{Method of Contraception}

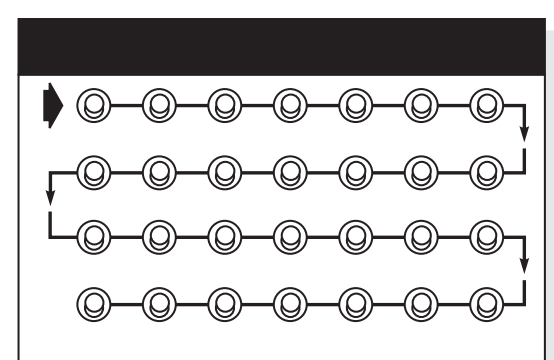

Oral pills

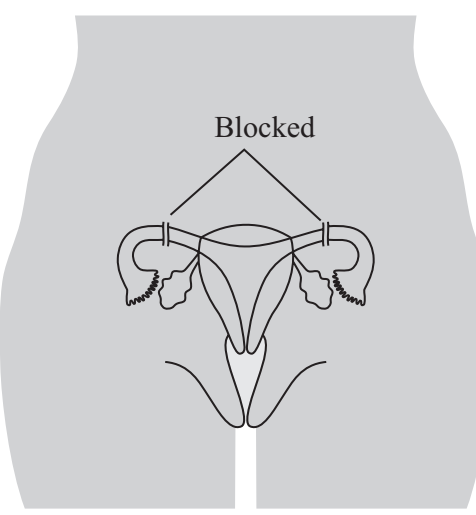

Female sterilization
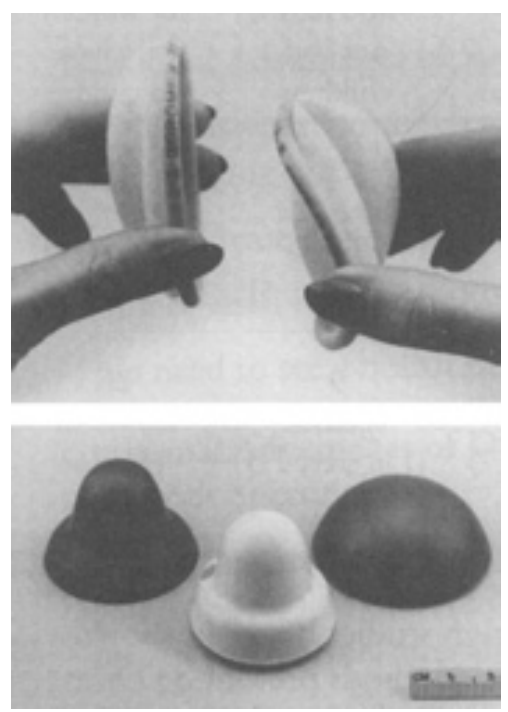

Diaphragm

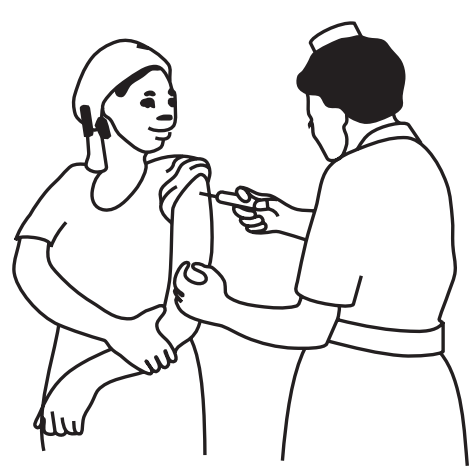

Injection method

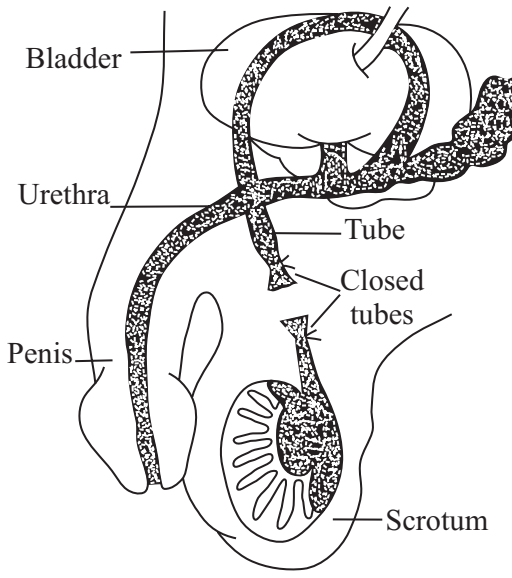

Male Sterilization

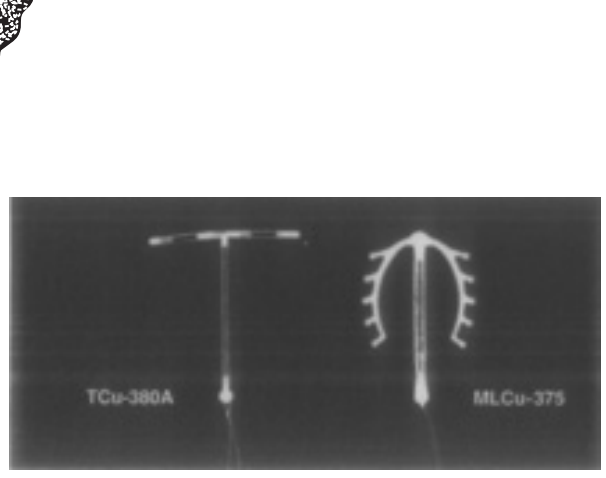

IUD

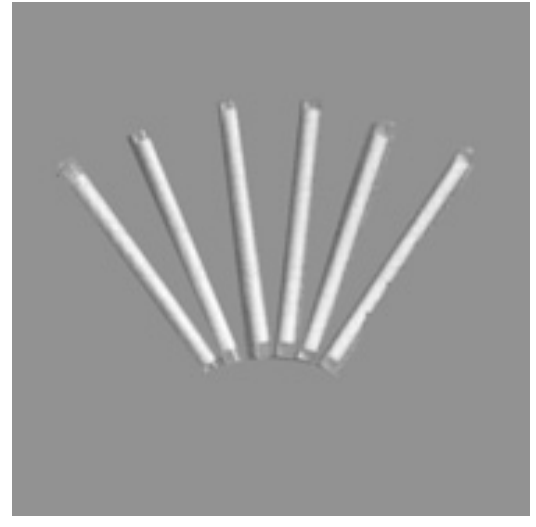

Norplant Seminal vesicle 
Purpose: To increase awareness and knowledge about the male sexual organs, as well as increase awareness about the need for self-care.

\section{Recommended time: 2 hours}

Materials Required: paper and pencil for all participants, a small bag or envelope with the names of the male and female internal and external sexual organs and their description (cards 1 and 2), figures of the male and female reproductive system.

Planning tips/notes: The majorities of young men do not know much about their own bodies, nor believe that it is necessary to devote time to understanding it. Many young men only know the mechanics of their genital tract (i.e. getting an erection). This lack of knowledge about their own bodies and its functioning often has adverse effects on their hygiene and health.

\section{Procedure}

1. Before starting the Activity, cut out the names of the female and male sexual organs from the card and place them in a small bag or envelope.

2. Divide the participants into two teams and ask them to choose a name for each team.

3. Explain that each person in the team will take a name from the bag and will have to mime or do a charade using the information contained on the card for the other team to guess which genital organ, male or female, was picked. Unlike other games, the team that presents the mime or charade will only receive a point if the opposing team guesses what the mime or charade refers to. Also tell them that the team that points to the organ or who speaks or writes the name instead of using a charade will lose points.

4. Toss a coin to decide which team goes first. The game continues until all the names in the bag have finished.
5. Keep the score on the board and comment on any interesting points that emerged from the workshop (competition, collaboration, etc).

\section{Discussion questions}

- What were the most difficult genital organs to guess? Why?

- What were the ones you already knew about?

- Do you think it important to know the name and function of the internal and external male genital organs? Why?

- Do most men know about these things? Why or why not?

- How should a man take care of his genital tract? And a woman?

- Which do you think is more complex, the female 


\section{Closing}

Show the group how having a limited knowledge of their own body can have adverse consequences on their health, such as in preventing STIs and HIV/ AIDS and various types of cancer which affect the male reproductive organs. Stress male involvement in reproductive decisions and discuss how spermatozoa are produced and the implications of this on reproduction. Explain the function of each organ of the male and female reproductive system, including the physical diversity, that is to say, there are different shapes and sizes of penis, vagina and breasts, etc. Show that the different types and sizes of the penis and do not determine sexual pleasure. Explore the fact that, although taking care of the reproductive tract is considered in many cultures to be a female concern, this should also be a male concern and that taking care of one's health is a key factor in safeguarding quality of life - in the present and in the future.

\section{Resource Sheet}

\section{MALE SEXUAL ORGANS}

\section{External Sexual Organs}

- Penis: A member with a urinary and reproductive function. It is a very sensitive organ, the size of which varies from man to man. Most of the time the penis remains soft and flaccid. But when the tissue of the corpus spongiosum fills up with blood during sexual excitation, it increases in volume and becomes hard, a process which is called an erection. In the sexual act, when highly stimulated, it releases a liquid called sperm or semen which contains spermatozoa. The ejaculation of the sperm produces an intense feeling of pleasure called an orgasm.

- Scrotum: A type of pouch behind the penis which has various layers, the external one being a fine skin covered with hair with a darker coloring than the rest of the body. Its appearance varies according to the state of contraction or relaxation of the musculature. In cold, for example, it becomes more contracted and wrinkled and in heat it becomes smoother and elongated. The scrotum contains the testicles.
- Prepuce or foreskin: The skin that covers the head of the penis. When the penis becomes erect, the prepuce is pulled back, leaving the glans (or the "head" of the penis) uncovered. When this does not occur, the condition is called phimosis, which can cause pain during sexual intercourse and hamper personal hygiene. Phimosis is easily corrected through surgical intervention using a local anesthetic. In some cultures or countries, or in some families, the foreskin of boys is removed in a procedure called circumcision.

- Glans: The head of the penis. The skin is very soft and very sensitive.

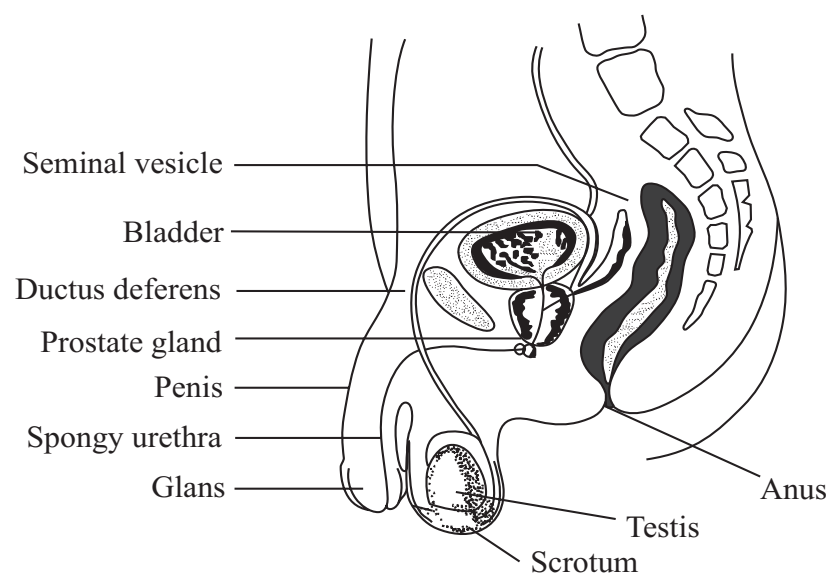




\section{Internal Sexual Organs}

- Testicles: The male sexual glands, the function of which is to produce hormones and spermatozoa. One of the hormones produced is testosterone, responsible for male secondary characteristics, such as skin tone, facial hair, tone of voice and muscles. They have the form of two eggs and to feel them one only has to palpate the scrotum pouch.

- Urethra: A canal used both for urination and for ejaculation. It is about $20 \mathrm{~cm}$ long and is divided into three parts: the prostatic urethra, which passes through the prostrate gland; the membranous urethra, which passes through the pelvic diaphragm; and the third part which traverses the corpus spongiosum of the penis.

- Epididymis: Acanal connected to the testicles. The spermatozoa are produced in the testicles and are stored in the epididymis until they mature and are expelled at the moment of ejaculation.

- Seminal Vesicles: Two pouches that provide the fluids for the spermatozoa to swim in.

- Deferent Ducts: Two very fine ducts of the testes which carry the spermatozoa to the prostate.

- Ejaculatory Duct: Formed by the junction of the deferent duct and the seminal vesicle. It is short and straight and almost the whole trajectory is located at the side of the prostrate, terminating at the urethra. In the ejaculatory duct fluids from the seminal vesicle and the deferent duct mix together and flow into the prostatic urethra.

\section{FEMALE SEXUAL ORGANS}

\section{External Sexual Organs}

- Mons Veneris or Mons Venus: The rounded protuberance located on the pelvic bone called the pubis. In an adult woman, it is covered with hair which protects the region. Labia majora: Covered with sparse hair, the most external parts of the vulva. They commence at the Mons Veneris and run to the perineum.

- Labia minora: A pair of skin folds, with no hair. They can be seen when the labia majora are parted with the fingers. They are very sensitive and increase in size during excitation.

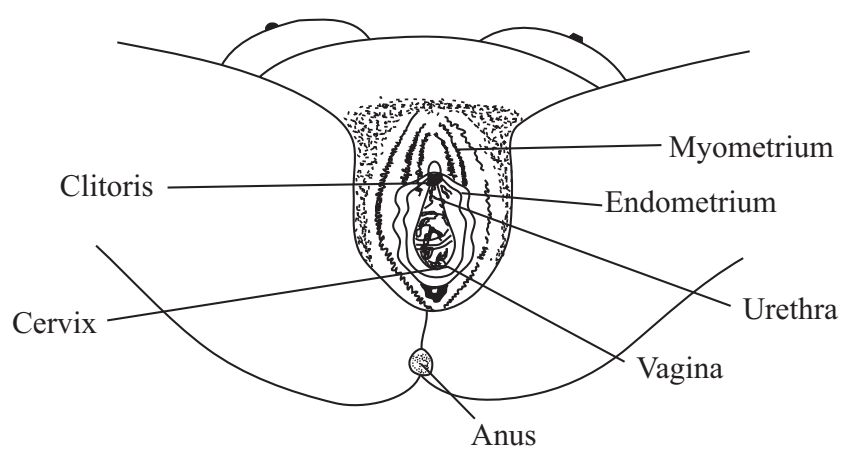

- Clitoris: A rounded organ, very small, but extremely important for the sexual pleasure of the woman. It is very sensitive and when a woman is not excited, touching it directly can be unpleasant. But when gently stimulated, the woman experiences an intense and pleasurable sensation called orgasm.

- Opening of the urethra: The opening where the urine comes out.

- Opening of the vagina: The elongated opening where discharge, menstrual blood and the baby come out.

\section{Internal Sexual Organs}

- Uterus: The organ where the fetus develops during pregnancy. When a woman is not pregnant, her uterus is the size of a fist.

- Cervix: The lower part of the uterus. It has an orifice where the menstrual fluids pass and where the spermatozoa enter. In a normal delivery, this orifice increases or dilates to allow the passage of the infant.

- Body of the uterus: The main part of the uterus, which increases in size during pregnancy and returns to normal size after the birth. It consists of two external layers, a membrane called the peritoneum and a

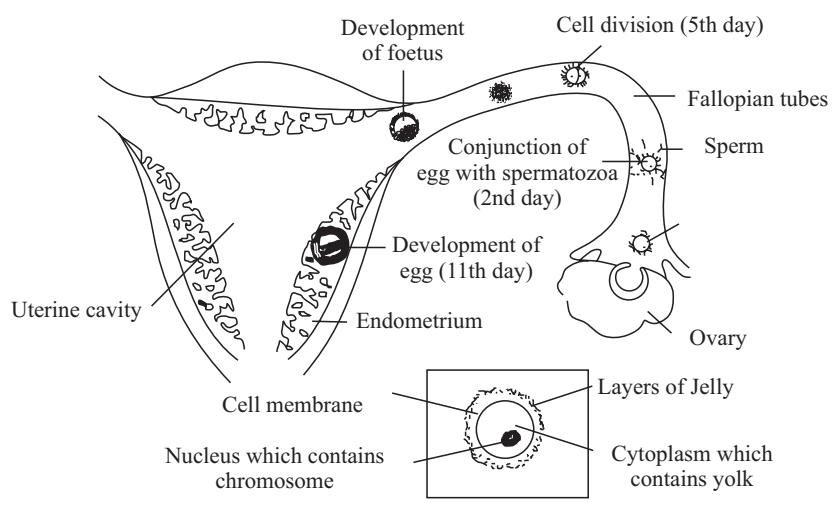


muscular tissue called the myometrium. The mucus membrane that lines the uterus is called the endometrium, which loosens and sloughs off during menstruation and is renewed monthly.

- Fallopian tubes: There are two, one on either side of the uterus. Where they join the ovary, they open out like a flower. Through the tubes, the ova or egg cells pass to the uterus.

- Ovaries: There are two, the size of a large olive, one on either side of the uterus, attached to it by a nerve ligament and by layers of skin. From birth, the ovaries contain about 500,000 ova. There, the ova are stored and develop. They also produce the female hormones.

- Vagina: The canal which starts at the vulva and runs to the cervix. Inside, it is made of tissue similar to the inside part of the mouth, with various folds that allow it to stretch during sexual intercourse or to allow passage at child birth. Some women feel pleasure during penetration of the penis in the vagina, others less; for most women, stimulation of the clitoris provides greater pleasure than stimulation of the vagina. 
Purpose: To discuss the beliefs, opinions and attitudes of the group concerning themes related to sexuality and reproductive health, with a focus on male sexuality and the need for self-care.

Recommended time: 30 minutes

Materials Required: Seven balloons (blown up) with small pieces of paper inside. On these strips of paper, the facilitator will have written questions.

Planning tips/notes: The idea for this activity is to be informal and have fun to introduce these themes in a light-hearted way. The facilitator should work to create an environment in which the young men feel comfortable expressing themselves and asking questions about sensitive themes. Do not worry if during the replies it is not possible to fully discuss each of the themes. At the end, return to the answers that remain incomplete.

\section{Procedure}

1. Ask the participants to form one large circle. Then tell them that they are going to pass a balloon with a question inside round the circle. When the facilitator says stop, the person who has the balloon should pop the balloon, read the question and try to answer it.

2. If the person is unable to answer it, the person on their right should answer. The other participants can help when necessary to complete the answer.

3. After a question has been answered, the procedure repeats itself, until all seven questions have been discussed.

\section{Probable questions which can be put inside the balloon}

- What is masturbation?
- Is it true that masturbation can make the penis smaller or make hair grow in the palm of your hand?

- How should you wash the penis?

- Does a "real man" have to worry about taking care of his body? How?

- How do you do a preventive exam for cancer of the testicles?

- How do you do a preventive exam for cancer of the penis?

- What is a preventive exam for prostate cancer?

- Can a man urinate inside a woman during sexual intercourse?

- What is a man most afraid of during the sexual act?

- What kinds of problems can a man have during sexual intercourse?

- What can a man do when he ejaculates too quickly? 
- Why does a man sometimes "come" while sleeping?

- Do men need sex more than women? Why?

- Does the size of the penis really matter? Why?

- How does a man feel when someone says he has a small penis? How does he react?

- Why do we sometimes say that a man "thinks with his penis"? Can a man control his sexual desire?

- What do you think about virtual or computer sex?

\section{Discussion questions}

- What does it mean to be a man?
- How does a man look after his body?

- Is the size of the penis important for the man? Why?

- Why is it so difficult for some men to go to a urologist?

- What preventive exams can a man do to prevent certain diseases?

- How can a man protect himself from sexual transmitted infections (STIs) and HIV and AIDS? (Ask if everyone in the group knows what sexually transmitted infections or STIs are.)

- What kind of personal hygiene should men practice?

\section{Closing}

Connect the model of masculinity found in our society with men's health and health problems. For example, if we look at various aspects of mortality and morbidity, we can see that men die earlier (usually from traffic accidents or violence) than women. In many countries, men also tend to use alcohol and other substances more. This theme will also come up in the other manuals, but can be introduced here. Discuss the concept of prevention and the difficulties of "preventing" given the myth that men are supposed to be ready to face any risk or to have sex at any time. 


\section{Resource Sheet}

\section{Preventive exam for cancer of the testicles}

Testicular cancer, while seldom discussed, accounts for $1 \%$ of all cancers in men and is the most common form of cancer among men 15 to 35 years of age. It generally occurs in only one of the testicles and once removed causes no problem to the sexual and reproductive functions of the man. Today, testicular cancer is relatively easy to treat, particularly when detected in the early stages. The most common symptom is the appearance of a hard nodule about the size of a pea, which does not cause pain. Carrying out a testicular exam step by step:

1. Self-examination should be carried out once a month, after a warm shower, as the heat makes the skin of the scrotum relax, enabling one to locate any irregularity in the testicles.

2. The man should stand in front of the mirror and examine each testicle with both hands. The index and middle finger should be placed on the lower part of the testicles and the thumb on the upper part.

3. The man should gently rotate each testicle between the thumb and the index finger, checking to see if they are smooth and firm. It is important to palpate also the epididymis, a type of soft tube at the back of the testicle.

4. One should check the size of each testicle to verify that they are their normal size. It is common for one of them to be slightly larger than the other.

5. Should one find any lumps, it is important to see a doctor at once. They are generally located on the side of the testicles but can also be found on the front. Not every lump is cancerous, but when it is, the disease can spread rapidly if not treated.

\section{Preventive Exam for Cancer of the Penis}

Lack of hygiene is one of the greatest causes of cancer of the penis. Thus, the first step to revent this disease is to wash the penis daily with soap and water and after sexual relations and masturbation. When discovered in the earlier stages, cancer of the penis can be cured and easily treated. If left untreated or caught late, it
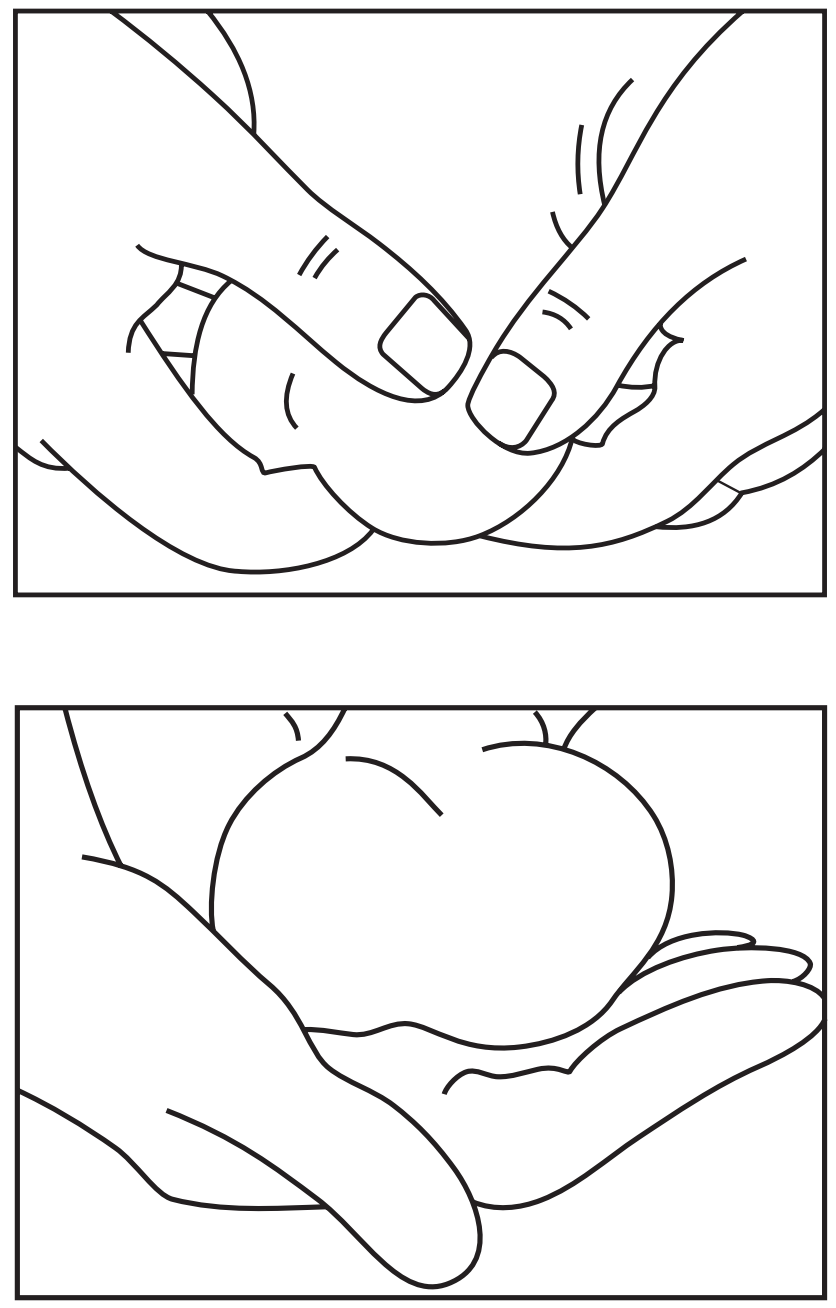

can spread to internal areas such as ganglions and cause mutilation or death.

\section{Self-Examination of the Penis}

Once a month, the man should carefully examine his penis, looking for any of these signs: wounds that do not heal after medical treatment; lumps that do not disappear after treatment and which present secretion and a bad smell; persons with phimosis who, even after succeeding in baring the glans, have inflammation (redness and itching) for long periods; whitish stains or loss of pigmentation; the appearance of bulbous tissues in the groin. These symptoms are more common in adults, and if any of them appear, it is necessary to 
consult a doctor immediately. Another important precaution is to be examined by a urologist once a year.

\section{Preventive Exam for Prostate Cancer}

Liquid produced by the prostate gland is responsible for $30 \%$ of a man's sperm volume. After the age of 40 , all men should have regular exams for prostrate cancer. About half the men in their fifties exhibit symptoms associated with prostrate cancer, such as difficulty in urinating, the need to go to the bathroom frequently, a weak urine stream and a feeling that the bladder is always full. These alterations appear as a consequence of the increase in size of the prostate and the increase in its muscular portion, which presses against the urethra and hinders the elimination of the urine stored in the bladder. These symptoms are known as benign prostate hiperplasia (BPH) and, at present, there is no efficient way of preventing it. But there are various treatments: medication, local heat therapy, vaporization, laser and conventional surgery through the urethra. A urologist (a doctor specialized in the male sexual organs) can recommend the best treatment. Left untreated, inflammation of the prostate can lead to serious complications including urinary infections, total interruption of the flow of urine and even renal insufficiency.

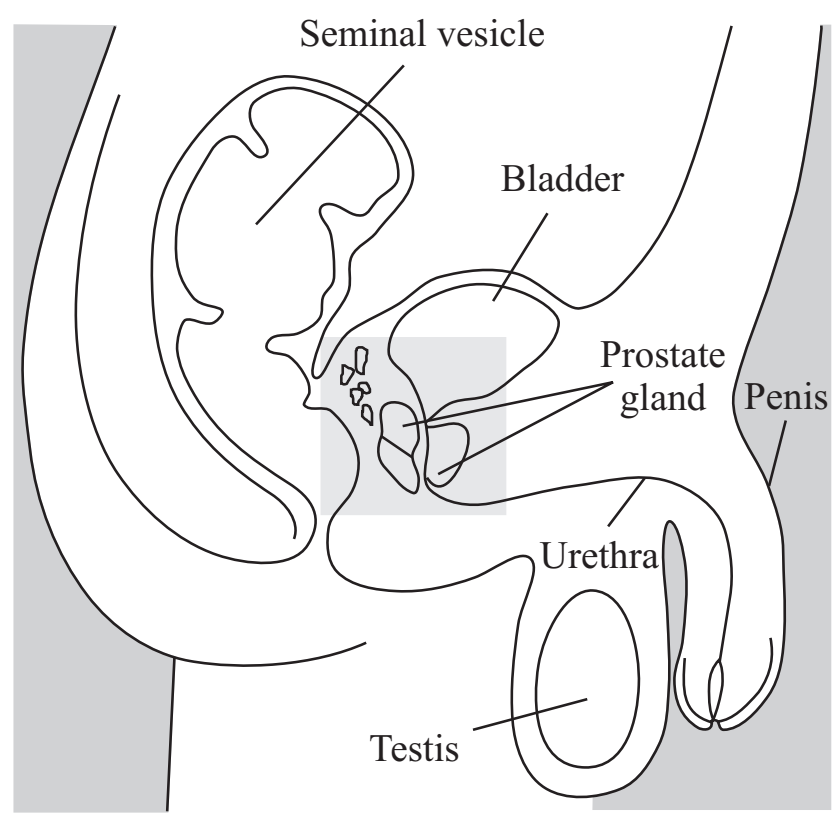

Cancer of the prostate is the uncontrolled growth of cells in the prostate. It affects 1 in every 12 men over the age of 50. In general, it only produces symptoms when it is already in a more advanced stage (such as pain and blood when urinating). When the disease is diagnosed will determine whether it can be controlled or not. When diagnosed early, prostate cancer has a high cure rate. There are three types of exams for prostate cancer prevention: rectal touch, ultra-sound and the PSA (a protein released by the prostrate itself and which increases considerably when the organ is affected by cancer) dosage in the blood. The rectal touch examination is the simplest. It consists of the doctor introducing a finger in the anus to examine the consistency and size of the prostrate.

\section{Sexual Dysfunction}

This is when a man or a woman presents certain difficulties, physical or psychological, in expressing or enjoying sexual pleasure, for example, men who are unable to have an erection, or suffer from premature ejaculation or women who do not feel sexual desire or who are unable to have an orgasm. The dysfunctions can have organic causes (cardiovascular conditions or diseases, diabetes, side effects of medication, substance use, etc.) or psychological (a repressive upbringing, anxiety about sexual performance, guilt, problems between the partners, previous frustrating or traumatic experiences, stress, etc.).

The most common sexual dysfunctions among men are:

Erectile Dysfunction - when a man is unable to have an erection. It can be in two forms: primary (when the man has never had an erection) or secondary (when it appears in a man who never had erection problems before).

Premature Ejaculation - when a man ejaculates involuntarily before penetrating the vagina or immediately after penetration.

Retarded Ejaculation - when a man is unable to ejaculate. 


\section{Story of Raghu and Pinki}

Aim: To discuss the importance of couple communication on reproduction-related issues among young men. Also to discuss sex determination tests and related consequences.

Recommended Time: 1 hour

Materials Required: Copy of Raghu and Pinki Story for everyone, pen or pencil

Starting tips: It is rarely that we discuss pregnancy, contraception, menstruation etc. with young people. Tell the group that this activity will enrich their awareness on the above issues, which are the essential components of healthy and successful life.

\section{Procedure}

1. Ask participants to form different groups with 5 to 6 participants in each group.

2. Tell them that they will be given a short story to read, which will be followed by discussion based on the story.

3. Tell them that there are three sections in the story and once they finish reading the first one, they will be provided with another story.

4. When the group finishes reading, then related questions will be discussed among the different group members.

\section{Discussion questions}

- If the wife becomes pregnant then what are the options for a couple?

- What will be the reaction of the husband if his wife becomes pregnant? What will be the reactions of his wife?

- What will be the outlook of a young man when he comes to know that he is going become a father?

\section{Closings}

- The facilitator should try to know the perceptions of young men towards pregnancy.

- Discuss that young people should know that whenever they perform sex without a condom, the woman can get pregnant.

- Also discuss that due to societal taboo people hesitate to talk about pregnancy and related issues with their wives. 


\section{The story}

\section{Part 1}

Raghu and Pinky recently got married. Raghu is happy that he married a girl of his choice. On the wedding night, he was very excited.

Now ask the group:

- Is it feasible for the couple to discuss contraceptives?

- Whose responsibility should it be to initiate discussion and why?

- Should they be aware of the ovulation cycle and fertile period ?

\section{Part 2}

After two months of marriage Pinky gets pregnant and Ragu takes her to a nearby health center. After a test they find out that she is going to have a girl child.

Now ask the group:

- Should they have got the test done for the sex of the fetus? Why, and why not?

- What are the social, familial and individual implications of the sex-determination test?

\section{Part 3}

They decide to keep the female child.

Now ask the group:

- What do you think of this decision?

- Now that the Pinky is pregnant, what should be Raghu's responsibilities?

- What should be the ideal number of children? Girls and boys, and why?

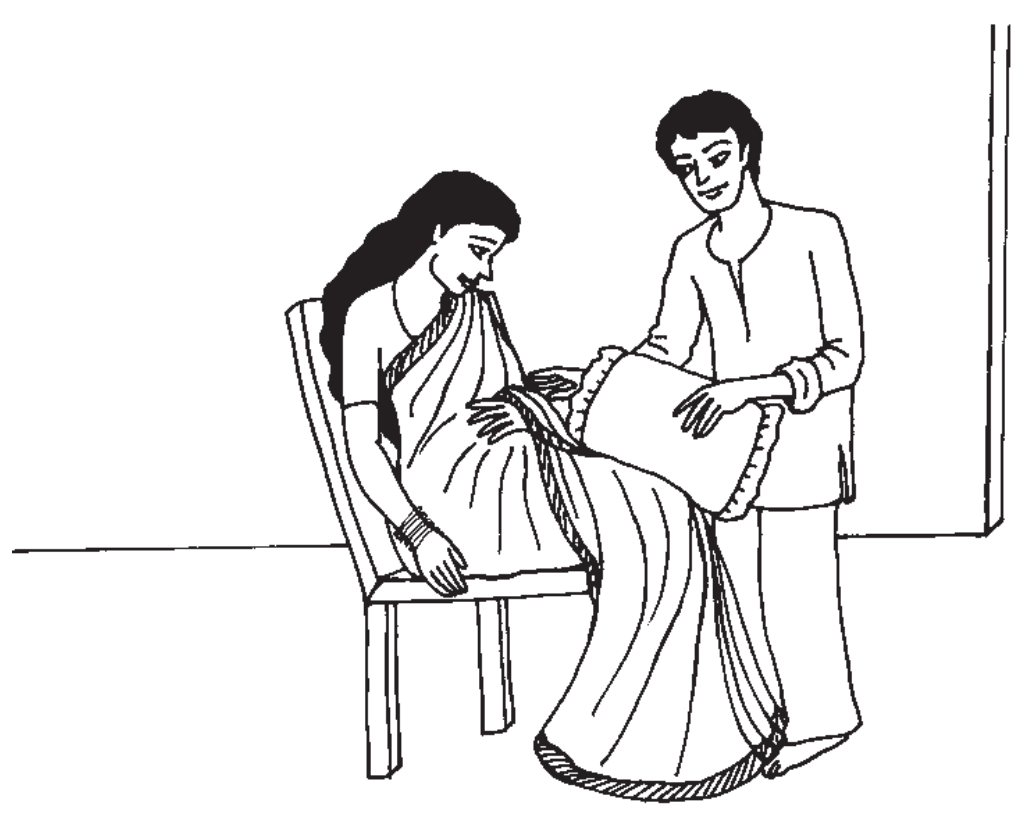


Purpose: To discuss desire, excitation and orgasm and to clarify that men and women have equal sexual drives, needs and desires.

\section{Recommended time: 1 hour}

Materials Required : old magazines, scissors, paper and glue.

Planning tips/notes: For many young men, sexuality is defined as sexual performance. Many young men feel pressure to prove themselves sexually. Providing information about sexual desire, excitation and orgasm can reduce the insecurity and discomfort of young men about these issues. In the course of this activity, the facilitator should emphasize that having an active sex life does not mean only sexual intercourse. The facilitator should emphasize that there are many other forms of sexual contact, intimacy and pleasure. Carry out the discussion in the most open and informal way possible, even when the young men laugh or joke about these issues. In fact, joking is one of the ways that young men use to "defend" themselves or express anxiety, particularly when faced with new information. Throughout the activity, it is important to emphasize the need to practice safer sex and the issue of mutual consent, that is that young people have the right to decide when, where and how they want, and if they want to have sexual contact.

\section{Procedure}

- Form groups of 4 to 5 persons and hand out a sheet of paper to each participant and some magazines and some glue to each group.

- Explain that each person should produce a collage on the "male erotic body" using pictures from the magazines.

- When they have finished, ask them to do the same, only this time making a collage about the "female erotic body." When they have finished, ask them to exhibit their collages. Ask volunteers to talk about their collages.

\section{Discussion questions}

- What is sexual desire? Do both men and women feel sexual desire? Are there any differences?

- How do we know when a man is excited? And a woman?

- How do men get excited? What excites a man sexually?

- How do women get excited? What excites a woman sexually?

- Do men and women get excited in the same way? What is the difference?

- What is orgasm? 
- What happens in a male orgasm?

- And what about a female orgasm?

- How important is affection in a sexual relationship?
- Is it different when you are in love with the person you have sex with?

- Is sex more enjoyable with affection or without affection?

\section{Closings}

- Discuss the importance of affection in a sexual relationship. Stress the need to practice safe sex, always using a condom.

- Emphasize to the young men that women have sexual desires and needs similar to their own, and the importance of understanding the needs and desires of their partner (whether male or female).

- Discuss the different ideas of eroticism presented, emphasizing that men and women have an erotic body and that the parts of the body that produce the most sexual excitement vary from person to person.

- Inform the group how the erotic body works.

\section{Resource Sheet: The Erotic Body}

Every part of the human body can produce pleasure when touched but, generally speaking, people have certain areas that are more sensitive to caressing than others. These are called erogenous zones (breasts, anus, vulva, clitoris, vagina, penis, mouth, ears, neck, etc.). They vary from person to person, thus, only by talking or experimenting will you know what excites your partner (be they male or female) most.

The human body is much more than its biological functions. Unlike most male animals, who become sexually aroused merely by the smell of a female when they are in heat, human male excitation depends on social and psychological factors that are closely interlinked, which influence each other and which depend on each other. For a woman, sexual desire does not depend on being in her fertile period. How does human sexual desire work?

\section{There are four stages to human sexual desire: \\ - Desire, \\ - Excitation, \\ - Orgasm and \\ - Relaxation.}

- Sexual desire is when one feels like having sex. It occurs through the activation of the brain when confronted with a sexually exciting stimulus. It should be remembered that a certain stimulus can be exciting in a certain culture and not in another. For example, a certain standard of beauty can arouse sexual desire in one place and not in another. Anxiety, depression, the feeling of danger and fear of rejection can affect a person's sexual desire. On the other hand, when a person feels relaxed, secure and has intimacy with his or her partner, this greatly facilitates the desire to have sexual relations.

- Sexual excitation is involuntary, that is to say, it occurs independently of a person's will. What man has not had the embarrassment of having an erection at the wrong moment? We know that a man is excited because his penis becomes hard and his testicles rise or feel tighter. We know a woman is sexually excited when her vagina becomes wet and her clitoris swells and becomes harder. Physiologically, the excitation results from the increased flow of blood into 
certain tissues (such as the penis, the vagina, the breasts) and from the muscular tension of the whole body during sexual activity. During this phase, respiratory movements and heartbeat increase. More important than knowing all this, however, is knowing that caressing and touching between partners is important in this stage. In the case of most man, all it takes is an erotic image for him to have an erection; for a woman to become excited requires more time, and more caressing and kissing.

- Orgasm is the stage of greatest sexual intensity and is difficult to describe objectively because the feeling of pleasure is personal - so much so that descriptions of orgasm are just as varied as people themselves. During orgasm, most individuals feel that the body builds up enormous muscular tension and then suddenly relaxes, accompanied by an intense feeling of pleasure. Furthermore, not all orgasms are the same. As the orgasm depends on sexual excitation; the same person can have orgasms of different intensities at different times. It is during the male orgasm that ejaculation occurs, that is, sperm is ejected through the urethra.

- Relaxation is the stage when the man relaxes and needs some time to get excited again. In young men this period is short (around 20 to 30 minutes); in adults, particularly those over 50 , it can take longer. Women do not need this interval, which explains why they can have more than one orgasm during sexual intercourse, or multiple orgasms. 


\section{Health, STIs and HIV and AIDS}

Purposes: To increase knowledge about STIs and promote the importance of STI diagnosis and treatment.

Recommended time: 2 hours

Materials Required: Chalk board or wall, paper, markers, glue, old magazines.

Planning tips/notes: It is important to emphasize that when a young man notices any STI symptom, he should consult a urologist and not resort to self-medication.Furthermore, the facilitator should emphasize that dealing with STIs, HIV and AIDS also involves ethical questions, that is, if a person has one of these infections, it is his responsibility to communicate this to his sexual partner(s). When discussing these themes, the facilitator should have available the most recent information about HIV transmission, the history and context of the disease, the difference between being HIV-positive and having full-blown AIDS, and current access to treatment. In our experience, these are issues that nearly always come up in group discussions. The facilitator should also seek to promote solidarity with persons affected by HIV and AIDS. The activity can also be used to promote a discussion about discrimination toward persons living with AIDS.

\section{Procedure}

- Working as a group, mention that the majority of the participants have probably heard of sexually transmissible infections or STIs.

- Ask the group as a whole what are the symptoms of STIs and write these on the board.

- When they have finished, complete the information on the board from the resource material provided at the end of this activity.

- Next, ask the group what are symptoms of having HIV and AIDS and write these on the board.

- Talk with the group about the importance of recognizing symptoms of STIs, the need to consult a doctor when symptoms are present and the importance of following all the doctor's instructions, and STI prevention.

- Explain to the group that HIV and AIDS does not always have noticeable symptoms and that the only way of knowing if one is infected by HIV is through a blood test.

- Next, ask them to divide into groups of 6 persons and think about how they can tell other people what the symptoms of STIs, HIV and AIDS are. Suggest that they make posters, leaflets, a play, TV commercial, etc.

- After working in the group setting for about 20 minutes, ask them to present their work to the other participants. 


\section{Discussion questions}

- What STIs have you heard about?

- Why do we say that self-medication is not advisable and that you should consult a doctor?

- Besides seeking medical assistance, what should a young person do when he finds out that he or she has contracted an STI?

- How do you tell your girlfriend that you have an STI? How would you tell her that you might have given it to her?
- And if she was not your girlfriend but just a casual acquaintance?

- Why is it so difficult to talk about STIs?

- What about HIV and AIDS? Has knowing about HIV and AIDS changed the sexual practices of young men?

- How is it possible to protect against HIV?

- How should HIV positive persons be treated? And persons who already have AIDS?

\section{Closing}

- Explore the myths that still exist in relation to HIV and AIDS, for example, that only "promiscuous" persons can have HIV or that HIV and AIDS is a gay disease.

- Explain that many men, as a way of showing their virility and masculinity, do not worry about their health, and may believe that taking care of the body or being overly concerned about health are female attributes.

- Emphasize that the idea that heterosexuality is the only normal sexual practice is marked in the social consciousness of our culture.

- Perceiving HIV and AIDS as being a disease related to "deviant" behavior, as a kind of punishment, leads heterosexual men and women to believe that they are not at risk for HIV.

- Explore the fact that, although HIV and AIDS is constantly being discussed in the media, including reports of experiences of people living with the virus for more than a decade, there is still a very strong prejudice toward contaminated persons. Explore with the group where they think this prejudice comes from and what they might do to change it. 
Summary: With this activity, one can reflect on the relation between alcohol consumption and other substance use, and risky sexual behavior.

Purpose: To identify the effects (physical, emotional and behavioral) of alcohol consumption, to present situations in which alcohol consumption hampers self-care and prevention of HIV and AIDS and to explain, collectively, alternatives so that self-care practices are always employed.

Materials required: Large sheets of paper, Markers, Adhesive tape, Cards

Recommended time: 2 hours

\section{Procedure}

1. Ask the group to write on the cards 3 ways of having fun, preferred by the adolescents they know, and then read them out to the group. Note down the answers one by one, and work out the statistics for the group.

2. If the group has not mentioned it, ask them "in which of these activities is alcohol present?"

3. The facilitator asks "why do adolescents consume alcohol?" and notes down each of the answers. Possible answers might be "to be accepted", "to have fun", "to show who can drink the most", or "not to feel odd with their friends", etc., all of which have to do with what is socially expected of a man.

4. After that, ask them about the different effects of alcohol consumption ${ }^{1}$ (physical and emotional effects, effects on the mind and behavior), while noting down each of the answers on a large sheet of paper.

5. The facilitator might want to add to the different effects of alcohol consumption ${ }^{2}$ by employing the following table:

6. Divide the participants in two groups and discuss what the consequences of these effects are on their sexuality, that is to say, how they lead to sexually risky behavior, unprotected sexual relations, coercion, etc.

7. Ask each group to organize a socio-drama, where the following situation is staged

A person who knows about condoms and is motivated to use one but who, under the effects of alcohol has sexual relations without protection, and what the consequences of this are.

\footnotetext{
${ }^{1}$ For reflection purposes, situations that they have experienced or observed in persons around them can be taken into account.

${ }^{2}$ It is important that the facilitator explains that the effects are not the same for everyone and in every situation. They vary depending on the: amount of alcohol consumed, speed or length of time of drinking, the size and weight of the person, etc.
} 
Effects of Alcohol Consumption

\begin{tabular}{|c|c|c|c|}
\hline Physical & On the Mind & On Behavior & Emotional \\
\hline $\begin{array}{l}\text { Nausea and vomiting } \\
\text { Loss of balance, } \\
\text { numbness in the legs } \\
\text { Loss of coordination } \\
\text { Reduction of reflexes } \\
\text { Bad recollections of } \\
\text { personal experiences } \\
\text { Obsession } \\
\text { Dreams }\end{array}$ & $\begin{array}{l}\text { Confusion and } \\
\text { difficulty in } \\
\text { concentrating. } \\
\text { Thought disturbances } \\
\text { and loss of memory } \\
\text { - unable to remember } \\
\text { what one does under } \\
\text { the effects of alcohol } \\
\text { - Altered judgment }\end{array}$ & $\begin{array}{l}\text { Violent or depressive } \\
\text { behavior } \\
\text { Difficulty to talk or speak } \\
\text { Uninhibited } \\
\text { Tearful }\end{array}$ & $\begin{array}{l}\text { Feeling of temporary } \\
\text { well-being } \\
\text { Relaxation } \\
\text { State of exacerbated } \\
\text { happiness or sadness, or } \\
\text { disgust } \\
\text { Sensation of being } \\
\text { omnipotent, invincible. }\end{array}$ \\
\hline
\end{tabular}

\section{Questions for discussion}

Put the following to the full group and get their comments.

- What attracted your attention the most?

- Are the social dramas staged similar to what happens in real life?

- What is the reaction of adolescents when someone does not want to consume alcohol?

- What can we do to care for ourselves and support others?

- What effects have other substance use on decision-making and self-care behavior?
- How can we create other forms of fun and social coexistence, where alcohol is not the most important thing?

\section{Links}

- It can be related to the theme of negotiating the use of the condom in the activity "I want... I don't want... I want... I don't want..." in this same manual.

\section{Closing}

- A person who practices alcohol abuse runs the risk of suffering sexual abuse, rape, STI and HIV and AIDS contagion, as under the effects of alcohol it is difficult to take adequate precautions, such as using a condom, even when the person is fully aware of its importance.

- Alcohol facilitates, for some men, the expression of affection and friendship toward other men. It is important to provide an opportunity to express oneself without the need to ingest alcohol.

- If young men know the symptoms of alcohol intoxication, it will be easier to identify them and have sufficient time to avoid alcohol abuse.

- For young men it is necessary to create other forms of having fun without alcohol being at the center and not to put pressure on those that do not want to consume.

- In the long term, alcohol abuse can give rise to dependence and other problems in the organism and in every aspect of a person's life. 

Violence

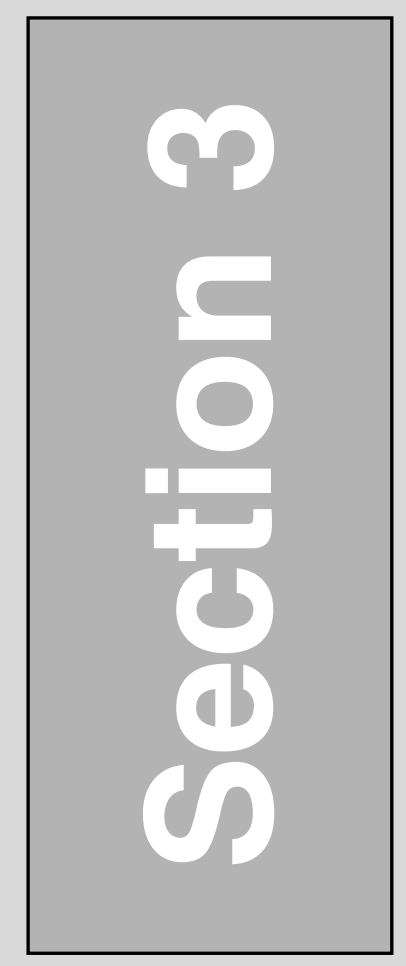





\section{Sexual Violence: Is it or Isn't It?'}

Activity at a glance: This activity presents various situations involving sexual violence, where young men are asked to determine what is and what isn't sexual violence.

\section{Purpose:}

To discuss what sexual violence is, what conditions foster it and how we can reduce it or prevent it.

Materials required:Flip-chart, pens and tape.

Recommended time: 1 hour.

Planning tips/notes: Before presenting this activity, it might be useful for the facilitator to look for data in his/her community or country concerning different forms of sexual violence, information about the laws in force, as well as information about organizations that offer support to persons who have suffered sexual violence. This information can be useful when replying to questions that the participants might ask during or following this activity. Also, before the activity, the facilitator should check the phrases to see which he/she thinks relevant, and adapt where required and add other examples appropriate to the local area. You may encounter some resistance in discussing the theme of sexual violence. In other places, there are already campaigns about sexual violence, and the examples included here might seem a little too obvious. In the same way that talking about other forms of violence might cause discomfort, in view of possible connections with the personal stories of the participants, in the case of sexual violence there might be young people in the group who have suffered some type of sexual violence in childhood or adolescence and who might need help. On various occasions, we have come across young men who have suffered sexual violence (from men and women), but have never spoken with anybody about the matter out of shame - they were convinced that nobody would believe that a man could be the victim of sexual violence (particularly when the perpetrator was a woman). Others, on some occasions, knew of female friends that had been victims of sexual violence. The facilitator should be prepared for such sensitive cases and even for participants who might need special help.

\footnotetext{
${ }^{1}$ The format of this activity was adapted from the activity 'Choice of Values' from the curriculum, 'Life Planning Education', Advocates for Youth, Washington, DC, USA. For more information, consult the Advocates for Youth website, www.advocatesforyouth.org.
} 


\section{Procedure}

1. Before starting the activity, write the following phrases, one each on sheets of paper:

- It is sexual violence

- It is not sexual violence

- I don't know.

2. Explain to the participants that you are going to read a series of cases and you want them to think about whether the situation described represents sexual violence or not. Tell them if they do not know or are not sure, they can say so.

3. Stick the three 'posters' on the wall leaving space between them. Explain that you are going to read a case and are going to ask the participants to decide which poster, in their view, fits. 'It is sexual violence', 'It is not sexual violence', 'I am in doubt (or I don't know)'.

4. Explain that once they have made a decision, you will ask one or more members of the group of each category to defend their point of view.

5. Before starting the activity consider what is most appropriate and, of course, include and invent others. Read out one of the following paragraphs.

6. Allow each group about 5 to 7 minutes to discuss each case.

7. After presenting the number of cases that you think fit, discuss in groups according to the three categories of opinion. The facilitator can make use of the legislation on sexual abuse or sexual violence in his/her country. The attached Resource Sheet would also be helpful.

\section{Discuss the following questions}

- Are these situations realistic?

- What is sexual violence?

- What is gender violence?

- Is all sexual violence a crime?

- What can we do to prevent sexual violence?

- Who is more subject to sexual violence, men or women? Why?

- Can a man also be a victim of sexual violence?

- What do you think are the consequences of having suffered sexual violence?

\section{Closing}

After commenting on the discussion questions, and depending on the level of knowledge, it might be worthwhile to talk with the group about the meaning of gender violence and its various forms as presented in the Resource Sheet that follows. If it seems useful for the group, someone from their community who is a specialist in the theme of gender violence or sexual violence can be invited to talk with the group. It might be worthwhile to consult other sources of additional information that talk about the consequences of sexual violence. It is known that many adult men who are sexually violent were also victims of some type of violence in their childhood or adolescence. Demonstrate the importance of identifying cases of sexual violence and other acts of violence against children and adolescents in order to interrupt the cycle of sexual violence. 


\section{Four stories: Is it violence?}

\section{Story 1}

Rahul liked a girl, Sunita, in his neighborhood. On quite a few occasions they came across each other. Once they got a chance to hang around in a lonely place. Both of them started to kiss each other. Rahul persuades Sunita to take off her cloths, eventually she agrees to it. But Sunita gets upset and now she wants to go back. Rahul tries to convince her that they have come this far and they can go still further and he repeatedly insists on Sunita having sex with him. He tells her that she is looking beautiful and that he cares about her. Rahul didn't use any physical coercion. Is it violence?

\section{Story 2}

Mangesh used to tease girls in the local trains. Whenever girls smiled or laughed, he tried to touch their bodies. Even then, some girls used to laugh and smile over his acts and Mangesh thought that girls liked these things. If he teases any girl and she smiles, then is it violence?

\section{Story 3}

Vishnu was part of a gang who used to coerce younger boys to have sex. One day Vishnu said to a young boy, Vikash, that if he agreed to have sex with him then he would protect him from older boys. Is it violence?

\section{Story 4}

Rajesh and Meena have been married for two years and they have an enjoyable sex life. Sometimes, Rajesh comes home late and by that time Mina is fast asleep. Rajesh generally wakes her up and ask for sex. Often, even if Meena is not willing, she gives in to Rajesh. Is this violence? 


\section{Resource Sheet: Defining gender violence}

- Incest: sexual relations between blood-related persons (fathers/daughters, mothers/sons, brothers, etc.).

- Sexual abuse: refers to any type of intimate (sexual) physical contact between an adult and a child.

- Rape: the use of physical force or threat in order to obtain sexual relations with penetration (oral, vaginal or anal).

- Sexual exploitation: taking advantage of or involving children or adolescents in the sexual satisfaction of adults, including activities such as child prostitution and pornography.

- Sexual harassment: is manifested through indecent proposals, obscene words and pressure to have sexual relations, which the other party does not want.

- Emotional violence: is violence manifested through insults, humiliations, threats, lack of affection, etc. The consequences for men and women may be low self-esteem, distrust and emotional insecurity.

- Physical violence: is violence which is expressed through punching, kicking, shoving and other acts which can provoke injury, endangering the health of a man or woman.

\section{Link}

The question of sexual violence also brings to light the question of abortion and emergency contraception, which is included in the manual on Sexuality and Reproductive Health.

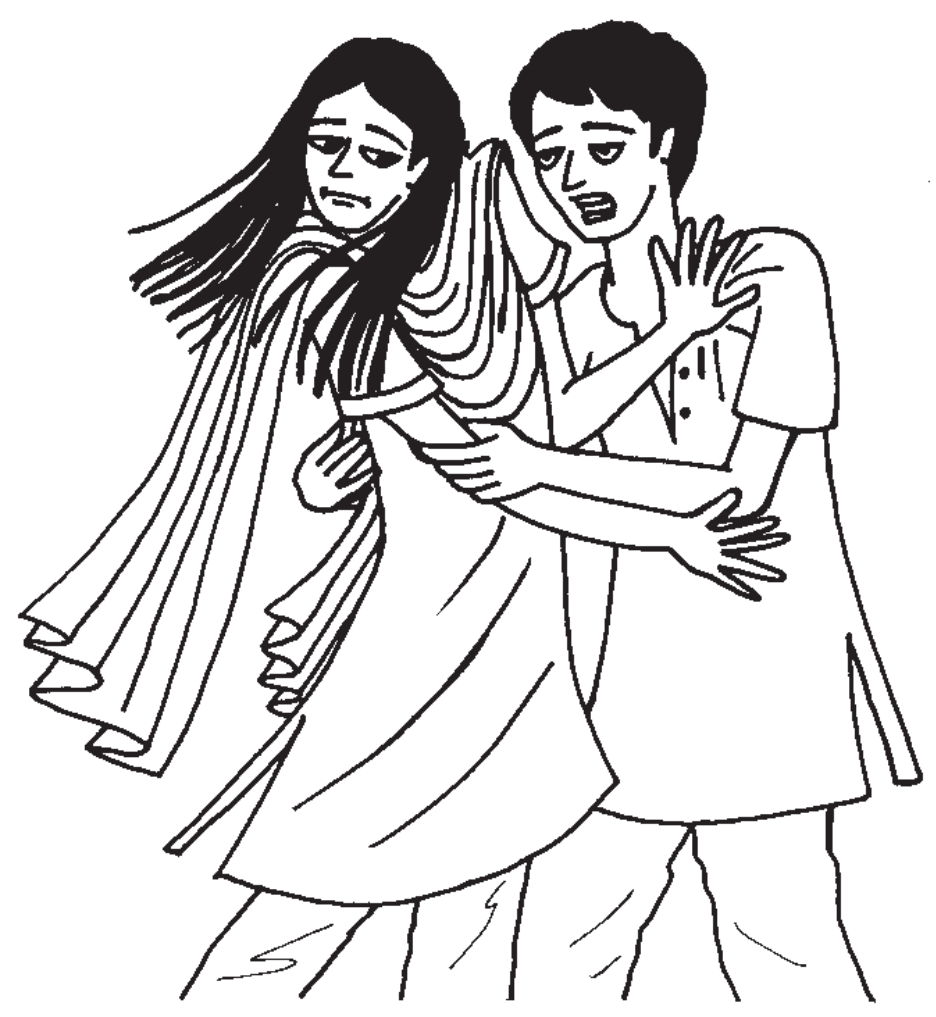




\section{Violence and Coercion in Sexual Relationship}

Planning tips/notes: When one talks of power and violence in sexual relations, the first thing which comes to our mind is rape, an extreme form of sexual coercion. However, in daily life many hidden forms of exercising power, and consequently, in a general way, men's violence against women, can occur, which can be translated into the language we use in relation to the partner, in disrespectful treatment, etc. We know that in affective partner relations, where there is an unequal exercise of power, negotiation concerning when to have sexual relations, of what type, of whether to use a condom or not, becomes the subject of conflict, sometimes escalating into situations of physical, psychological and even sexual violence, as we describe in the manual 'From violence to peaceful coexistences'.

For many young men, peer group pressure, the feeling of 'having to maintain sexual relations in order to vouch for their manhood', very often makes them view their sexual partner as a sexual object, endangering their own physical and/or psychological integrity and that of the other person during the exercise of sexuality.

Thus, our intention is to promote healthier and more enjoyable sexual relations, where respect for the will of the other person and care for one's own health and that of the partner are always present.

\section{Procedure}

1. Explain that the purpose of the activity is to talk about the exercise of power and violence in sexual relations.

2. Do some brainstorming with the group concerning the types of violence that can occur in sexual relations.
3. Depending on the number of participants, divide them into 2 or 3 sub-groups, handing out the text of the story of Nitin to each one, carrying out a directed reading with the participants for 15 to 20 minutes.

4. Return to the initial formation of the group and open a collective discussion. 


\section{Story of Nitin and Reshma}

Reshma lives in Santosh Nagar and Nitin is her neighbour. Both of them are of the same age and they like each other. Reshma liked to talk to Nitin and she always looked for excuses to do so. Sometimes they would touch each other and that was very exciting for them. Their relationship was gossiped about among their friends. Nitin would tell his friends about his meetings with Reshma. His friends always made fun of him for not having sex with Reshma. One day Nitin asked Reshma to accompany him to the cinema. Reshma agreed. But instead of taking Reshma to the film he took her to a room in a lodge that he knew of. After locking the door he hugged Reshma. Reshma asked him when they would go to the film. 'Darling this is our movie. I am the hero and you are the heroine,' he said and started to kiss Reshma. She reciprocated. When Nitin tried to take her towards the bed, Reshma suspected his intention and she stopped him and asked to be taken home. Nitin pleaded with her repeatedly to have sex with him, but Reshma was not ready. They started to quarrel. Nitin was very angry with Reshma but he did not want to coerce her to have sex. Nitin said, Okay, if you don't agree, from now onwards, we are no more friends. We no more love each other. Everything is over now. You don't have faith in me. We won't, meet from now onwards. Reshma was undecided. Finally she gave in. 'Okay. I love you,' she said. They had sex. Nitin didn't even use a condom. Nitin was very happy and was just waiting to break this news to his friends.

After reading the story of Nitin, discuss the following points, encouraging them to reflect on the episode and what other paths could have been followed:

- Is this story just fiction or does it have anything to do with reality?

- What do you think of Nitin's behavior in having sex with Reshma?

- Do you think he only did this due to peer pressure?

- What could be the consequences of Nitin's conduct for him? And for the Reshma?

- And if he had not given in to the pressure, how do you think his friends would have treated him?

- And what about him, how would he have felt?

\section{Discussion questions}

- Can what Nitin did be classified as violence? Why?

- What type of consequence do you think this might entail for them?

- Have you ever been in a similar situation to this? What was your reaction?
- How do you view negotiating sexual relations? Can there be pressure to have sex?

- And to use condoms? Can there also be pressure not to use a condom?

- In what situations can this occur? In what situations can this not occur?

- Can women commit acts of violence in sexual relations against a man?

- What type? And how do men generally react?

\section{Closing}

Ask the group what they felt about the story of Nitin. Encourage negotiation and attitudes of respect in sexual relations, where the desire of each person should be respected. If anyone in the group has practiced or suffered violence and disrespect in relation to the exercise of his sexuality, and expresses this to the group, do not judge or condemn. Try to understand the reasons why such a situation occurred, clarifying the need for respect as the basis for just and equitable relationships. 


\section{Diversity and Rights: Me and Others}

This activity uses role plays to imagine what it would be like if we were other people living in different conditions and realities.

Purpose: To encourage empathy with persons from different realities and discuss the origin of violence associated with persons from different ethnic groups and/or sexual orientation.

Materials Required: A4 paper sheets. Fine-tip pens. Tape.

Recommended Time: One hour and a half

Planning tips/notes: This activity generally causes considerable laughter as the participants have to play the role of persons of different sexual orientations and social realities. Try to keep a light touch during the activity, without censuring anyone and seeking to foster respect for the differences that exist. Using this activity with a number of groups of young men, they asked for more phrases and we used this activity twice. Using it a second time allowed other themes, which they had doubts about and which needed clarification, to be dealt with: HIV and STIs, substance abuse, suicide, domestic violence- themes included in this manual and in the others in this series. In this way, this activity is a way of integrating the themes dealt with in the five manuals included here.

\section{Procedure}

1. Before the group begins these activities, choose phrases that you consider to be most appropriate according to the list below. Write these phrases on a sheet of paper. Select a suitable number of sentences for each participant. If you like, create other phrases, other examples or repeat some, as required.

2. Ask the participants to sit in a circle and close their eyes. Explain that a sheet of paper will be placed in their hands containing a word or phrase. After receiving the paper, the participants should read the phrase without making a comment and reflect personally on what they would do if they were in that situation.

3. Ask each person to take a piece of tape and stick the paper on the front of his shirt.

4. Ask everyone to stand up and slowly walk around the room, reading the phrases of the other participants, greeting each other, but without speaking.

5. Afterwards ask the participants to form a circle and look at each other. Explain that each one should impersonate a character and invent a story that has something to do with the phrase they have received - a story that talks about the situation or reality of their character. Allow some time (5 minutes or so) for them to come up with their story. 


\section{Possible sentences}

\begin{tabular}{|l|l|}
\hline I am HIV-positive & I am a criminal (member of a gang or a drug trafficker) \\
\hline I am bisexual & My father is in jail \\
\hline My girlfriend cheated on me & I am heterosexual \\
\hline My mother is a sex worker (a prostitute) & I can't read \\
\hline I am an executive & I have had sexual relations with another man, but I am not gay \\
\hline I have AIDS & I am gay \\
\hline I am of Black & I hit my girlfriend once \\
\hline I once tried to kill myself & I am a cocaine addict \\
\hline I am deaf & I am a street kid \\
\hline I am a millionaire & I lost my arm in an accident \\
\hline My girlfriend hit me & I am a father and I take care of my children \\
\hline I am an alcoholic & I am unemployed \\
\hline
\end{tabular}

6. Ask if someone will volunteer to begin. Then, each one, at random or going round the circle, talks about his story until everyone has had their turn. In some cases, one can allow participants to exchange their "case" with another participant.

7. Once everyone has told their story, ask them to return to their places, with the paper still stuck to their shirts.

8. Ask the participants, while still retaining their characters, to ask the others questions about their lives, their present situation, their problems and their realities. You may want to use the talking stick (see activity 1 ) to facilitate the discussion. Allow 20 to 30 minutes for this.

\section{Discuss the following questions}

- Do you know any young person who has faced a similar situation to that described on your paper?

- What was it like for you to impersonate this character? How did you feel?

- In many places a young man that is "different" or who represents a minority is a target for discrimination and violence. Where do you think this hate comes from?

- How can the fact that someone is "different" from us lead to violence?

\section{Closing}

You can conclude this activity by asking the participants about other examples of different persons or even of minorities that were not included. Sometimes examples of persons perceived as being different or minorities about which we have not thought provide more material for the activities and the work with young men. 


\section{Activity 3.4 \\ From Violence to Respect in Intimate Relationships ${ }^{1}$}

Activity at a glance: This activity uses role plays to present couple relationships showing violence and respect.

Purpose: To discuss how we use violence in our intimate relationships and envision and identify intimate relationships based on respect.

Materials Required: Flip-chart, pens and tape.

Recommended time: One hour and a half

Planning tips/notes: This activity uses role plays with female characters. If you are working with a maleonly group, some of them may be reluctant to interpret a female character. Encourage the group to be flexible. If none of the young men want to interpret a female character, you can ask them to describe the scenes using the flip-chart, for example. What is very apparent, in the Brazilian context where we work and developed this activity, is the impotence that young men feel in responding to the violence that they see other men perpetrating. Many are afraid to talk about domestic violence, repeating a common saying in Brazil that in a husband-and-wife fight, no one should stick their nose in. Through this activity the facilitator should try to talk about the silence and impotence which we feel in witnessing domestic violence. Another thing we notice in using this activity is that the young men in the setting where we work have little contact or knowledge of intimate relationships - whether courting or adult couple relationshipsbased on mutual respect and dialogue. The degree of conflict in daily, intimate relationships where we work is extremely high, showing the need to work with men and women and get them to think about the question: How can we form relationships between men and women based on respect? What does a healthy intimate relationship look like?

\section{Procedure}

1. Explain to the group that the objective of this activity is to discuss and analyze the various types of violence that we sometimes use in our intimate relationships and discuss ways of demonstrating and experiencing intimate relationships based on respect.

${ }^{1}$ When we refer to intimate relationships and intimacy, we are seeking to emphasize courting/dating and "casual" relationships, that is to say, those with amorous, affectionate/romantic involvement which might or might not include sexual involvement. We prefer not to use "couple relationships" because young people do not always associate "casual"/ dating relationships with a stable "couple relationship." 
2. Divide the participants into 4 groups (or less, depending on the total number of participants in the group), with 5 or 6 members in each group, and ask them to invent a short role play or skit.

3. Ask two groups to present an intimate relationship - boyfriend/girlfriend, husband/ wife or boyfriend/boyfriend-which shows scenes of violence. Explain that the violence can be physical but does not necessarily have to be. Ask them to try to be realistic, using examples of persons and incidents that they have witnessed or they have heard about in their communities.

4. Ask the other groups to also present an intimate relationship but based on mutual respect. There may be conflicts or differences of opinion, but the presentation should show respect in the relationship and should not include violence. Allow 15 to 20 minutes to develop the story or the scenes and then ask them to present it to the group.

5. Each group should have around 5 to 10 minutes to present their skits, with the other groups being allowed to ask questions at the end.

6. When all the groups have had their turn, using the flip-chart, make a list: what are the characteristics of a violent relationship? Encourage the participants to reflect on the different forms of violence in intimate relationships (control, coercion, shouting ...) as well as physical violence. Use the stories as an example and ask: what are the characteristics of the individual or of the relationship itself, in the cases that were presented, which demonstrate violence?

7. Placing the list on the wall, begin to list the following: what characteristics make a relationship healthy? Ask the group to think about what is necessary to achieve a relationship based on respect.

\section{Discuss the following questions}

- Were the examples used in the skits realistic? Do we see these things in our daily life?

- What for you are the causes of the domestic violence or the violence in the relationship?

- Do only men use physical violence against women, or are women also violent toward men?

- When you see this type of violence, what do you normally do? What could you do?

- Are the examples of a healthy relationship that were shown in the stories realistic? Is it possible to construct an intimate relationship based on respect? Do we see it in our daily lives?

- What can we do individually to construct healthy intimate relationships?

\section{Closing}

This activity seeks to encourage young men to discuss the realities of domestic violence, using examples from their own setting. Depending on the group, you can encourage the participants to look for additional information on domestic violence in their communities. The facilitator can also invite someone who works with women that has been the victim of domestic violence or who works with perpetrators of violence against women. In India many such organization are functional, the need of the hour is to integrate and bring it at national forums. MASWAW for example is working extensively in Uttar Pradesh to bring together the men to curb the violence against women. 


\section{From Violence to peaceful co-existence}

Activity at a glance: This activity consists of openly talking about the violence that we suffer and perpetrate.

Purpose: Identify the forms of violence that we perpetrate or that are committed against us.

Materials required: String for the clothesline. Tape. Three sheets of paper (A4 size or equivalent) for each participant. Clothes pins.

Recommended time: One hour and a half

Planning tips/notes: When we talk about violence, we think mainly of physical aggression. It is important to discuss other forms of violence besides physical violence. It is also important to help young people think about the acts of violence that they perpetrate, because very often we think that it is the other persons who are violent but never ourselves. With the use of this activity, we observed that for the young people we worked with it was much easier to talk about the violence they had suffered. Describing acts of violence - particularly those that occur outside their homes - was easy. We even noticed that they felt a certain relief in being able to relate these experiences which they had survived. Commenting on or talking about violence committed against them inside their homes was a more delicate matter. Some commented on domestic violence, but did not want to go into details, and we did not insist. Talking about violence which they had committed was even harder. First, because they always wanted to justify themselves, blaming the other person for being the aggressor. This activity provided material for two work sessions. Should you feel that the participants do not wish to expose personal details about themselves, consider alternative activities in this manual that require less personal "disclosure."

As mentioned earlier, being a victim of interpersonal violence is associated with committing acts of violence later. Helping young men grasp this connection and think about the pain that violence has caused them is a potential way of interrupting the victim- to-aggressor cycle of violence. If any young person reports that he is suffering any type of violence or that he has suffered recently any type of abuseincluding sexual abuse or systematic physical abuse at home - and is less than 18 years old, in some countries, the facilitator must report the fact to the child and adolescent protection authorities. Before carrying out any task in this manual, the facilitator should consult his or her own organization to clarify the ethical and legal aspects related to that country concerning violence against young persons under 18 .

\section{Procedure}

1. Explain that the purpose of this activity is to talk about the violence we practice and the violence practiced against us, and talk about our feelings in relation to this.

2. Explain that we will set up 4 clotheslines and that all the participants should write a few 
words on the sheets of paper and hang them up on the line.

3. Give each participant 4 sheets of paper (A4 size).

4. Place on each clothesline the following titles:

- Violence practiced against me

- Violence that I practice

- How I feel when I practice violence

- How I feel when violence is practiced against me

5. Ask each participant to think for a while and write a short reply for each item. Each person should write at least one reply for each clothesline (or category). Allow about 10 minutes for this task. Explain to them that they should not write much, just a few words or a phrase, and place it on the corresponding clothesline.

6. Ask the participants, one by one, to read out their replies to the group. They can give other explanations which become necessary, and the other participants can question them about their reply.

7. After each person has placed their replies on the clothesline, the following questions are discussed, using the talking stick if so desired.

\section{Discussion questions}

- What is the most common type of violence practiced against us?

- How do we feel about being a victim of this type of violence?

- What is the most common type of violence we commit against others?

- How do we know if we are really committing violence against someone?

- Is there any connection between the violence we practice and the violence we are victims of?

- How do we feel when we practice violence?

- Is any kind of violence worse than another?

- In general, when we are violent or when we suffer violence, do we talk about it? Do we report it? Do we talk about how we feel? If we do not, why not?

- Some researchers say that violence is like a cycle, that is to say, someone who is a victim of violence is more likely to commit acts of violence later. If this is true, how can we interrupt this cycle of violence?

\section{Closing}

Ask the group what it was like for them to talk about the violence they have experienced. If anyone in the group shows a need for special attention due to an act of violence they have suffered, the facilitator should consider referring the young man to appropriate services and discuss the issue with other senior staff at your organizations. 
This activity seeks to enable young men to recognize when they are angry and how to express their anger.

Purpose: To help the participants to think about how to identify when they are angry and how to express their anger in a constructive and non-destructive way.

Materials required: Flip-chart. A4 paper. Felt-tip pens. Tape. Copies of the Resource Sheet for each participant.

Recommended Time: One hour.

Planning tips/notes: In general, boys and men are socialized not to talk about what they feel. When we feel frustrated or sad, we are encouraged not to talk about it. Very often by not talking, the frustration or anger builds up until it is expressed through physical aggression or houting. This activity can be useful and can be a reference for the rest of the process, since there will always be conflicts in the group. In the event of conflicts, the facilitator should remind them: "Use words, but don't offend."

\section{Procedure}

1. Begin the activity with a short introduction to the theme, as for example:
Many adolescents and men confuse anger and violence, thinking they are the same things. It should be stressed that anger is an emotion, a natural and normal emotion that every human being feels at some point in life. Violence is a way of expressing anger, that is to say, it is a form of behavior that can express anger. But there are many other ways of expressing anger-better and more positive ways - than

violence. If we learn to express our anger when we feel it, it can be better than allowing it to bottle up inside us, as many times when we allow our anger to build up, we tend to explode.

2. Explain to the group that in this activity we are going to talk about how we react to anger.

3. Hand out a Resource Sheet (which follows) to each participant. Read out each question and ask the participants to answer the questions individually, giving them 2 or 3 minutes for each question.

4. After filling in the sheet, divide the group into small groups of 4 or 5 participants at the most.

${ }^{1}$ This activity was adapted from the manual "Learning to Live without Violence: A Handbook for Men, Volcano Press, 1989. 
Ask them to comment, giving a short time for each one to say what he wrote to the others in the group. Allow 20 minutes for this group work.

5. With the participants still in the small groups, hand out a flip-chart and ask them to make a list of:

A) Negative ways of reacting when we are angry

B) Positive ways of reacting when we are angry

6. Allow the groups 15 minutes to write out their lists and then ask each group to present their answers to the whole group.

7. It is very likely that on the list of "Positive Ways" one will find the tactics of: (1) take a breath of fresh air, or count to 10; and (2) use words to express what we feel without offending. It is important to stress that to "take a breath of fresh air" does not mean going out and jumping into the car (if that is the case) and driving around at high speed exposing oneself to risk or going to a bar and tanking up on alcohol. If these two tactics proposed here are not on any of the lists presented, explain them to the group. In short:

To take a breath of fresh air is simply to get out of the situation of conflict and anger, to get away from the person toward whom one is feeling angry. One can count to 10 , breathe deeply, walk around a bit or do some other kind of physical activity, trying to cool down and keep calm. Generally, it is important for the person who is angry to explain to the other that he is going to take a breath of fresh air because he is feeling angry, something like: "I'm really fed up with you and I need to take a breath of fresh air. I need to do something like go for a walk so as not to feel violent or start shouting.
When I've cooled down and I'm calmer, we can talk things over."

Use words without offending is to learn to express two things: (1) To say to the other person why you are so upset, and (2) to say what you want from the other person, without offending or insulting. For example:

I am angry with you because:

I would like you to::

\section{Give an example for the group:}

If your girlfriend arrives late for a date, you could react by shouting: "You're a bitch, it's always the same, me standing here waiting for you."

Or then, looking for words that do not offend, you could say:

Look, I'm angry with you because you're late. I would like you to be on time, if not, let me know that you're going to be late.

\section{Discuss the following questions}

- Generally speaking, is it difficult for men to express their anger, without using violence? Why?

- Very often we know how to avoid a conflict or a fight, without using violence, but we don't do so. Why?

- Is it possible "to take a breath of fresh air" to reduce conflicts? Do we have experience with this activity? How did it work out?

- Is it possible "to use words without offending?"

\section{Closing}

If there is time, an interesting way of concluding this activity is to ask the group to produce some role plays or think of other examples of situations or phrases that exemplify the difference between shouting or using offensive words and using words that do not offend. 


\section{Resource sheet: What to do when I am angry?}

1. Think of a recent situation when you were angry. What happened? Write here a short description of the incident (one or two sentences).

2. Now, thinking about this incident when you were angry, try to remember what you were thinking and feeling. Try to list here one or two feelings that you felt in your body when you were angry:

3. Very often after we feel angry, we begin to react with violence. This can even happen before we realize that we are angry. Some men react immediately, shouting, throwing something on the floor, hitting something or someone. Sometimes, we can even become depressed, silent and introspective. Thinking about the incident when you felt angry, how did you demonstrate this anger? How did you behave? (Write a sentence or a few words about how you reacted, what you did or how you behaved when you were angry). 


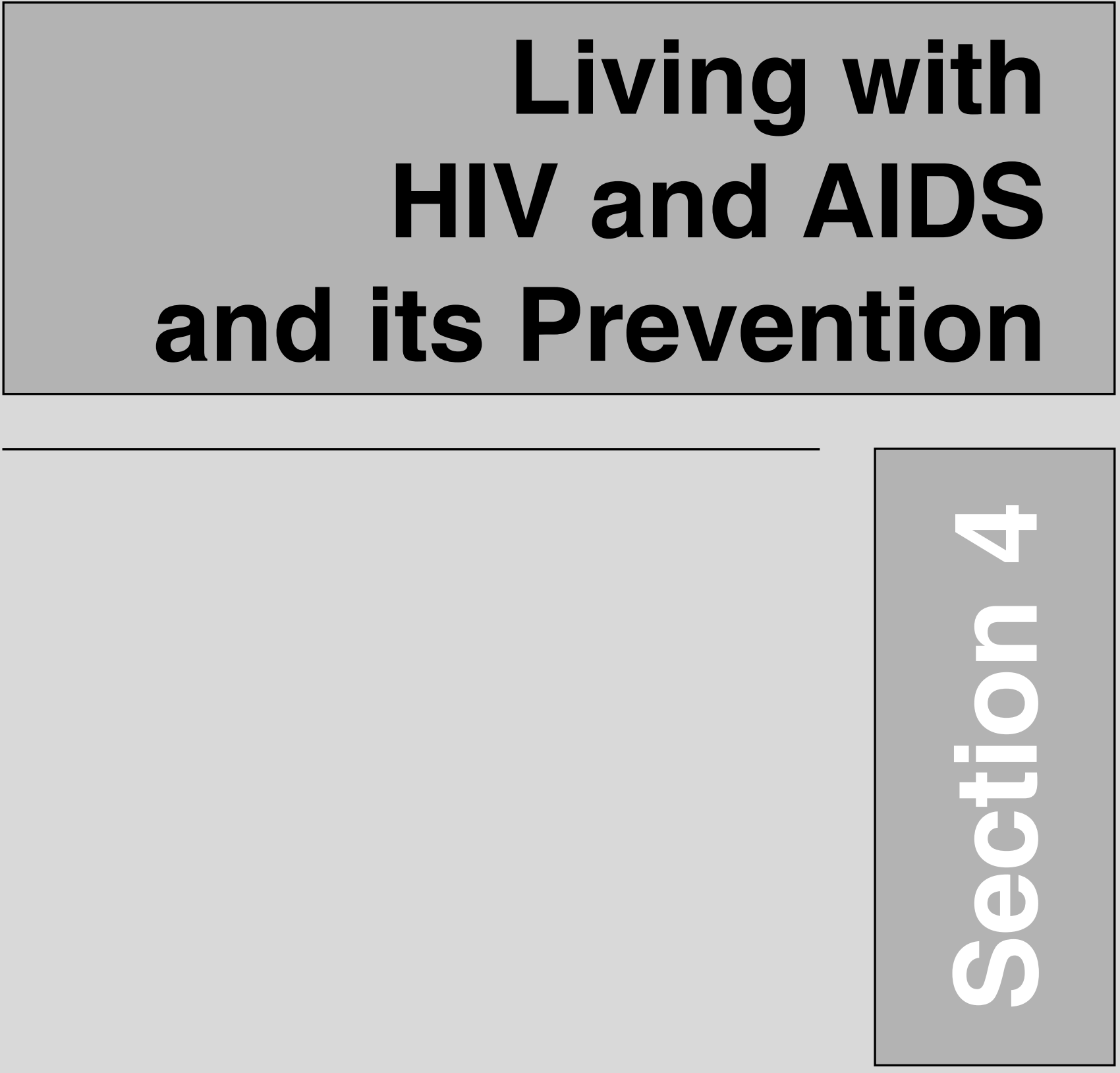

Activity 4.1

The story of Raju

With this activity one can pass on different information about AIDS, while at the same time, reflecting on the values and prejudices that still exist in relation to carriers of the virus.

Purpose: To provide accurate information about what AIDS is, the forms of transmission, prevention and anti-retroviral medication. To inform where one can do the HIV exam and how this type of service is carried out. To foster the need for solidarity among people.

Material required: script of the case study The story of Raju for the group of volunteers.

Time: 2 hours

Planning tips/notes: This activity requires previous contact with the group in order to ensure respect for the young men that are playing the female roles. It is also a good opportunity to discuss prejudice and what lies behind making fun of somebody.

\section{Procedure}

- At least one week in advance, get in touch with the group and inform them that you need eight volunteers to take part in a work activity.

- When the volunteers are gathered, inform them that the proposal is to prepare a short play called The story of Raju, which is to be presented later to the other members of the group. Ask them to keep the story a secret so as not to lose the impact.

- On the day it is to be presented, announce that a play, The story of Raju, will be presented and ask everyone to pay careful attention to the story line.

- After presenting the play, explain that it will be presented repeatedly until the group as a whole finds a satisfactory ending. Tell them that to come up with this ending, they will have to change the dialog of some of the characters.
Thus, when someone in the group thinks that he should take the place of some character, he should say: "freeze the scene, I'm taking the place of ...." and the story resumes where it stopped. For example: if someone thinks that the health professional is badly informed, that person should take their place and give the correct information. The play will be repeated until the group is satisfied.

\section{Discussion questions}

- What did you feel when the play was presented for the first time?

- What did you think of the changes that were made?

- What is HIV and AIDS?

- How can a person be contaminated by the AIDS virus? 
- How do you protect yourself?

- Do people usually have an exam to know if they have AIDS? Why?

- How do you think people are treated in the health services that do this exam?

- How do you think they should be treated?

- What happens in the health service when someone is suspected of having contracted the AIDS virus?
- What fantasies do people have when they are waiting for the result of the HIV exam?

- Do you know where this exam is carried out in your town?

- Is there any medication to treat people who are HIV-positive?

- Do people usually show sympathy with people, male or female, who are HIV-positive?

\section{Closing}

- It is vital to have up-to-date information about the ways of transmitting the HIV virus, the historical background of the disease, the distinction between being HIVpositive and PLWA, and the treatments that exist.

- One basic point in this work is to foster solidarity with people that have contracted the disease. Discuss with the young men the social discrimination and prejudice which people who are HIV-positive and PLWA are subjected to.

- Emphasize that the idea that AIDS is a disease related to deviant behavior or a punishment, still leads heterosexual men and women to believe that they are free from the possibility of contagion. Show statistical data that disproves this ideas;

- Explore the fact that, although AIDS is constantly being discussed by the media, including accounts of experiences of people living with the virus for more than a decade, prejudice toward contaminated people is still very strong. Explore what the prejudices are and why they are still so strong in our society;

- Remind them that prejudice is also related to the idea that someone with AIDS is promiscuous, a homosexual or a drug addict. All these qualifications are discriminatory. 


\section{The story of Raju}

Narrator: Raju is an 18-year-old adolescent, who studies at night and during the day works as an officeboy in a firm of accountants. A colleague at work had an accident and needed a blood donation. Raju went to the clinic, donated blood and some days later was asked to return there to talk with a health professional.

Health professional : Raju, have you been feeling anything different lately?

Raju : No, everything is OK.

Health professional : (the Health professional takes the blood exam and looks at it at length). Raju, your blood test shows that you are HIV-positive.

Raju : What?

Health professional : You might have AIDS.

Raju : What's that! I don't get it...

Health professional : Well, it's just that ... your blood test indicates you have the AIDS virus, but we're going to do another exam to see if that's the situation. In any case, I'm going to refer you to a psychologist and she'll give you a better idea about the case. Her room is just over there.

Narrator: After hearing this, Raju simply flipped. He rushed out of the clinic and didn't even want to know about a psychologist, let alone do another exam. He wandered the streets aimlessly. He could hardly hold his tears back, until he finally bumped into Sanju his best friend.

Sanju

Raju

Sanju

In the bar

Raju

Sanju

Raju

Sanju

Raju
: Raju, what are you doing here? Oh God, you look terrible.

: Something terrible has happened. I'm really bad. I don't know what to do.

: Come on man! Let's go to a diner and have a soda and you can tell me what's going on. That's what friends are for.

Narrator: The two talked a little more and then went their different ways. At night Sanju met up with his friends.

\section{Rakhi \\ Sanju \\ Chingi \\ Bandya \\ Chingi \\ Rakhi \\ Chingi}

: I don't know how to tell you this ... I donated blood the other day and they called me back and told me that I might have AIDS.

: (taken a back, and pausing before speaking) But are you sure about this?

: The guy told me to do another exam to make sure, but I was out of there in a flash.

: But how did it happen? What have you been getting up to?

: I don't know, I was walking along wondering where the hell I picked the damn thing up. I'm not a homosexual, I don't do drugs. Why did this happen to me? 


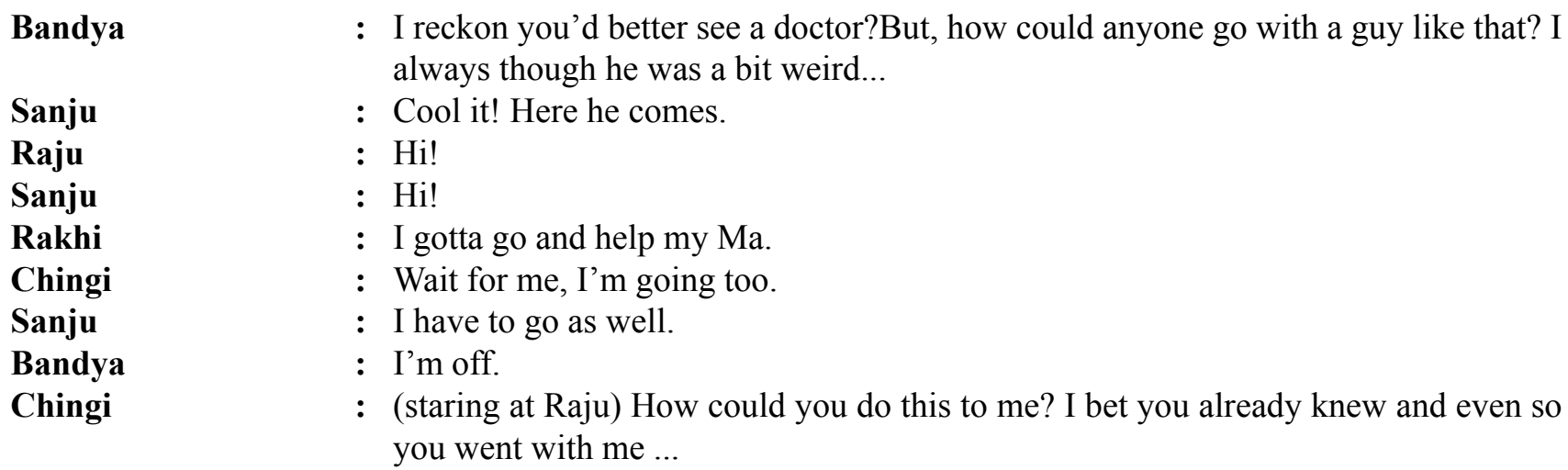

\section{They go off, leaving Raju alone}

\section{The Story of AIDS}

The story of AIDS begins at the beginning of the 1980s, when various people in the United State and Europe began to contract a very rare type of skin cancer (Kaposi's sarcoma) or severe pneumonia. What all these people had in common was a very debilitated defense system of the body and most of them died shortly afterward. As the majority of the patients were homosexual it was initially believed that it was a disease that only attacked men that had sex with men (which gave rise to countless stories of persecution, discrimination and prejudice) However, new cases began to appear and not only in the homosexual community. Injectable drug users, men and women that had received blood transfusions, particularly hemophiliacs, also began to present the same symptoms.

In 1982, the name of Acquired Immunodeficiency Syndrome (AIDS) was given to this syndrome of diseases and, in the following year, French scientists identified the virus and baptized it HIV, Human Immunodeficiency Virus.

Today, even knowing that this disease can be transmitted through sexual relations without the use of a condom and through contact with contaminated blood, many people still have not realized what is necessary to protect themselves. To think and act like this is very risky. AIDS can affect any person: men and women; children, adolescents and adults; rich and poor; all races; heterosexuals, homosexuals and bisexuals.

\section{What is it?}

AIDS, is also an STD, but which can be transmitted in other ways besides sexual relations, and does not present visible symptoms like the other diseases. It requires a blood exam to know if the person is contaminated or not.

\begin{tabular}{|l|l|}
\hline \multicolumn{2}{|l|}{ AIDS - what each of these words means } \\
\hline Acquired & $\begin{array}{l}\text { That is contracted through } \\
\text { a virus transmitted by } \\
\text { another person }\end{array}$ \\
\hline Immunodeficiency & $\begin{array}{l}\text { the body has a reduced } \\
\text { capacity or has lost its } \\
\text { capacity to defend itself } \\
\text { from diseases }\end{array}$ \\
\hline Syndrome & $\begin{array}{l}\text { set of symptoms or signs } \\
\text { of a disease }\end{array}$ \\
\hline
\end{tabular}

AIDS is caused by a minute living being, the HIV virus, which attacks the organism's defense system, increasing the possibility of the patient acquiring certain diseases, which can lead to death. These diseases are caused by bacteria, viruses and others parasites normally combated by the body's defense system. When they come into contact with someone 


\section{AIDS Spreads by ...}

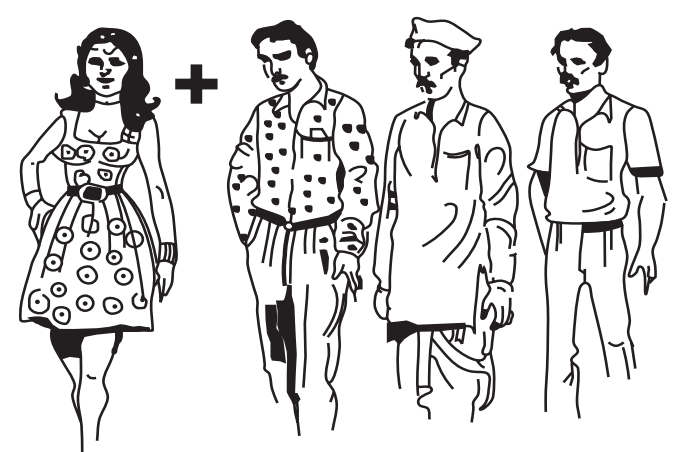

Woman having multiple male sex partners

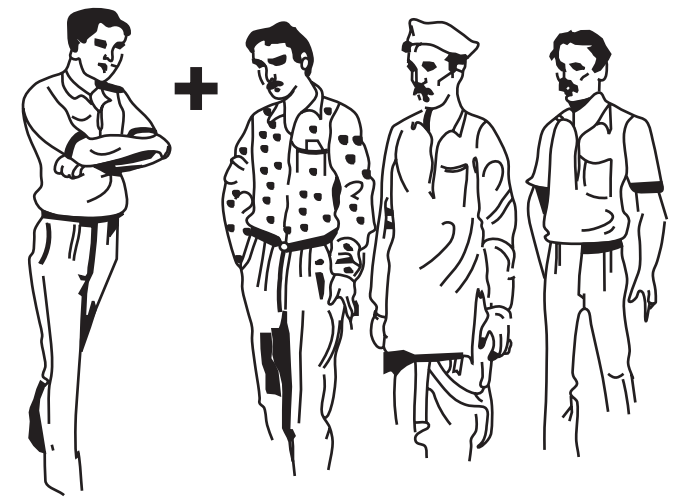

Man having multiple male sex partners

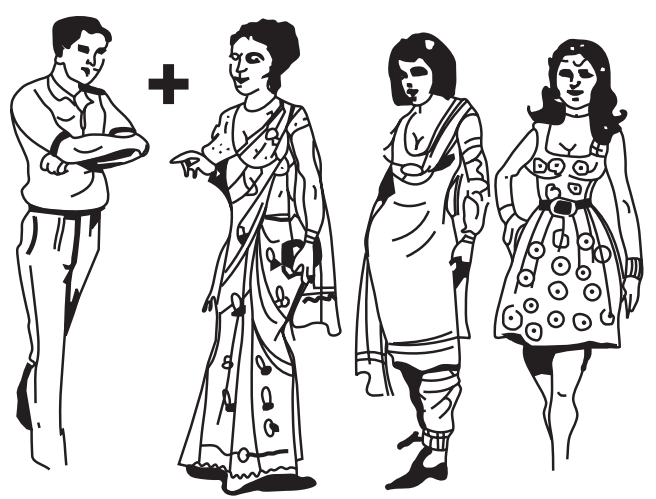

Man having multiple female sex partners

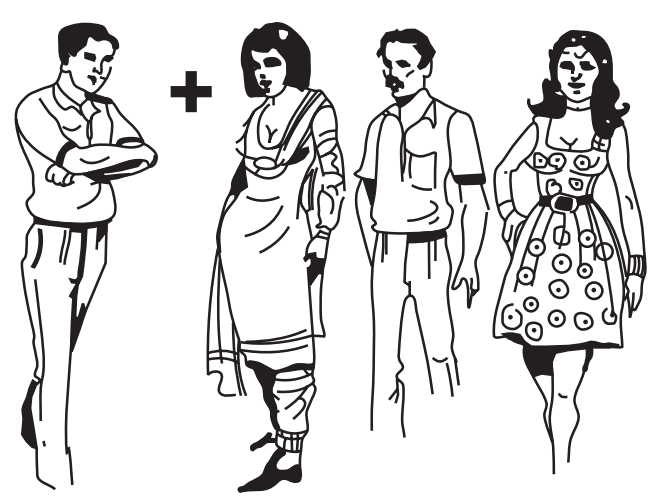

Man having multiple male and female sex partners

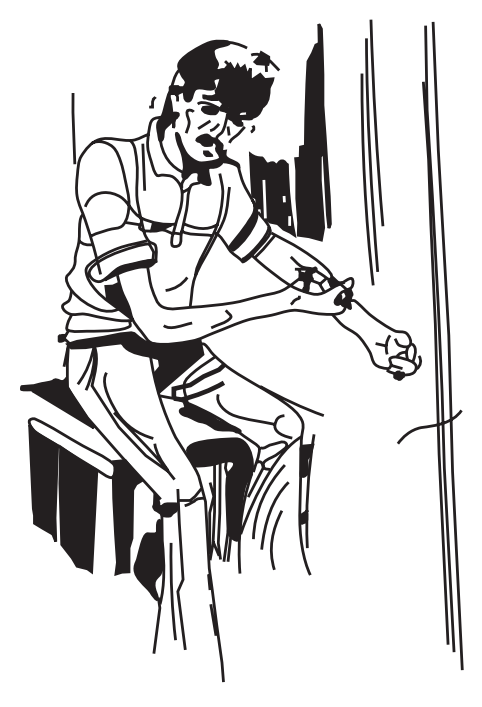

Intravenous drug use

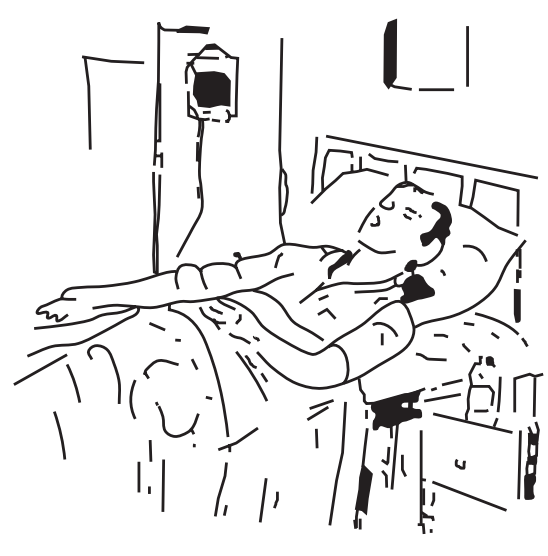

Infected blood transmission

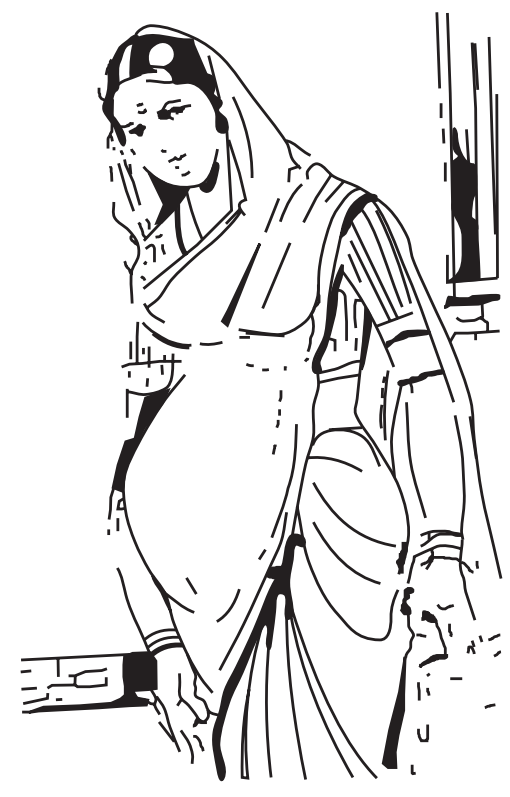

Mother to child 
who is HIV-positive they become very dangerous, as they take advantage of the person's immunodeficiency condition, producing the so-called opportunist diseases: herpes, tuberculosis, pneumonia, candidiases and tumors.

\section{The body's defense system}

The blood is the most important defense system of the body. It produces white globules which, like an army, receive missions of identifying, combating and destroying attacking organisms. The lymphocytes are "soldiers" trained to identify each foreign agent that enters the organism and produce a substance, antibodies, whose function is to destroy the invader.

In relation to the AIDS virus, unfortunately, this "army" has lost the majority of the battles. After getting into the bloodstream, the HIV enemy becomes practically indestructible. The lymphocyte T4 - exactly the one responsible for coordinating the immunological system - is the main target of the enemy. In overcoming the lymphocytes, HIV transforms them into allies. They start to produce more and more enemy viruses until they are destroyed. The new virus is released to attack new lymphocytes, restarting the whole cycle. The more the lymphocytes are attacked, the lower the capacity of the organism to defend itself, since it has less agents to recognize its aggressors.

\section{The cure for AIDS}

Unfortunately, the cure for AIDS still has not been discovered. What has been discovered so far are medicines capable of prolonging the life, and with a better quality, of persons that have contracted the virus. Nevertheless, advances in this area are visible. Initially, PLWA received only medication that inhibited the multiplication of an enzyme that was essential for the HIV to begin to multiply. In the $1990 \mathrm{~s}$, the pharmaceutical laboratories began to develop a new class of medicine that neutralized an enzyme fundamental to the maturing of the HIV. Since 1995, many patients have been treated with a combination of drugs, the so-called "cocktail," technically known as "anti-retrovirals", which reduces the quantity of virus

\section{AIDS: How it is transmitted}

\section{Sexual relations}

The virus is transmitted through vaginal, oral and anal sexual relations, since it is found in the semen and vaginal fluid. The use of condoms is recommended in all sexual relations.

\section{Use of a contaminated syringe}

Syringes can transfer the virus from the blood of a possible drug user to other users. For this reason it is recommended that only disposable needles and syringes be used.

\section{Blood transfusion}

If the donor is contaminated, his blood will take the virus directly to the receptor. Every blood donor should do a test that detects contamination by the AIDS virus. The packs used for the transfusion must carry a compulsory TESTED stamp.

\section{Vertical Transmission}

This type of contamination occurs from mother to child. It can occur in the mother's womb at the time of child birth or through breast feeding. Ideally, for the couple should have an HIV test when they plan to have a children.

in the blood. Even patients in an already advanced stage of the disease begin to recover their immunological system and even return to their normal activities. New activities are being developed for those people that show resistance to the cocktail combination. Vaccines also have been tested with the aim of protecting people who do not have the AIDS virus, but so far there has been no proof of the efficiency of any of them and according to specialists it will still take a few more years to discover an efficient vaccine. 


\section{AIDS does not spread by ...}

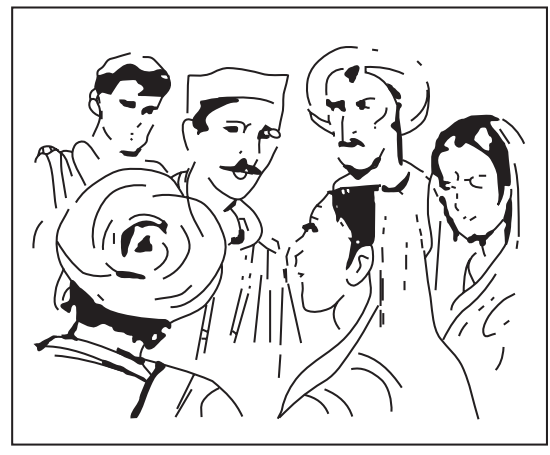

Talking in a group

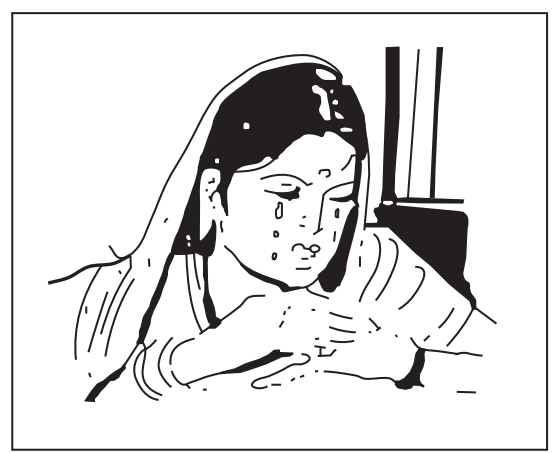

Through tears

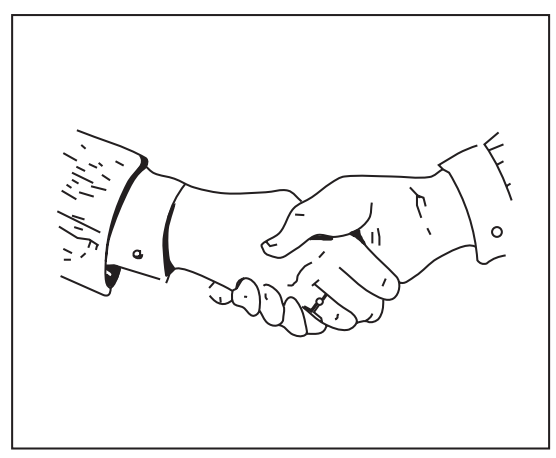

Shaking hands

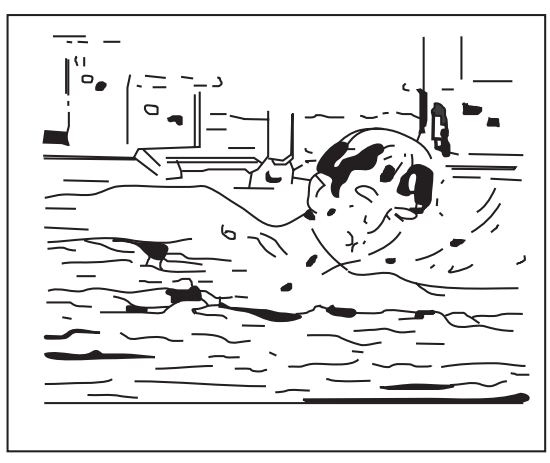

Swimming in a pond

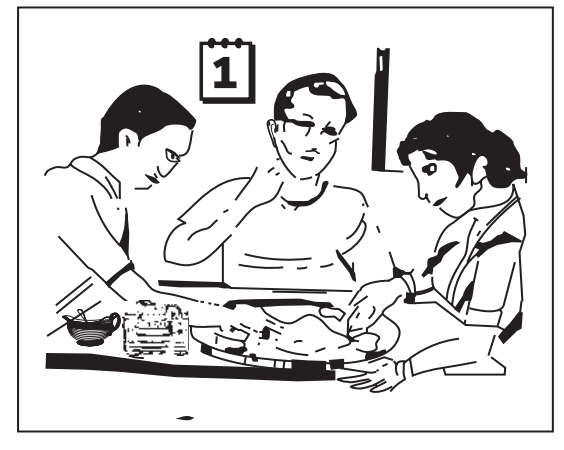

Eating together

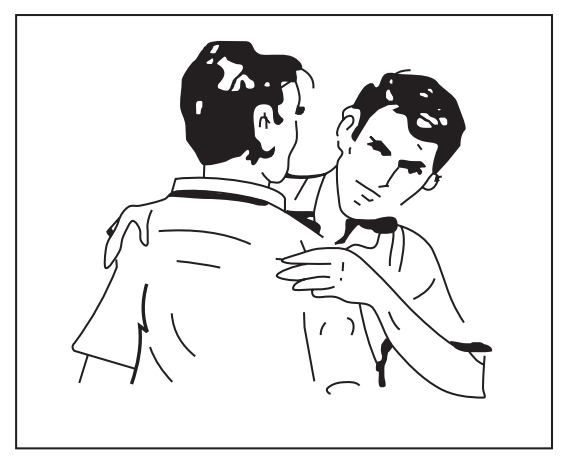

Hugging

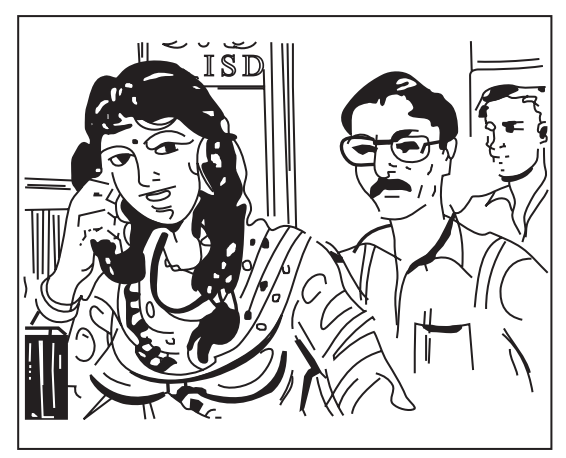

Using public telephone

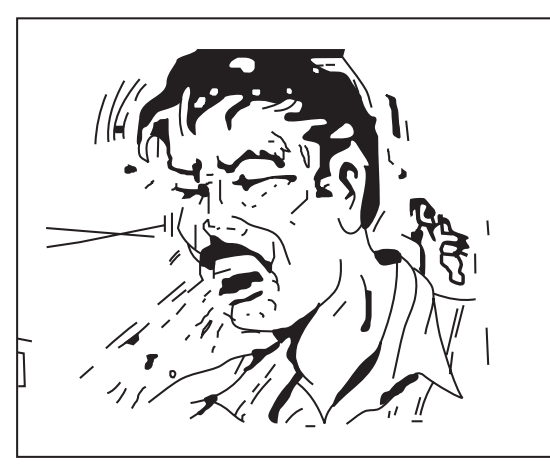

Coughing

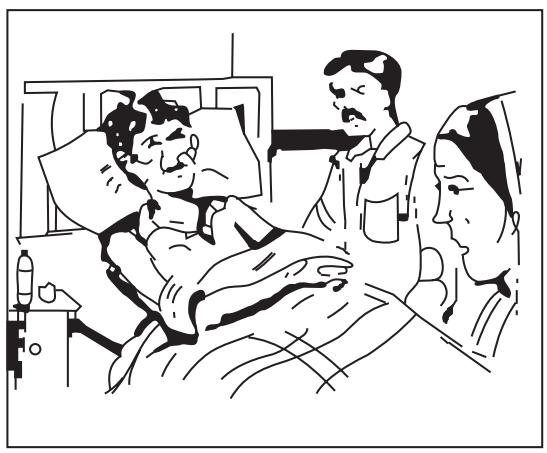

Taking care of HIV infected person

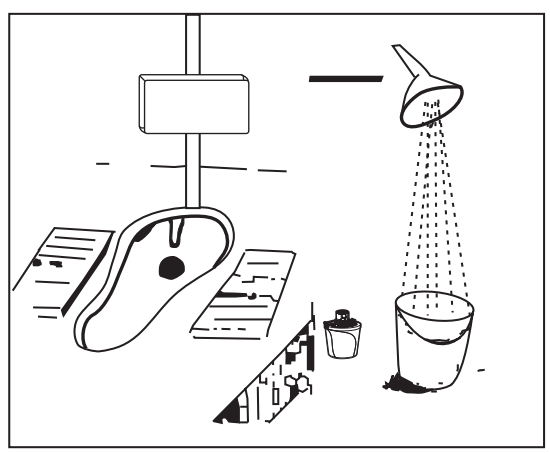

Sharing same toilet

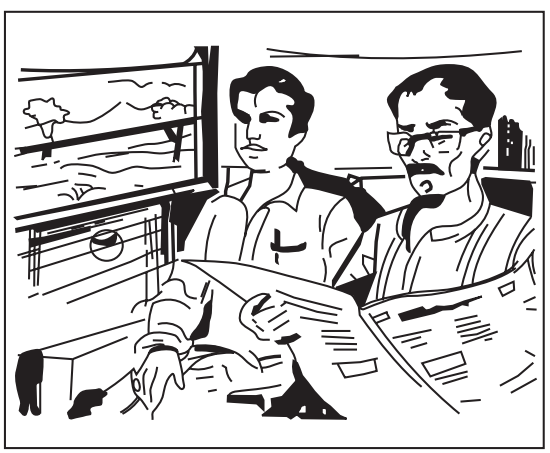

Travelling together

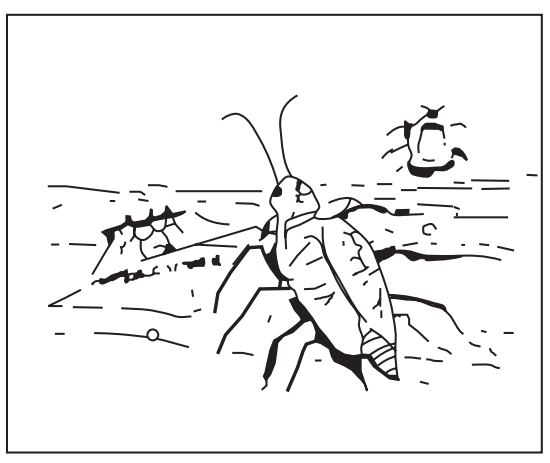

Mosquito/insect bite

Source: Bhatalwande and Gangakhedkar, Yovan Ki Dehlij Par, 2002, (UNICEF) 
Activity 4.2

Signature Hunt

Purpose: To show how AIDS and other STDs are rapidly transmitted and how we could avoid this. This activity serves to illustrate how peer pressure can influence our behavior.

Materials required: Large post-it cards, Pens

Recommended time: 30 minutes

Planning tips/notes: Before distributing the cards, it is necessary to mark three of them with a "C", another three with the message "Do not participate in the activity and do not follow my instructions until we sit down again" and one card with an "H". On the remaining cards write the message "Follow all my instructions", including those marked with a "C" and an " $\mathbf{H}$ ".

\section{Procedure}

1. Hand out a card to each participant. Ask them to keep the instructions on the card they have received secret and obey the instructions contained on their card;

2. Ask them to stand up and choose three people to sign their card;

3. When everybody has collected their signatures ask them to sit down;

4. Ask the person that has the card marked "H" to remain standing;

5. Ask everyone who has their cards signed by this person, or has signed that person's card, to stand up;

6. Ask everyone who has the signature of these persons to stand up. Continue like this until everyone is standing up, except those who were requested not to participate;
7. Tell the young men to pretend that the person marked with an " $\mathrm{H}$ " is infected with HIV or some STD and that they had sexual relations without any protection with the three persons who signed their cards. Remind them that they are pretending and that the participants are not in fact contaminated;

8. Ask the group to imagine that the persons who did not take part in the activity, that is to say, those that received the "do not participate" card, are persons that have not maintained sexual relations;

9. Finish off by asking the group to continue pretending and explain to the participants who have the cards marked with a " $C$ " that they used a condom and, for this reason, run less risk. These young men can also sit down. 


\section{Discuss the following questions. ${ }^{1}$}

- How did person " $H$ " feel? What was his reaction when he found out he was "infected"?

- What were the feelings of the young men toward person "H"?

- How did those who did not participate in the activity at the start feel? Did this feeling change during the course of the activity? What did the rest of the group feel toward those who did not participate?
- Is it easy or difficult not to participate in an activity where everybody takes part? Why?

- How did those who "used a condom" feel?

- What were the feelings of those that discovered that they might have been contaminated? How did they feel about having signed the card of someone "infected" by STD or HIV?

- Person "H" did not know he was infected. How could "H" have known?

\footnotetext{
${ }^{1}$ This activity was adapted from the activity "In Search of Signatures" contained in the manual "Adolescência:
} Administrando o futuro" produced by Advocates for Youth and SEBRAE, 1992. 

Activity 4.3

\section{I am vulnerable when...}

This activity tries to get adolescents to reflect and recognize situations of vulnerability in terms of AIDS, both from the individual point of view and the social and programming standpoint.

Purpose: To stimulate reflection on the situations in the life of young men that make them vulnerable to contracting a sexually transmissible disease or the AIDS virus.

Time: 1 hour

Materials required: sentences, paper and pencil.

Planning tips/notes : To deal with the vulnerability of adolescents boys or young men it is important to listen to them. It is important to know that besides the lack of information, many young people put themselves in situations of vulnerability also because of the pressure they feel in having to correspond to the role that is expected of men and the difficulties they have in dealing with emotion. In the same way, the absence of specific programs for young men increases their vulnerability in relation to STD/AIDS.

\section{Procedure}

- Begin the activity by commenting that very often we get into some situations that make us vulnerable because there is some risk involved. For example, if a person does not know that having sexual relations without a condom one can get AIDS, they are more vulnerable to contracting this disease than someone else that has this information.

- Next, explain that they should form groups of 4 persons and each of them will be given a sentence taken from a serialized album elaborated by adolescents and about situations in which a young man is more vulnerable.

- Ask each group to read their sentence, discuss what it means, if they agree or not with the statement and why.
- When they have finished, each group should choose a representative to read out the sentence and the findings of the group.

\section{Discussion questions}

- Do you think that young men are a vulnerable group in relation to AIDS? Why?

- In what situations do you see this vulnerability?

- In a relationship, what makes the persons vulnerable to contracting this disease?

- What aspects in our culture makes young men more vulnerable? And women?

- In your region, are there any specific health services for young men? What

- Are there educational programs that deal with the question of AIDS and substance use? What? 

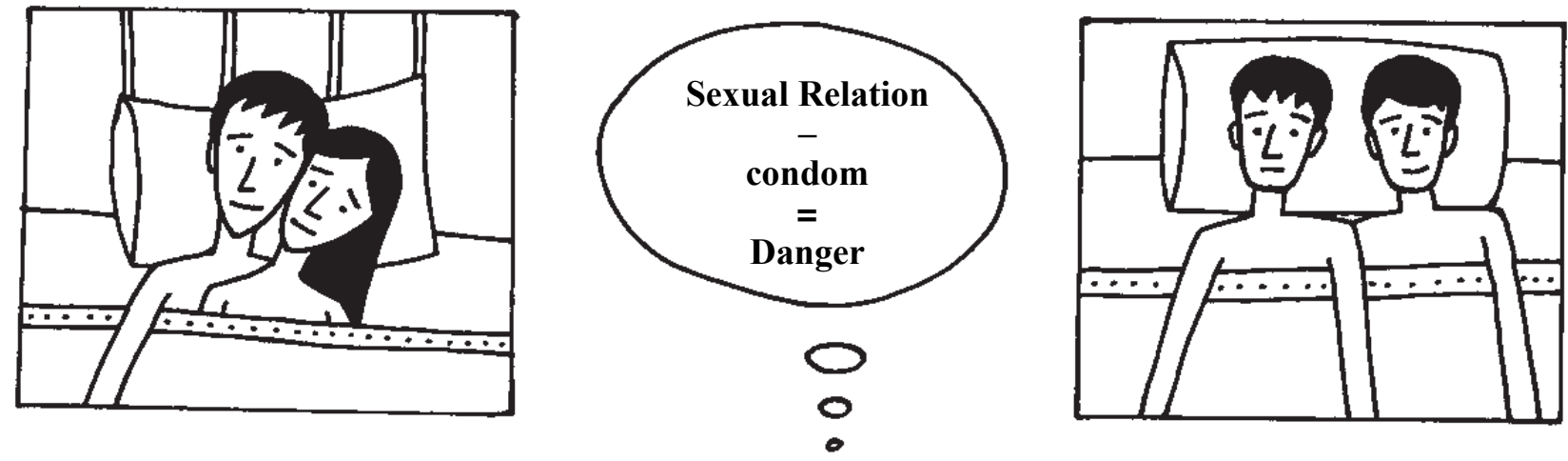

\section{Closing}

- Discuss what are the cultural factors that make it difficult for men to care for themselves and avoid situations of vulnerability.

- Emphasize that, besides the situations discussed in the activity, other components that demonstrate vulnerability in relation to STD/AIDS can be analyzed: programming vulnerability and social vulnerability.

- Explain that social vulnerability concerns the political commitment of each country to health and education. After all, to obtain information and incorporate it in your life does not depend only on people, but on factors such as "access to the means of communication, degree of schooling, availability of material resources, power to influence political decisions, possibilities of challenging cultural barriers etc." . Finally, programming vulnerability is that which focuses on the existence or not of programs and activities designed to meet the needs of the younger generation, since it is fundamental that effective and democratic measures are taken to help young people protect themselves from HIV. The greater the degree and quality of the State's commitment and of the resources made available for programs in the area of sexuality and reproductive health, the greater the possibility of fortifying young men in their search for a healthier and more responsible affective and sexual life.

\footnotetext{
${ }^{1}$ Ayres, J. R, et ali. Vulnerabilidade do adolescente ao HIV and AIDS. In : Gravidez na Adolescência. São Paulo: ASF,
} 1999. 


\section{Resource Sheet ${ }^{1}$}

I am vulnerable when I think that nothing is going to happen to me.

I am vulnerable when I do not have anyone reliable to help me when I need it.

I am vulnerable when I do something for him or her to like me.

I am vulnerable when I do anything to get laid.

I am vulnerable when I am afraid to show what I feel.

I am vulnerable when I am unable to think for myself.

I am vulnerable when I do not know how to take care of my own sexual health.

I am vulnerable when I do not take responsibility for my own sexual life.

\footnotetext{
${ }^{1}$ Sentences taken and adapted from Álbum Seriado Adolescência e Vulnerabilidade. Projeto Trance esta Rede. São
} Paulo: GTPOS, 1998. 
Activity 4.4

\section{There are people who do not use a condom because...}

Purposes: to provide basic information about correct with condom use and increase acceptability of the condom in sexual relations.

Recommended time: 2 hours

Materials required: Cards; pens; a small box; male and female condoms; bananas, a rubber penis (dildo), cucumbers or some other object that can serve as a penis; clear plastic cups.

Planning tips/notes: With this activity, the facilitator should try to create the participants' attitudes about the condom - working to associate the idea of condom with sexual pleasure rather than disease prevention. Encourage the participants to adopt precautions - to use a condom, to use gloves in dealing with blood and to be honest about the difficulties associated with condom use. Remind the participants that each decision they make related to their sexuality is important and can lead to long-lasting consequences. For an extra motivation for condom use, and to let the young men get used to handling condoms, provide a supply of condoms at the end of the activity. Finally, provide the young men with tips on where to get free condoms - health centers, for example.

\section{Procedure}

\section{Stage 1}

- Hand the participants a card and ask them to write a phrase or idea that they have heard and that is related to sexuality and the use of the condom.

- Ask them, initially, to put their cards in the box, which should be placed in front of the group. Explain that each one should come forward, take a card from the box, read it out loud and say if the idea written there is true or false.
- As they are being read, the facilitator can complement or correct the information given by the participant who has taken out the card.

\section{Stage 2}

- Following this, show a male condom and explain the care that should be taken in buying a condom and how it should be used. Use a banana or a cucumber or a rubber penis for this explanation.

- Having demonstrated the use of a male condom, do the same with the female condom, 
making use of a transparent plastic cup so they can understand how it is placed and fixed inside the female vaginal canal.

\section{Stage 3}

- Propose that two or more participants provide a dramatization, demonstrating the most common difficulties that young men have when it comes to talking about the use of the condom and how they can deal with these difficulties.

\section{Discussion questions}

- What are the reasons that lead young men, including those who know the importance of using condoms, not to use them?
- How can you tell a young woman that you are going to use a condom?

- What if the woman asks you to use a condom and you don't have one? What do you do?

- What if the young woman says she will only have sex with you if you have a condom? How would you feel? Who should suggest condom use?

- What would you think about a young woman who carried a condom with her? What do you think about the female condom?

- Would you feel like having sexual relations with a young woman who uses one?

\section{Closings}

- Discuss that it is common for a young man, when he is going to have sex for the first time, to become tense, to be afraid of failing (of "coming" too soon), and that condom use can be even more complicated. Explore with the young men these feelings, the difficulties and fears that they may have.

- Work with the young men to deconstruct the various beliefs that discourage condom use, for example, that using a condom is "like sucking on a candy with the paper on." Clarify that safer sex includes condom use for vaginal or anal penetration and also involves precautions during oral sex.

- Clarify that statistical data has shown that in stable relationships the use of condoms is often ignored and this behavior increases vulnerability in relation to STIs and HIV.

- Inform the group that currently heterosexual women in stable relationships (married women) are one of the groups with the fastest growing rates of HIV infection. Discuss the difficulty of adopting the condom (the most efficient preventive method against contamination) as part of a couple's intimate routine. The same discussion can be extrapolated for homosexual couples.

- Comment on the existence of the female condom as an alternative for prevention and contraception and how to use it correctly. In some countries, the female condom is not available and even where it is, most young men will not be familiar with it. Work with them to explore their ideas about it.

- Reinforce the importance of negotiation in condom use (male and female) before sexual relations occur. 


\section{Female Condom}

The female condom is a soft and thin plastic tube, about $25 \mathrm{~cm}$ long, with a ring at either end. The internal ring is used to place and fix the female condom inside the vagina. The other ring remains outside and partially covers the area of the labia minora and labia majora of the vagina.

\section{How to use}

- First, find a comfortable position, for example, standing with one foot on a chair or crouching. Then, check that the internal ring is at the end of the condom.

- Take hold of the internal ring, squeezing it in the middle to form an " 8 ". Introduce the condom by pushing the internal ring along the vaginal canal with the index finger.

- The internal ring should be right over the pubic bone, which the woman can feel by bending her index finger when it is about $5 \mathrm{~cm}$ inside the vagina.

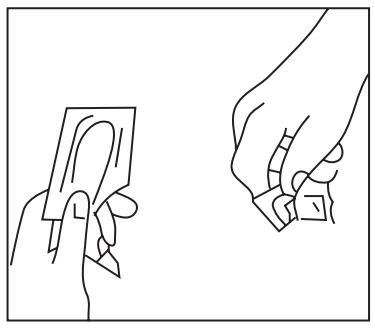

1. Take out the condom from the packet, squeeze the closed end or tip of the condom slightly, between finger and thumb of one hand to expell air.

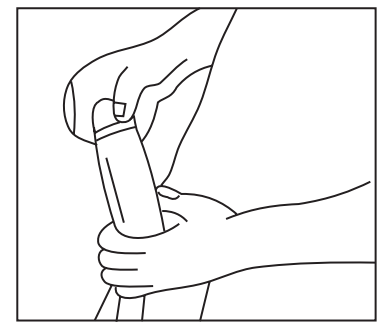

2. With the other hand put the condom on the tip of the erect penis and unroll down the length by pushing down the rim of the comdom.

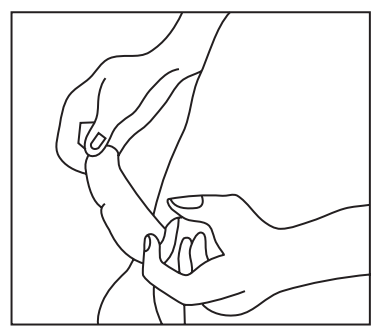

3. When the rim of the condom is at the base of the penis, penetration can begin.

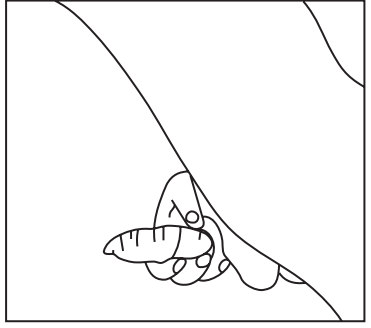

4. Immediately after ejaculation, withdraw the penis while it is still hard, holding the rim of the condom to prevent it from slipping.

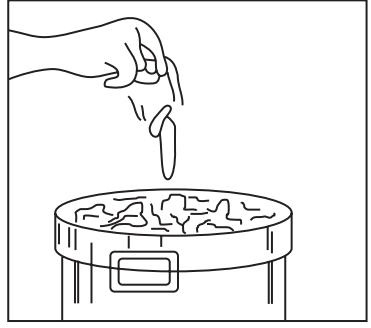

5. Wrap used condom in waste paper before disposing them off safely 


\section{Male Condom}

The male condom is made of a thin and resistant type of rubber, which, if worn correctly, rarely bursts.

\section{How to use}

Before opening the pack, check the expiration date, whether the pack has been pierced or torn and if the condom is lubricated.
To put the condom on, it is necessary for the man to be already aroused, with the penis erect. Make sure the condom is the right way round, leaving a little slack at the end to serve as a deposit for the semen. Hold the end to squeeze out the air. Having done this, slide it down to the base

The condom should be removed immediately after ejaculation, with the penis still erect. Hold the end so the seminal fluid does not escape and dispose of. 


\section{Want ... don't want, want .... don't want ...}

This activity allows male and female adolescents to express their views on the pros and cons of the use of the condom.

\section{Purpose}

- To stage situations that occur in negotiating safe sex, incorporating the arguments on the pros and cons of the use of the condom

- Reinforce the tools for negotiating safe conditions.

Materials required: Large sheets of paper, Markers, Adhesive tape

Recommended time: 2 hours

\section{Procedure}

1. Divide the participants at random in 4 groups, numbering them or giving them different colors. ${ }^{1}$

2. Each group will be given 5 minutes to perform a different task:

\section{Negotiating}

Negotiating not knowing beforehand with whom they are going to negotiate, each group will be asked to discuss the theme they were assigned. The groups assigned with the female reasons will have to personify them.

\begin{tabular}{|c|l|}
\hline Group & Themes for discussion \\
\hline H1 & $\begin{array}{l}\text { The reasons why men want to use a } \\
\text { condom }\end{array}$ \\
\hline H2 & $\begin{array}{l}\text { The reasons why men do not want to } \\
\text { use a condom }\end{array}$ \\
\hline M1 & $\begin{array}{l}\text { The reasons why women want to use a } \\
\text { condom }\end{array}$ \\
\hline M2 & $\begin{array}{l}\text { The reasons why women do not want } \\
\text { to use a condom }\end{array}$ \\
\hline
\end{tabular}

Each group notes down the reasons on a card.

\footnotetext{
${ }^{1}$ This Activity obviously can be used also with mixed groups, which confers more credibility to it. Likewise, it can be used with homogeneous groups of male who have sex with a male or female who have sex with a female.
} 
Thus, the first negotiation takes place:

Group H1 (men who want to use it) negotiates with group M2 (women who do not want to use it). Get the groups to negotiate, imagining that sexual intercourse is desired. After negotiating, ask them how they felt and what they have realized

Following this, ask the other two groups who were observing to present their comments.

\section{The second negotiation now takes place:}

Group $\mathrm{H} 2$ (men who do not want to use it) negotiates with group M1 (women who want to use it) The discussion is conducted in the same way. In both cases the facilitators write on a sheet of paper the most important arguments, both in favor and against.

\section{Questions for discussion}

The whole group is asked to analyze various aspects:

a. In which way is this negotiation similar to what happens in real life?

What are the consequences of unsuccessful negotiation?

It is important to pay special attention to the strongest reasons for NO. The reasons are reviewed, and the group thinks collectively of arguments that might lead to YES. If time allows, a third stage of the negotiation should be conducted, incorporating these new arguments.

b. It is necessary to reflect on the different levels which occur in a negotiation like this. The group is asked "what other aspects of the persons involved are present in a negotiation like this? The aim is for the group to realize that not only rational argument are present, but also gender (as a power relationship), ways of communication, emotions, erotic attraction, self-esteem and the different experiences the persons have gone through. In the case of women, the fear of losing their partner or low self-esteem might lead them to accept unsafe sex. Among men, the decision of using or not a condom depends, very often, on whom they are going to have sex with, whether with their steady partner, a friend of a sex professional.

c. One last question concerns "when is the best moment to negotiate this? Obviously and above all, if an agreement is not reached, it is better to negotiate this in advance and not just before the sexual act.

\section{Closing}

Negotiating does not mean winning at all cost, but to seek the best situation for both parties, that is to say, where both parties win. In the field of sexuality, things can be very complex because of all the human aspects that intervene. When you have someone who is sure about wanting safe sex and someone else who does not accept it, the moment can come when one of the parties ( or both) decides not to have sexual relations. 
Activity 4.6

Testing and Counseling

This activity serves to promote reflection on the importance of HIV and AIDS testing and prevention counseling in the Health Services, representing by means of "human statues" the three principal moments in the process of testing and counseling: arrival at the health center; getting the result and the follow-up to the result.

Purpose: To reflect on the importance of testing and counseling, considering the motivations and the embarrassments involved in this situation.

Materials :Two cards with the results of the test, one "positive" and the other "negative"

Recommended time: 1 hour and 30 minutes

Planning tips/notes: The facilitator can suggest to the group that they stage a meeting between the two young men that come out of the health center with different results and see what they talk about before and after the result.

\section{Procedure}

Ask for two volunteers to enact the scene of a young person arriving at the health center to do an HIV test and being attjended by one of the staff. The participants themselves should decide what the scene is like, the expression on the boy's face, his behavior and the appearance of the health service official. Explain that it takes some time to get the result of the exam and that this is the boy's first contact with the health center. Stop the scene with a command, e.g., FREEZE!

- Then ask the group:

1. Concerning the young man: what made him want to do the test? How long did it take him to decide? How will he cope with the result? What does he expect from the health services? Hjow is he feeling? Is he afraid? Confident? Why? ? Does his family know what he has come to do?

2. Concerning the heath professional: why has he chosen to work there? Does he like what he does? What dojes he think about a boy who asks to do the HIV test? Is he helpful when dealing with the public?

- After posing and discussing the questions, ask two other pairs to enact the same scene, but now, at the time the test result is given. The results, one positive and the other negative, are drawn by lots and handed out to each pair shortly before staging the second scene, without the group knowing which of them is positive or negative. 


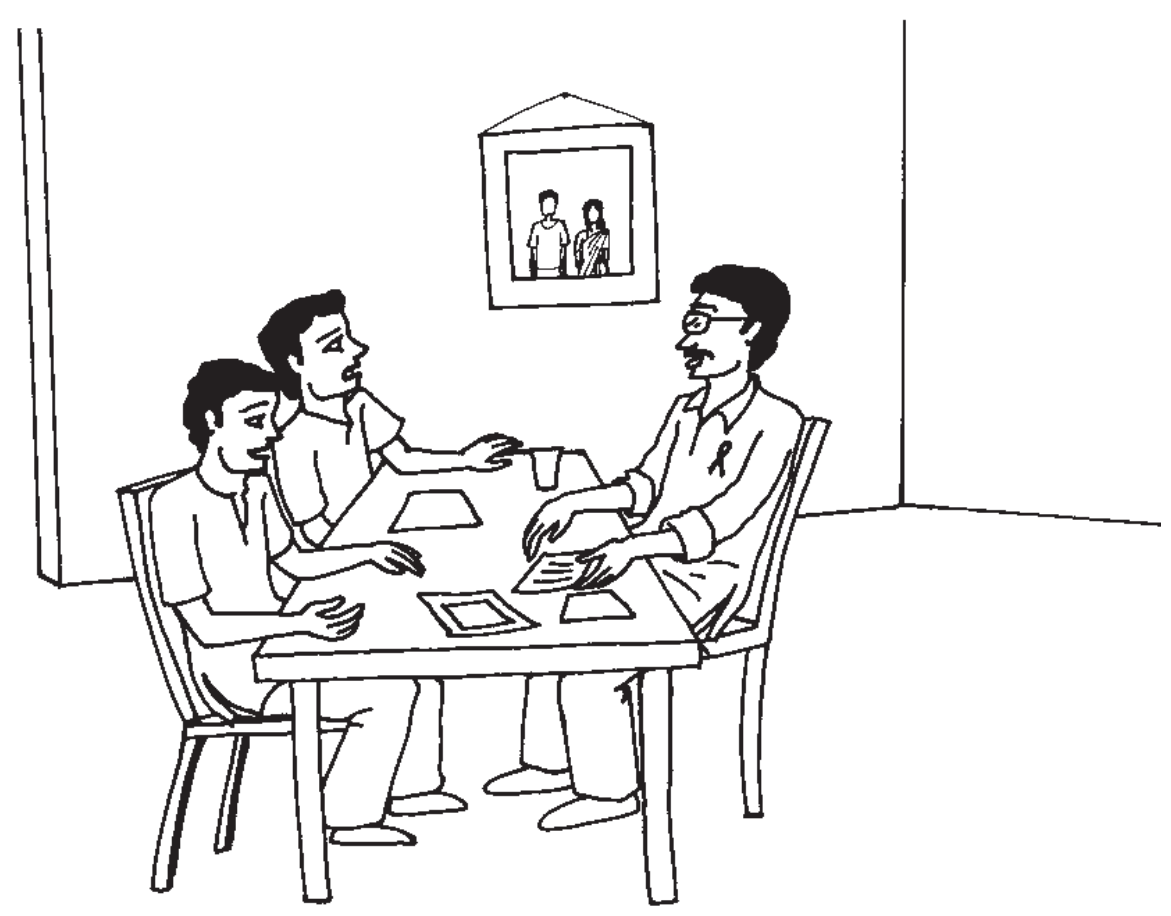

- As in the previous scene, prompt the group with questions:

1. Which one is positive/negative and why?

2. How did he receive the news?

3. Who do you think the first person he looks for will be?

4. Why do you think the result of the test was negative/positive? and

5. What is he thinking of doing now he knows the has/does not have the virus?.

- Get the group to discuss the realities of each of the cases.

- In the final stage, the pairs enact two different scenes representing what the future holds for each of the two users of the service.

- Discuss with the group, based on the enacted scenes, "What initiatives should each of them take?" and "What are the expectations in relation to each one's life?"

\section{Questions for reflection}

- Why are people afraid of doing the HIV test?

- Do you know where the test can be done safely and anonymously?

- What should STI/AIDS counseling and prevention be like?
- Who should be responsible for the prevention and treatment of STI/AIDS?

- What kind of negotiation should take place between sexual partners when there is a need for STI/AIDS treatment?

- Do PLWA have a right to an active sexual life?

- When someone finds out that he has been infected with HIV, what initiative should they take in relation to their partner?

- What should the life (sexual, family, etc.) of a couple be like, when one of the partners is HIV positive and the other not?

\section{Closing}

At the end, the facilitator concludes by making use of what the group themselves have said, particularly during the third stage of the workshop, analyzing the exclusive alternatives, in order to demonstrate the importance of testing. One should also highlight the importance of prevention for everybody, independently of being infected or not. 


\section{I am HIV-positive: and what now?}

This activity is a directed fantasy which deals with possible life projects following the discovery that one is HIV-positive.

Purpose: To reflect on the construction of life projects for young HIV-positive men, including links that need to be severed and possible conquests in this stage of life.

Material required: A quiet place and creativity.

Recommended time: 2 hours.

Planning tips/notes: Many people imagine the moment one finds out one is HIV-positive that life is over: professional life, academic, personal, affective, sexual, family, etc. Certainly recognizing the one is HIV-positive has a strong emotional impact, but it does not mean the end of life. Projects can and should be started in constructing a new stage of life where, in fact, certain breaks are necessary so that one can achieve possible conquests, within each person's limits.

The psychological and affective support of friends and family are fundamental in overcoming the initial shock and getting on with life. At the moment, in most parts of the Americas and in other regions too, one finds a series of government and non-governmental services for persons living with HIV and AIDS, offering full psychological, juridical, clinical and family support in the person's own community. In this respect, one needs to appreciate and realize the full potential of each person, offering the necessary support to confront this new stage of life.

This activity seeks to do exactly this, based on a directed fantasy, exploring the potential for facing such a situation, analyzing and highlighting the solutions that appear. Furthermore, it is necessary to distinguish the person who is HIV-positive from someone who has already contracted opportunist infections due to HIV

In this way, the affective and sexual partnership between HIV-discordant young persons (in which one is HIV-positive and the other not) is becoming a possible and viable practice. Questions of how to deal with this possibility run up against prejudice and pre-conceptions, which each one of us brings from our own experiences of life. Facing the difficulties and the prejudices can lead to new common life projects being formed.

\section{Procedure}

1. Ask the group to sit down, or if there is enough space, to lie down in a comfortable position and close their eyes. One can also use, if this is possible, soft background music.
2. Ask them to breath slowly and deeply, and try to be as relaxed as possible. Then, speaking slowly, clearly and with long pauses, begin to suggest stages for a "journey", such as: 
a. Let us think a little about your daily life.... think about your home ... think about the people that you like... someone from your family .... some of your friends ... who are they?

b. Think of a great piece of music that you would like to hear...

c. And a game of sport, or some activity that you would like to practice...

d. And in your daily life, what do you like to do most ... Do you expect to do anything great today?

e. Now, let's think about a special person, a girlfriend/boyfriend perhaps ... or then someone who you are interested in ... trying to get close to...

f. What do you like most about this person? What do you think this person likes most about you?

g. How do you feel when you are with her/ him?

h. Now let's us think a little about the future... What do you think next year will be like? And in 5 years' time, How do you imagine you will be? What will you be doing? Will you be studying? Working? Dating? Let your imagination flow...

i. Let's come back to the present ... to today ... Let us imagine that you went to the doctor to do a routine test. Are you alone or with someone? What is the place (clinic or health center). Is it empty or very busy? What sounds can you hear around you? What does the place smell like? ?hat are the surroundings like?

$j$. The doctor suggests that you do an HIV test as well. You agree and are now waiting for the result...

$k$. When you go back, the doctor tells you that you are HIV-positive...

l. What now? What is your life like now? Do you tell the people you are close to? And you partner, how will he/she react? And your family? And your friends? Your colleagues at school? What changes from now on?

3. Allow some time for each person to imagine the sequence of their journey. Remind them that there is not a right or wrong journey, but that each person does their journey according to their experience and their knowledge about life. Allow 15 to 20 minutes for this activity.

4. Ask each person, when they are ready, to return to their original places. Suggest that they begin by wriggling their toes, moving their legs, and if anyone feels like stretching, they can do so. Wait for everybody to come back, ask them to look at their companions and around them and to sit down once again so that they can start to talk about the "journey".

5. One other fantasy possibility is, instead of being HIV-positive, to learn that their boyfriend/girlfriend is HIV-positive and their reaction to this.

6. Discuss the following questions.

\section{Discussion questions}

- What was this journey like for each of you?

- How did they feel in one example and in the other?

- Was one easier or more difficulty?

- Do you think that life is over when somebody becomes HIV-positive? What possibilities does this person have?

- What changes in the life of someone who is HIV-positive? (at school, in the family, in the community, at work)?

- What feelings are aroused in each person (shame, despair, anger, grief, solidarity, others)?

- And in relation to one's sex life, what changes?

\section{Closing}

Ask the group how they feel imagining the possibility of being HIV-positive or of knowing that their girlfriend/boyfriend is HIV-positive. Point out to the group that life continues for someone who is HIV-positive and that nowadays, with the advances in medicine in relation to the treatments offered, there is an increase in life expectancy, and also in the quality of life, for PLWA. If possible, give positive examples of people known in their community or in their country or region. 



\section{A 'real man'........}

- is not Gud (feminine; homosexual)

O has sex only with women

leads the physical fighting

- always needs to prove that he is a real man.

\section{OR}

- establishes relationship based on equity, intimacy and respect rather than sexual conquest

- takes responsibility towards partner and provides care to children

- shares responsibility for sexual and reproductive health issues with partner

- does not support or use violence against partners 